\title{
DEMODULATION FOR INTERSYMBOL INTERFERENCE CHANNELS IN THE PRESENCE OF COLORED GAUSSIAN NOISE
}

\author{
by \\ R. M. A. P. Rajatheva
A thesis
Presented to the University of Manitoba in Partial Fulfillment of the Requirements for the Degree of
Master of Science
in \\ the Department of Electrical Engineering
}

Winnipeg, Manitoba

May 1991 
The author has granted an irrevocable non. exclusive licence allowing the National Library of Canada to reproduce, ban, distribute or sell copies of his/her thesis by any means and in any form or format, making this thesis available to interested persons.

The author retains ownership of the copyright in his/her thesis. Neither the thesis nor substantial extracts from it may be printed or otherwise reproduced without his/her permission.
L'auteur a accordé une licence irrévocable et non exclusive permettant à la Bibliothęque nationale du Canada de reproduire, prêter. - distribuer ou vendre des copies de sa thèse de quelque manière et sous quelque forme que ce soit pour mettre des exemplaires de cette thèse à ta disposition des personnes intéressées.

L'auteur conserve la propriété du droit d'auteur qui protège sa thèse. Ni la thèse ni des extraits substantiels de celle-ci ne doivent être imprimés ou autrement reproduits sans son autorisation. 


\section{DEMODULATION FOR INTERSYMBOL INTERFERENCE CHANNELS IN THE PRESENCE \\ OF COLORED GAUSSIAN NOISE}

\section{BY}

R.M.A.P. RAJATHEVA

A thesis submitted to the Faculty of Graduate Studies of the University of Manitoba in partial fulfillment of the requirements of the degree of

\author{
MASTER OF SCIENCE
}

\title{
(c) 1991
}

Permission has been granted to the LIBRARY OF THE UNIVERSiTY OF MANITOBA to lend or sell copies of this thesis. to the NATIONAL LIBRARY OF CANADA to microfilm this thesis and to lend or sell copies oi the film, and UNIVERSITY MICROFILMS to publisin an abstract of this thesis.

The author reserves other publication righis, and neither the thesis nor extensive extracts from it may be printed or otherwise reproduced without the author's written permission. 


\begin{abstract}
Maximum likelihood sequence estimation (MLSE) in additive white Gaussian noise with finite intersymbol interference has been thoroughly investigated by several authors. Generally the Viterbi algorithm is applied for the estimation of data. Extension to the case of infinite intersymbol interference has been developed recently using the Sequential algorithm.

Application of these algorithms for an intersymbol interference channel with additive colored Gaussian noise is presented in this thesis. A maximum likelihood metric for the Viterbi algorithm is derived using a finite time whitening approach and is referred to as a finite time metric. The receiver structure in this case consists of $\mathrm{L}$ matched filters where the channel impulse response is of finite duration LT seconds. A receiver structure for the Sequential algorithm is also obtained considering an infinite time whitening interval. Only one matched filter is required at the receiver.

Simulations have been carried out in an attempt to acquire some knowledge as to how these metrics perform under different noise conditions and with different channels. The results show that the Viterbi algorithm with a finite time metric and the Sequential algorithm give a better error performance in comparison to the Viterbi algorithm applied with an infinite time metric particularly, when the noise is more colored. The computational complexity of the Sequential algorithm is comparably less than that required by the Viterbi algorithm at moderate signal to noise ratios.
\end{abstract}




\section{ACKNOWLEDGEMENTS}

The author wishes to express his sincere thanks to Professor E. Shwedyk for his supervision and continual guidance throughout the M. Sc, program and during the work on this thesis. Grateful acknowledgement is also due the Association of Universities and Colleges of Canada for the Commonwealth Scholarship. 
I hereby declare that I am the sole author of this thesis. I authorize the University of Manitoba to lend this thesis to other institutions or individuals for the purpose of scholarly research.

R. M. A. P. Rajatheva

I further authorize the University of Manitoba to reproduce this thesis by photocopying or by other means, in whole or in part, at the request of other institutions or individuals for the purpose of scholarly research.

R. M. A. P. Rajatheva 


\section{Contents}

1 Introduction $\mathbb{1}$

2 Background 4

2.1 Introduction $\ldots \ldots \ldots \ldots \ldots \ldots \ldots \ldots \ldots \ldots \ldots \ldots \ldots \ldots$

2.2 ISI with Additive White Gaussian Noise $\ldots \ldots \ldots \ldots \ldots 4$

2.3 Finite ISI $\ldots \ldots \ldots \ldots \ldots \ldots \ldots \ldots \ldots \ldots \ldots \ldots \ldots \ldots \ldots \ldots \ldots$

2.4 Sequential algorithm and Infinite ISI $\ldots \ldots \ldots \ldots \ldots \ldots 10$

2.5 Colored noise $\ldots \ldots \ldots \ldots \ldots \ldots \ldots \ldots \ldots \ldots \ldots \ldots \ldots \ldots$

3 Theory 16

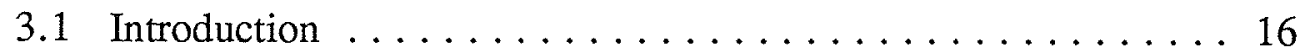

3.2 Development of the maximum lilkelihood metric in colored

Gaussian noise $\ldots \ldots \ldots \ldots \ldots \ldots \ldots \ldots \ldots \ldots$

3.3 Examples . . . . . . . . . . . . . . . . . . 19

3.4 Comparison between finite and infinite time metrics ........ 23

3.5 Application of the Sequential algorithm ........... 24

4 Simulation Results 28

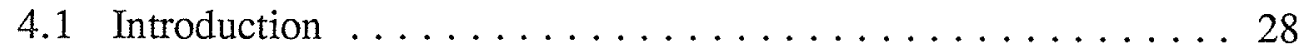

4.2 Simulation : General $\ldots \ldots \ldots \ldots \ldots \ldots \ldots \ldots \ldots \ldots$

4.3 The Raised Cosine Channel . . . . . . . . . . . . . . . 29 
4.4 The Truncated Single Pole Channel . . . . . . . . . . . . . 29

4.5 The Butterworth Channel . . . . . . . . . . . . 35

4.6 Summary and Discussion $\ldots \ldots \ldots \ldots \ldots \ldots \ldots \ldots$

5 Conclusions $\quad 46$

$\begin{array}{ll}\mathrm{REFERENCES} & 48\end{array}$

APPENDIX A: Generation of colored noise

APPENDIX $B$ : Viterbi algorithm program listing

$A P P E N D I X \quad C$ : Sequential algorithm program listing 


\section{List of Figures}

2.1 PAM Communication System .............. 5

2.2 Viterbi Receiver $\ldots \ldots \ldots \ldots \ldots \ldots \ldots$

2.3 Finite state machine $\operatorname{model} \ldots \ldots \ldots \ldots \ldots$

2.4 Four state trellis $\ldots \ldots \ldots \ldots \ldots \ldots \ldots \ldots \ldots \ldots$

2.5 Feed back filter $\ldots \ldots \ldots \ldots \ldots \ldots \ldots \ldots \ldots \ldots$

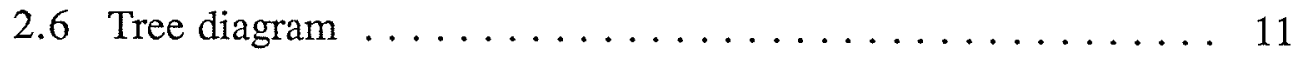

2.7 PAM channel model $\ldots \ldots \ldots \ldots \ldots \ldots$

2.8 Prewhitener (infinite time) $\ldots \ldots \ldots \ldots \ldots \ldots \ldots$

2.9 (a), (b), (c) Receiver structures for colored noise . . . . . . 15

3.1 PAM channel model in colored noise $\ldots \ldots \ldots \ldots . \ldots . \ldots 17$

3.2 Receiver structure for finite time whitening $\ldots \ldots \ldots 17$

3.3 Prewhitener (infinite time) $\ldots \ldots \ldots \ldots \ldots \ldots \ldots \ldots \ldots$

3.4 PAM communication model with receiver for the Sequential algorithm ......................... 25 
4.1 - 4.5 Error performance of the Raised Cosine channel for different interference lengths and different noise bandwidths ..... 30 - 34

4.6 - 4.9 Error performance of the Truncated Single Pole channel for different noise mixtures $\ldots \ldots \ldots \ldots \ldots \ldots \ldots \ldots .36-39$

4.9 Error perofrmance of the Butterworth channel $\ldots \ldots \ldots \ldots 42$ 


\section{List of Tables}

4.1 (a) Average number of computations, (b) Average CPU time, per decoded symbol : Truncated Single Pole channel . . . . . . . 40

4.1 (a) Average number of computations, (b) Average CPU time, per decoded symbol : Butterworth channel $\ldots \ldots \ldots \ldots \ldots$ 


\section{Chapter 1}

\section{Introduction}

It is required in many communication systems to transmit digital data at high speed over channels with limited bandwidth. Bandlimited channels usually produce intersymbol interference (ISI) where the transmitted pulse overlaps with other transmission pulses. The number of pulses that overlap with a given transmitted pulse is known as the memory of the channel or the length of ISI. The simplest communication system to exhibit ISI is a pulse amplitude modulation (PAM) communication system. The input to the channel is a real number sequence drawn from a finite alphabet which, if it passes through a linear channel whose impulse response is longer than one transmission time interval, shall result in ISI. The presence of ISI degrades the receiver performance.

Various techniques have been developed for combating ISI. These techniques date back to Nyquist [12] who introduced baseband spectrum shaping for completely eliminating ISI. Lender [9] introduced the duobinary technique which allowed one ISI term. This was later generalized to partial response techniques by Lender [10] and Kretzmer [7] where any number of ISI terms are allowed. Tomlinson [18] suggested a precoding technique to eliminate ISI. The input sequence is coded according to the inverse of the discrete channel response. Other methods for eliminating or controlling 
of ISI are linear equalization [11] and decision feed back equalization (DFE) [1]. Both reduce ISI by subtracting out the actual ISI. The decision at the receiver is taken on symbol by symbol basis for all the methods described above. Chang and Hancock [2] presented a method which bases the decision on $L$ consecutive symbols.

As an alternative to forcing ISI to zero or introducing controlled ISI the problem can be treated using decision theoretic estimation methods [6,19]. Forney [5] showed that the Viterbi algorithm (VA), which was originally developed by Viterbi [22] for the decoding of convolutional codes, can be applied to ISI channels for maximum likelihood sequence estimation (MLSE). The detection problem is modelled as a graph search which in this case can be implemented through a trellis. The receiver consists of a whitened matched filter and a symbol rate sampler. The advantages of the VA are that there are a fixed number of computations per decoded symbol and that its structure is regular. However, the computational complexity of the VA grows exponentially with the channel memory, therefore making it difficult to apply when the memory is large.

To decrease memory requirement other algorithms known as reduced state algorithms have been developed. The common characteristic of these algorithms is that they reduce the computational complexity by reducing the number of sequences to which they are applied. They can be classified as variations of the VA.

The VA with decision feed back to search a reduced state sub trellis has been introduced by Eyuboglu and Qureshi [4]. Duel and Heegard [3] applied this technique to binary transmission and called it decision feed back sequence estimation. With some changes, Polyduros and Kazakos [13] showed that the VA can be applied to infinite ISI channels with rational spectrum. It is known as a modified Viterbi algorithm (MVA). Sheshadri and Anderson [15] used the M-algorithm which keeps only best M paths for the trellis search. A similar algorithm to the $\mathrm{M}$ algorithm is the $\mathrm{T}$ algorithm proposed by Simmons [17] which searches paths with metrics less than an adaptive 
threshold. All of the above algorithms obtain reduced complexity while retaining the VA structure with a justifiable loss of optimality in estimation. Recently, the Sequential algorithm (SA), another well known algorithm for the decoding of convolutional codes, has been extended to the ISI case by Xiong [24]. The average number of computations for the SA is variable and is independent of the channel memory. Therefore the SA can be easily applied for cases where channel memory is very large or even infinite. A review of the literature regarding ISI can be found in [25].

Most of the research has been concerned with the estimation of the data sequence in the presence of additive white Gaussian noise (AWGN). Comparably little work has been done when data is corrupted with colored noise $[8,14,16,20]$. The straightforward procedure in this case is to use a whitening filter to whiten the colored noise. Because theoretically the resulting ISI can be infinite this approach is suitable only if the SA is used. The VA may be applied with the ISI terms truncated as discussed by Ungerboeck [20]. To be applied without truncation a whitening filter which does not cause infinite ISI has to be found. Then the maximum likelihood metric for the VA can be derived.

In this thesis MLSE in colored Gaussian noise is studied. Chapter 2 provides the general background about ISI and MLSE and a description of the VA and SA as they are used in the thesis. Chapter 3 describes the theoretical procedures to develop maximum likelihood metrics for the VA and SA. Computer simulations and results are presented in chapter 4. The VA using the maximum likelihood metric and a sub optimal metric are compared with the SA. Two kinds of noise models, one with a white noise component and the other without, are considered for simulations. Chapter 5 presents conclusions. 


\section{Chapter 2}

\section{Background}

\subsection{Introduction}

This chapter provides a description of the application of the Viterbi algorithm to ISI in additive white Gaussian noise as developed by Forney [5]. Then the procedure to apply the sequential algorithm is explained for the infinite ISI case. Finally the methods available when colored noise is present without ISI are discussed.

\subsection{ISI with additive white Gaussian noise (AWGN)}

Consider the PAM communication system shown in Figure 2.1 where the $\mathrm{x}_{\mathrm{k}}$ 's are the input alphabet which initially pass through an impulse modulator before transmission. The channel impulse response is $h(t)$. The length of ISI present in $s(t)$ is determined by the length of $h(t)$.

The received signal is

$$
\begin{aligned}
r(t) & =s(t)+n(t) \\
& =\sum_{k} x_{k} h(t-k T)+n(t) \\
\text { If sampled at IT } \quad r(l T) & =\sum_{k} x_{k} h(1 T-k T)+n(1 T)
\end{aligned}
$$




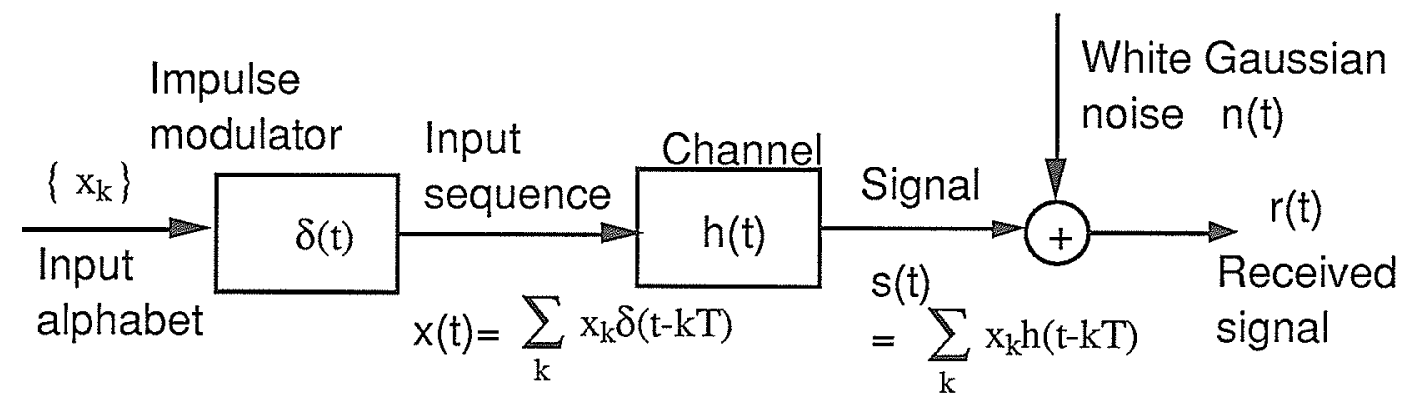

Figure 2.1

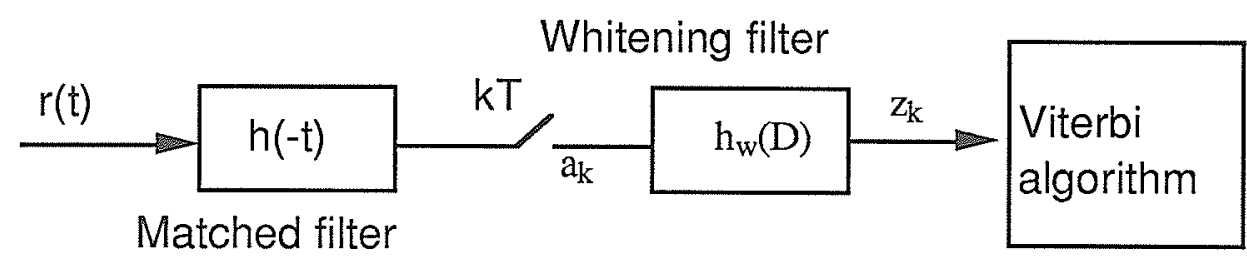

Figure 2.2 


$$
=h_{o} x_{1}+\sum_{k \neq 1} x_{k} h_{1}-k+n_{1}
$$

The term $\sum_{k \neq 1} x_{k} h_{l}-k$ represents the intersymbol interference.

For maximum likelihood sequence estimation(MLSE) in additive white Gaussian noise(AWGN) the receiver structure, shown in Figure 2.2, can be used [5]. The sampled output of the matched filter forms a set of sufficient statistics.

$$
\begin{aligned}
a_{k} & =\int_{-\infty}^{\infty} r(t) h(t-k T) d t \\
& =\int_{-\infty}^{\infty} \sum_{k^{\prime}} x_{k^{\prime}} h\left(t-k^{\prime} T\right) h(t-k t) d t+\int_{-\infty}^{\infty} n(t) h(t-k T) d t \\
& =\sum_{k^{\prime}} x_{k^{\prime}} R_{k^{\prime}-k}+n_{k}^{\prime}
\end{aligned}
$$

where $\mathrm{R}_{\mathrm{k}^{\prime}-\mathrm{k}}$ represents the sampled autocorrelation function of the channel impulse response and $n_{k^{\prime}}$ represents the noise sample at the output of the matched filter.

The above difference equation may be expressed using the delay operator $-D($ similar to $\mathrm{z}^{-1}$ in Z-Transform theory) as

$$
a(D)=\sum_{k} a_{k} D^{k}=x(D) R(D)+n^{\prime}(D)
$$

$-R(D)$ is the D-transform of the discrete autocorrelation function of $h(t)$.

The statistics of the noise samples at the output of the matched filter are given by

$$
\begin{aligned}
E\left\{n_{k^{\prime}}^{\prime}{ }^{\prime} m\right. & =E\left\{\int_{-\infty}^{\infty} n(t) h(t-k T) d t \int_{-\infty}^{\infty} n(\tau) h(\tau-m T) d \tau\right\} \\
& =\int_{-\infty}^{\infty} d t \int_{-\infty}^{\infty} h(t-k T) h(\tau-m T) E\{n(t) n(\tau)\} d \tau
\end{aligned}
$$


Since $n(t)$ is white Gaussian noise

$$
E\{n(t) n(\tau)\}=\sigma^{2} \delta(t-\tau)
$$

where $\sigma^{2}$ is the spectral strength of the noise in watts/ $\mathrm{Hz}$.

$$
\begin{aligned}
E\left\{n_{k}^{\prime} n_{m}^{\prime}\right\} & =\sigma^{2} \int_{-\infty}^{\infty} h(t-k T) h(t-m T) d t \\
& =\sigma^{2} R_{k-m}
\end{aligned}
$$

Therefore $n^{\prime}(D)$ is colored Gaussian noise with autocorrelation function $\sigma^{2} R(D)$. It can be shown that $R(D)$ has the spectral factorization $R(D)=f(D) f\left(D^{-1}\right)$ whether $h(t)$ has a finite length or infinite length [26]. Since

$$
R_{n^{\prime}}(D)=\sigma^{2} R(D)
$$

the colored noise $n^{\prime}(D)$ can be expressed as

$$
\text { Thus } \begin{aligned}
\mathrm{n}^{\prime}(\mathrm{D}) & =\mathrm{n}(\mathrm{D}) \mathrm{f}\left(\mathrm{D}^{-1}\right) \\
\mathrm{a}(\mathrm{D}) & =\mathrm{x}(\mathrm{D}) \mathrm{f}(\mathrm{D}) \mathrm{f}\left(\mathrm{D}^{-1}\right)+\mathrm{n}(\mathrm{D}) \mathrm{f}\left(\mathrm{D}^{-1}\right) \\
\mathrm{z}(\mathrm{D}) & =\frac{\mathrm{a}(\mathrm{D})}{\mathrm{f}\left(\mathrm{D}^{-1}\right)} \\
& =x(D) f(D)+\mathrm{n}(\mathrm{D}) \\
& =y(D)+\mathrm{n}(\mathrm{D})
\end{aligned}
$$

where, provided it is stable, $1 / f\left(\mathrm{D}^{-1}\right)$ represents the whitening filter .

\subsection{Finite ISI}

The discrete model described above can be realized as a finite state machine when the ISI is finite. Since $h(t)$ is of finite length $L T, R(D)$ can be expressed as

$$
R(D)=\sum_{k=-v}^{v} R_{k} D^{k}=f(D) f\left(D^{-1}\right) ; v=L-1
$$




$$
f(D)=\sum_{i=0}^{v} f_{i} D^{i}
$$

In the time domain $\quad y_{k}=\sum_{i=0}^{v} f_{i} x_{k-i}$

Therefore the model shown in Figure 2.3 can be used to obtain $y_{k}$. The channel symbols $y_{k}$ are a function of the current input $x_{k}$ and $v$ past inputs. ie, $y_{k}=g\left(x_{k}, s_{k-1}\right)$ where $s_{k}$ is a state uniquely determined by the previous $v$ inputs prior to time $\mathrm{kT}$. The one to one mapping between input sequence $\mathrm{x}$ and channel symbol sequence $\mathrm{y}$ is described by a trellis of width $\mathrm{s}=\mathrm{m}^{\mathrm{V}}$ states, where $\mathrm{m}$ is the input alphabet size. There are $\mathrm{m}$ branches out of each state, one per possible input symbol, and each branch has a corresponding channel symbol $\mathrm{y}_{\mathrm{k}}$. A four state trellis is shown in Figure 2.4 as an example.

The maximum likelihood metric for the sequences $\mathbf{x}$ and $\mathbf{y}$ can be denoted by

$$
\begin{aligned}
\Gamma(\mathrm{x}, \mathrm{y}) & =\log _{\mathrm{e}} \mathrm{p}(\mathrm{y} \mid \mathrm{x})=\log _{\mathrm{e}} \prod_{\mathrm{k}} \mathrm{p}\left(\mathrm{y}_{\mathrm{k}} \mid \mathrm{x}_{\mathrm{k}}\right) \\
& =\sum_{\mathrm{k}} \log _{\mathrm{e}} \mathrm{p}\left(\mathrm{y}_{\mathrm{k}} \mid \mathrm{x}_{\mathrm{k}}\right) \\
& =\sum_{\mathrm{k}} \lambda\left(\mathrm{y}_{\mathrm{k}}, \mathrm{x}_{\mathrm{k}}\right)
\end{aligned}
$$

where $\lambda\left(\mathrm{y}_{\mathrm{k}}, \mathrm{x}_{\mathrm{k}}\right)$ is the branch metric.

where the probability density function $\mathrm{p}(\mathrm{y} / \mathrm{x})$ factors into a product of terms since the noise samples are statistically independent.

The number of states $\mathrm{m}^{\mathrm{V}}$ grow exponentially with the length of ISI. Hence the Viterbi algorithm cannot be applied to infinite ISI. The whitening filter used in the approach described earlier can be avoided using the procedure described by Viterbi and Omura [23]. 


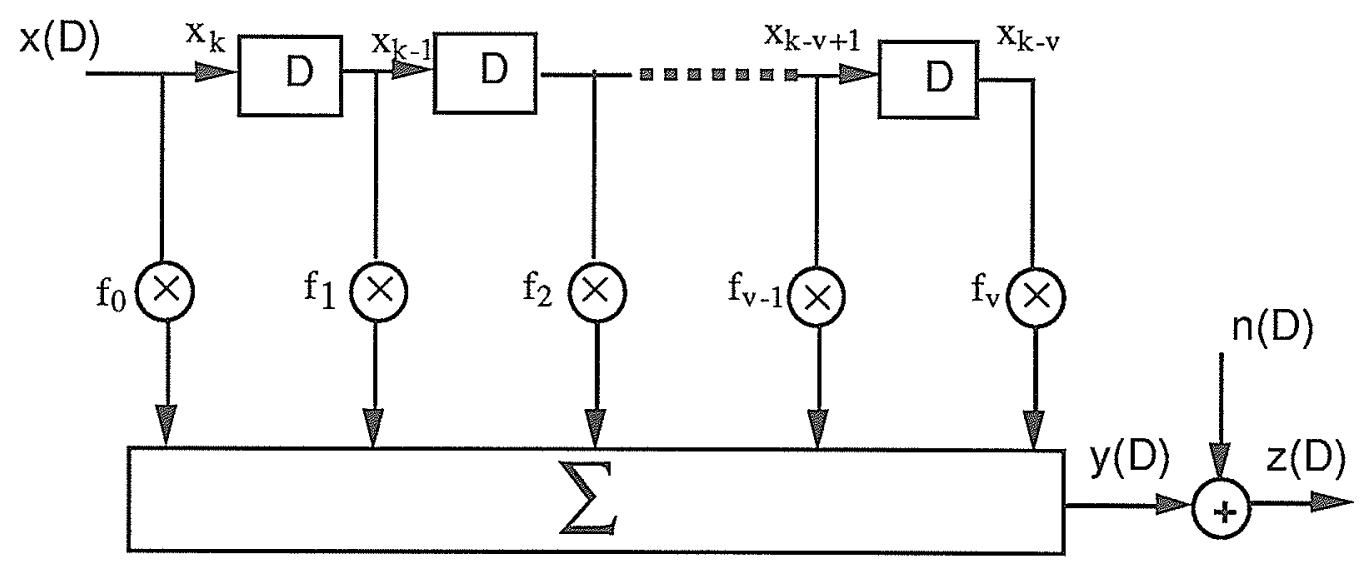

Finite State Model

Figure 2.3

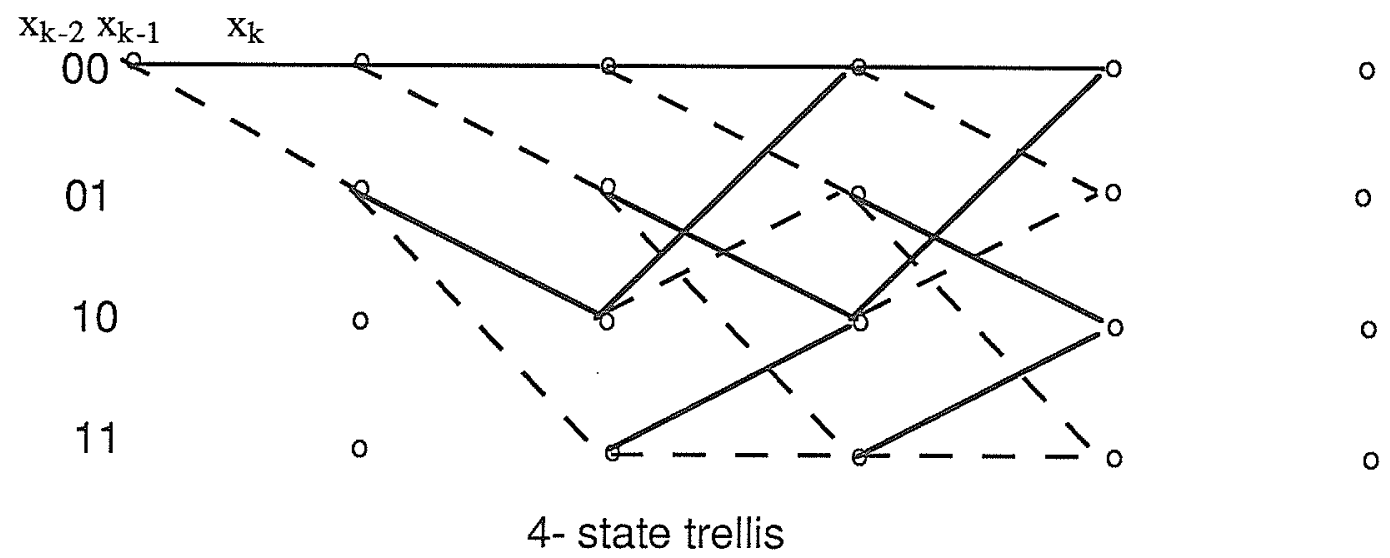

Figure 2.4 
Here one starts from the maximum likelihood metric for a signal in AWGN

$$
\lambda=\int_{-\infty}^{\infty} r(t) s(t) d t-1 / 2 \int_{-\infty}^{\infty} s^{2}(t) d t
$$

which can be simplified to [23, pp. 272-284]

$$
\lambda=\sum_{\mathrm{k}}\left[\left(\mathrm{a}_{\mathrm{k}}-\sum_{\mathrm{i}=1}^{\mathrm{v}} \mathrm{x}_{\mathrm{k}-\mathrm{i}} \mathrm{R}_{\mathrm{i}}\right) \mathrm{x}_{\mathrm{k}}\right]
$$

with the notation used earlier. Therefore in this case it is sufficient to obtain the output of the matched filter. A similar trellis search can be done in this situation as well. What changes is the branch metric of the trellis.

\subsection{Sequential algorithm and infinite ISI}

The difference between finite ISI and infinite ISI is apparent from the form of $f(D)$. For infinite ISI $f(D)$ is of the form

$$
\begin{aligned}
& f(D)=\frac{U(D)}{V(D)}=\frac{\sum_{i=0}^{n} u_{i} D^{i}}{1+\sum_{i=1}^{m} v_{i} D^{i}} \\
& y(D)=x(D) f(D)
\end{aligned}
$$

In the time domain

$$
y_{k}=u_{0} x_{k}+\sum_{i=1}^{n} u_{i} x_{k-i}-\sum_{i=1}^{m} v_{i} y_{k-i}
$$

Based on the difference equation for $\mathrm{y}_{k}$ the system can be modelled as a feedback filter and a tree can be developed as illustrated by Figures 2.5 and 2.6 respectively for f(D). As shown by Xiong [24] the sequential algorithm can be applied in this case. The algorithm searches a tree to determine the maximum likelihood path among the explored paths of different lengths. 


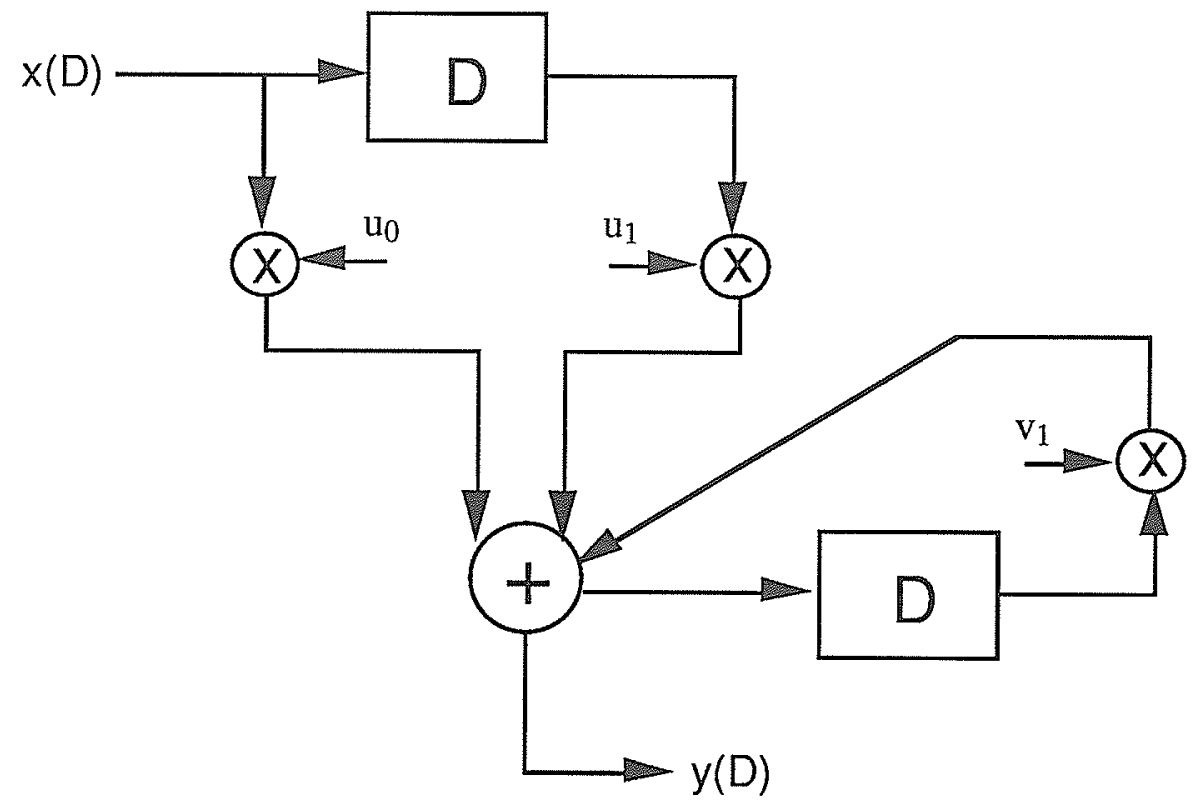

Figure 2.5: Feed Back Filter; $f(D)=\frac{u_{0}+u_{1} D}{1+v_{1} D}$

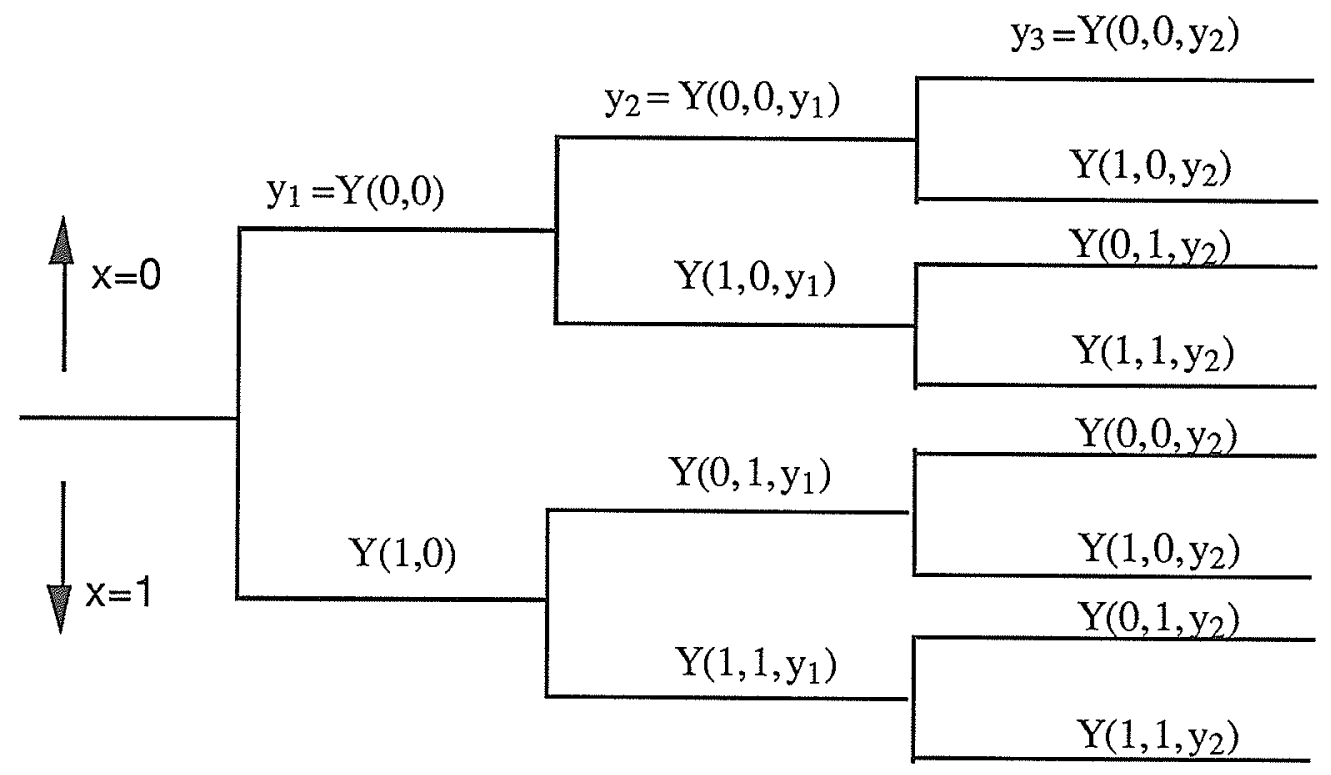

Figure 2.6: Tree $\quad y_{k}=Y\left(x_{k}, x_{k-1}, y_{k-1}\right)$ 
The metric for the sequential algorithm for the ISI channel with an equally likely m-ary input sequence, is given below.

$$
\begin{aligned}
L\left(X_{1}, z\right) & =\sum_{k=1}^{n_{1}}\left[\log \frac{p_{n}\left(z_{k}-y_{k}\right)}{p_{z}\left(z_{k}\right)}-\log m\right] \\
& =\sum_{k} L\left(y_{k}, z_{k}\right)
\end{aligned}
$$

where

$$
L\left(y_{k}, z_{k}\right)=\log \frac{p_{n}\left(z_{k}-y_{k}\right)}{p_{z}\left(z_{k}\right)}-\log m
$$

is the branch metric.

Here $X_{1}$ is the input sequence, $n_{1}$ is the number of input symbols, $z_{k}$ is the received sequence and $p_{n}($.$) is the noise probability density function, i.e.$

$$
\mathrm{p}_{\mathrm{n}}(\mathrm{x})=\frac{1}{\sqrt{2 \Pi} \sigma} \exp \left\{\frac{-\mathrm{x}^{2}}{2 \sigma^{2}}\right\}
$$

In the finite case

$$
\begin{aligned}
\mathrm{p}_{\mathrm{z}}\left(\mathrm{z}_{\mathrm{k}}\right) & =\frac{1}{\mathrm{~m}^{\mathrm{L}}} \sum_{\mathrm{j}=1}^{\mathrm{m}^{\mathrm{L}} \frac{1}{\sqrt{2 \Pi} \sigma}} \exp \left\{\frac{-\left(\mathrm{z}_{\mathrm{k}}-\mathrm{b}_{\mathrm{j}}\right)^{2}}{2 \sigma^{2}}\right\} \\
\mathrm{b}_{\mathrm{j}} \varepsilon \mathrm{y}_{\mathrm{k}} \quad \mathrm{y}_{\mathrm{k}} & =\mathrm{f}\left(\mathrm{x}_{\mathrm{k}}, \ldots ., \mathrm{x}_{\mathrm{k}-\mathrm{v}}\right)
\end{aligned}
$$

For the infinite case, although the channel has infinite memory, $y_{k}$ is a function of the input sequence up to time $\mathrm{k}$. ie,

$$
\mathrm{y}_{\mathrm{k}}=\mathrm{f}\left(\mathrm{x}_{1}, \ldots . ., \mathrm{x}_{\mathrm{k}}\right)
$$

as is easily seen from equation (2.29). Thus

$$
\mathrm{p}_{z}\left(\mathrm{z}_{\mathrm{k}}\right)=\frac{1}{\mathrm{~m}^{\mathrm{k}}} \sum_{\mathrm{j}=1}^{\mathrm{m}^{\mathrm{k}}} \frac{1}{\sqrt{2 \Pi \sigma}} \exp \left\{\frac{-\left(\mathrm{z}_{\mathrm{k}}-\mathrm{b}_{\mathrm{j}}\right)^{2}}{2 \sigma^{2}}\right\}
$$

Unlike the finite ISI case, here $\mathrm{p}_{\mathrm{z}}\left(\mathrm{z}_{\mathrm{k}}\right)$ is dependent on the time index $\mathrm{k}$. However, since the impulse response of physical channels decays with time one can safely truncate it at a length $\mathrm{L}^{*} \mathrm{~T}$. Beyond this length the terms should not have a significant effect on ISI and also on $\mathrm{p}_{\mathrm{z}}\left(\mathrm{z}_{\mathrm{k}}\right)$. 


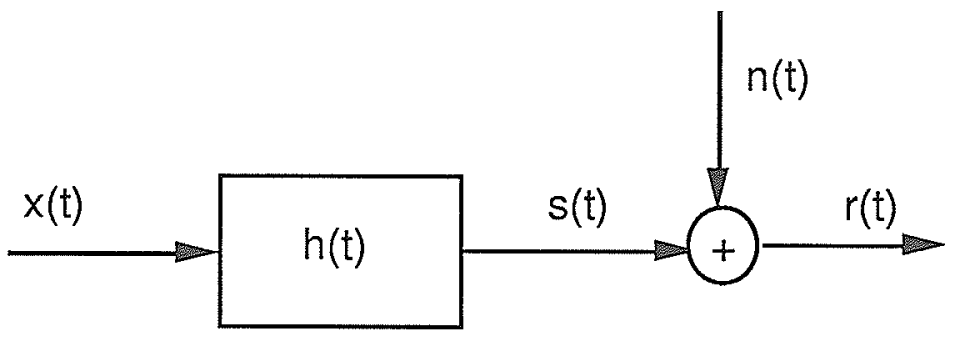

$$
E\{n(t), n(\tau)\}=K_{n}(t-\tau) ; S_{n}(\omega)=\int_{-\infty}^{\infty} K_{n}(t-\tau) e^{-j \omega(t-\tau)} d(t-\tau)
$$

Figure 2.7

\begin{tabular}{|l|l|l|l|l|l|}
$\mid H(t)=\frac{1}{S_{n}(\omega)}$ & $\begin{array}{l}r^{*}(t)=s^{*}(t)+n^{*}(t) \\
n^{*}(t)-\text { white noise } \\
s^{*}(t) \text { - may have infinite ISI }\end{array}$
\end{tabular}

Figure 2.8 


\subsection{Colored noise}

The communication system model, shown in Figure 2.7 is same as previously discussed except that the noise is colored. As mentioned if this problem can be transformed into a white Gaussian problem, then the methods discussed earlier can be applied. A straightforward approach is to use a simple prewhitener to whiten the noise. (See Figure 2.8). Since, in general, the autocorrelation function extends to infinity the impulse response of the prewhitener can also last an infinite time leading to infinite ISI. One may use the sequential algorithm or the Viterbi algorithm if the ISI is truncated. Ungerboeck [20] used the Viterbi algorithm where he obtained finite ISI by truncation.

An alternative approach would be to develop a prewhitener whose impulse response is finite. Without ISI this is a well studied problem and is described in many texts. Van Trees [21] suggested three different interpretations of the same method for obtaining a finite impulse response prewhitener. These are shown in the block diagrams of Figures $2.9 \mathrm{a}, 2.9 \mathrm{~b}$ and $2.9 \mathrm{c}$. Here $\mathrm{h}_{\mathrm{w}}(\mathrm{t}, \mathrm{u})$ is the whitening filter over the finite time interval $\left[T_{i}, T_{f}\right], s(t)$ is the signal transmitted in $\left[T_{i}, T_{f}\right]$ and $K_{n}(t, u)$ is the covariance of the colored noise. $Q_{n}(v, x)$ and $g(z)$ are the solutions of the following integral equations.

$$
\begin{gathered}
\delta(z-v)=\int_{T_{i}}^{T_{f}} K_{n}(x, z) Q_{n}(v, x) d x, T_{i} \leq z, v \leq T_{f} \\
g(z)=\int_{T_{i}}^{T_{f}} Q_{n}(z, v) s(v) d v \quad, T_{i} \leq v \leq T_{f} \\
s(t)=\int_{T_{i}}^{T_{f}} K_{n}(t, u) g(u) d u \quad, T_{i} \leq u \leq T_{f}
\end{gathered}
$$




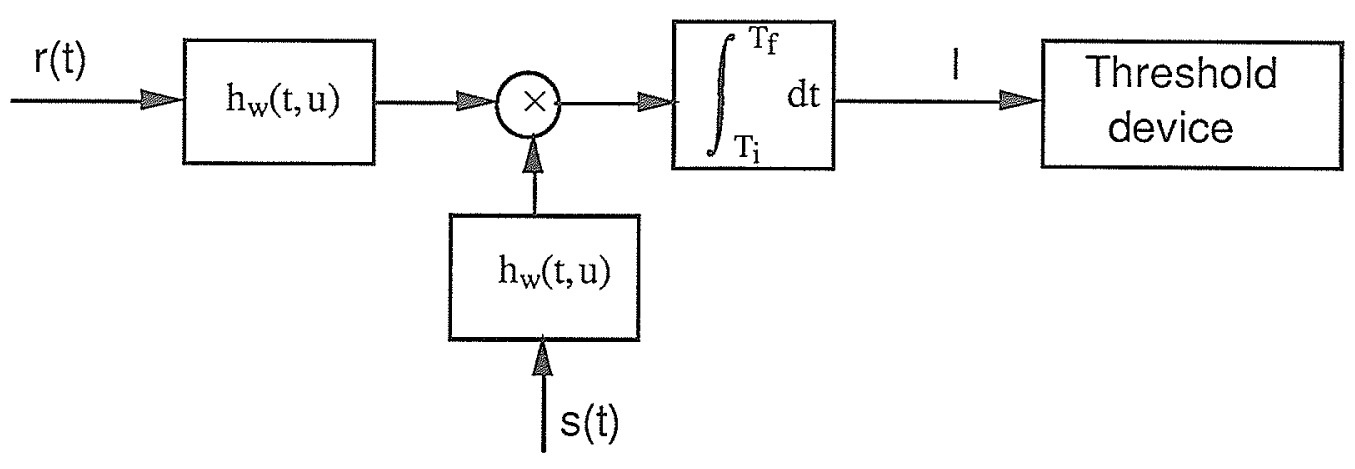

Figure 2.9a

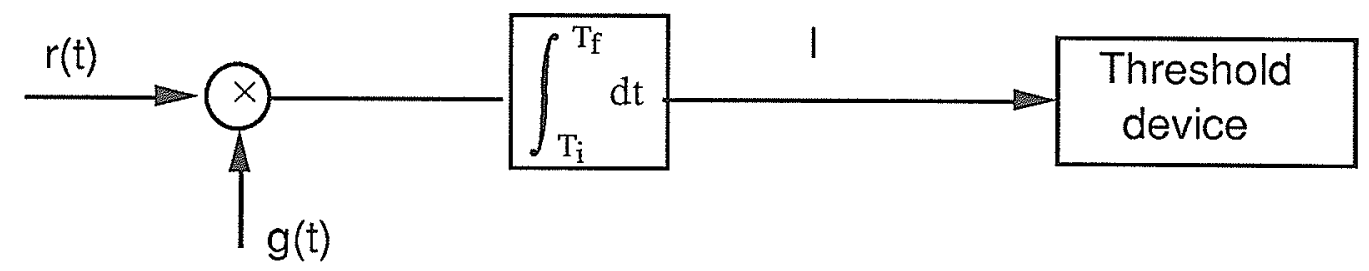

Figure $2.9 \mathrm{~b}$

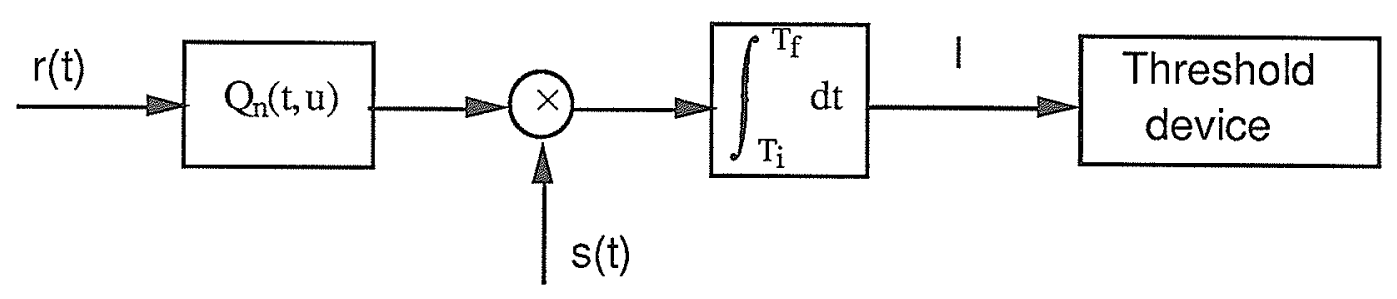

Figure 2.9c 


\section{Chapter 3}

\section{Theory}

\subsection{Introduction}

In chapter 2, various options available to deal with the colored noise problem were discussed. The procedures are different depending on whether the Viterbi algorithm or the sequential algorithm are to be used. In this chapter a method is presented to obtain the maximum likelihood metric for the application of the Viterbi algorithm. Also the receiver structure to obtain sufficient statistics for the sequential algorithm is derived. The metric in the case of the sequential algorithm is the same as that developed by Xiong [24].

\subsection{Development of the maximum likelihood metric for ISI in colored Gaussian noise}

The approach here is to whiten the colored noise. To apply the Viterbi algorithm the intersymbol interference should be finite. Therefore a whitening filter with a finite impulse response has to be used. A PAM communication system with additive colored Gaussian noise introduced previously is used as shown in Figure 3.1.

The receiver is shown in Figure 3.2, where the receiver structure of Figure 2.9b, 


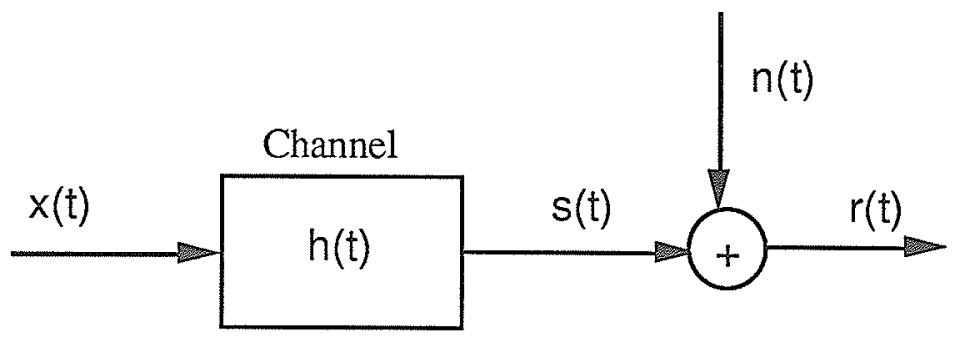

Figure 3.1

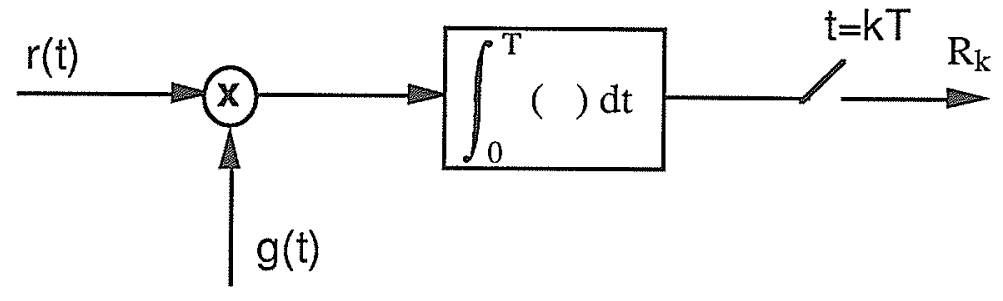

Figure 3.2 
is used to whiten the noise. The whitening is achieved through $g(t)$, and is equivalent to passing both $r(t)$ and $s(t)$ through a whitening filter. The output samples provide the sufficient statistics for the maximum likelihood sequence estimation (MLSE).

Given the finite time whitening of the colored noise of Figure 3.2 the metric to be evaluated is

$$
\lambda_{\mathrm{T}}=\int_{0}^{\mathrm{T}} \mathrm{r}(\mathrm{t}) \mathrm{g}(\mathrm{t}) \mathrm{dt}-1 / 2 \int_{0}^{\mathrm{T}} \mathrm{s}(\mathrm{t}) \mathrm{g}(\mathrm{t}) \mathrm{dt}, 0 \leq \mathrm{t} \leq \mathrm{T}
$$

where $g(t)$ satisfies the integral equation

$$
\mathrm{s}(\mathrm{t})=\int_{0}^{\mathrm{T}} \mathrm{g}(\mathrm{u}) \mathrm{K}_{\mathrm{n}}(\mathrm{t}, \mathrm{u}) \mathrm{du} \quad, 0 \leq \mathrm{t} \leq \mathrm{T}
$$

Since the time interval is $[0, T]$, the only part of $s(t)$ that needs to be considered in the equations is that within the time interval $[0, T]$. It is equal to

$$
\mathrm{s}_{\mathrm{T}}(\mathrm{t})=\sum_{\mathrm{k}=-\mathrm{v}}^{0} \mathrm{a}_{\mathrm{k}} \mathrm{h}(\mathrm{t}-\mathrm{kT})
$$

${ }^{s_{T}}(t)$ is affected by the present input and previous $v$ inputs, ie, the length of ISI.The metric, $\lambda_{T}$, also is calculated over this interval.

Since at the output of the receiver the noise samples are statistically independent, one can express the complete metric as

$$
\lambda=\sum_{\mathrm{k}} \lambda_{\mathrm{T}_{\mathrm{k}}}
$$

where $\lambda_{\mathrm{T}_{\mathrm{k}}}$ is the branch metric for the $\mathrm{k}^{\text {th }}$ interval.

To illustrate the procedure of whitening, a model for the noise spectrum has to be assumed. When the spectrum does not have a white noise component, it can be expressed as

$S_{n}(\omega)=\frac{N\left(\omega^{2}\right)}{D\left(\omega^{2}\right)}$, degree $N\left(\omega^{2}\right) \leq$ degree $D\left(\omega^{2}\right)+1$

Since there is no white noise component, the noise autocorrelation function $\mathrm{K}_{\mathrm{n}}(\mathrm{t}, \mathrm{u})$ does not contain singularities. 
The general solution to the integral equation (3.2) in this case is given by

$$
g(t)=g_{\infty}(t)+\sum_{i} a_{i} g_{i}(t)+\sum_{k}\left[b_{k} \delta^{(k)}(t)+c_{k} \delta^{(k)}(t-T)\right], 0 \leq t \leq T .
$$

$g_{\infty}(t)$ is the infinite time solution and $g_{i}(t)$ 's are the homogeneous solutions for the corresponding differential equation. The coefficients $b_{k}$ 's and $c_{k}$ 's associated with the impulse function, $\delta$, and its derivatives, $\delta^{(\kappa)}$, are determined by the end conditions.

When a white component is present in the noise spectrum it can be given by

$$
S_{n}(\omega)=\frac{N_{0}}{2}+S_{c}(\omega)=\frac{N\left(\omega^{2}\right)}{D\left(\omega^{2}\right)}
$$

where $S_{C}(\omega)$ is the colored component. Both $N\left(\omega^{2}\right)$ and $D\left(\omega^{2}\right)$ are of the same degree due to the white component .

The autocorrelation function therefore, has the form

$$
\mathrm{K}_{\mathrm{n}}(\mathrm{t}, \mathrm{u})=\frac{\mathrm{N}_{0}}{2} \delta(\mathrm{t}-\mathrm{u})+\mathrm{K}_{\mathrm{c}}(\mathrm{t}, \mathrm{u})
$$

The integral equation (3.2) now becomes

$$
s(t)=\frac{N_{0}}{2} g(t)+\int_{0}^{T} K_{c}(t, u) g(u) d u
$$

with a solution of the form

$$
g(t)=g_{\infty}(t)+\sum_{i} a_{i} g_{i}(t)
$$

The presence of the white component results in a solution for $g(t)$ that does not contain singular functions.

\subsection{Examples}

Derivation of the metrics for the noise models given above are presented using the following examples. First finite time whitening is considered.

(i) Noise does not contain a white component

$$
S_{n}(\omega)=\frac{2 k \sigma_{n}^{2}}{\omega^{2}+k^{2}} \Rightarrow K_{n}(t, u)=\sigma_{n}^{2} \exp (-k|t-u|)
$$


The results are not dependent on the channel and all that is assumed about the channel impulse response, $h(t)$, is that it is of finite duration, LT seconds.

The integral equation corresponding to (3.11) is

$$
\mathrm{s}_{\mathrm{T}}(\mathrm{t})=\sigma_{\mathrm{n}}^{2} \int_{0}^{\mathrm{T}} \exp (-\mathrm{k}|\mathrm{t}-\mathrm{u}|) \mathrm{g}(\mathrm{u}) \mathrm{du}
$$

Converting this into a differential equation, the infinite solution, $g_{\infty}(t)$, is obtained from the differential equation

$$
s^{\prime \prime} T(t)+k^{2} S_{T}(t)=2 k \sigma_{n g_{\infty}}^{2}(t), 0 \leq t \leq T
$$

and is

$$
\mathrm{g}_{\infty}(\mathrm{t})=\frac{1}{2 \mathrm{k} \sigma_{\mathrm{n}}^{2}}\left\{-\mathrm{s}^{\prime \prime} \mathrm{T}(\mathrm{t})+\mathrm{k}^{2} \mathrm{ST}_{\mathrm{T}}(\mathrm{t})\right\}
$$

To get the complete solution for $g(t),(3.13)$ is substituted back into the integral equation, where $\delta$ functions are included in the solution to satisfy the end conditions. Therefore,

$$
\begin{aligned}
g(t) & =g_{\infty}(t)+b_{1} \delta(t)+c_{1} \delta(t-T) \\
b_{1} & =\frac{k s_{T}(0)-s_{T}^{\prime}(0)}{k \sigma_{n}^{2}} \quad c_{1}=\frac{k s_{T}(T)+s_{T}^{\prime}(T)}{k \sigma_{n}^{2}} \\
s_{T}(t) & =\sum_{l=-v}^{0} a_{1} h(t-1 T), 0 \leq t \leq T
\end{aligned}
$$

Given $g(t)$ and $s_{T}(t)$, the branch metric from equation (3.1) is

$$
\begin{gathered}
\lambda_{\mathrm{T}}=\sum_{\mathrm{l}=-\mathrm{v}}^{0} \mathrm{a}_{1}\left[\mathrm{R}_{\mathrm{l}}-\sum_{\mathrm{m}=-\mathrm{v}}^{0} \mathrm{c}_{\mathrm{lm}} \mathrm{a}_{\mathrm{m}}\right]+ \\
\text { where } \mathrm{R}_{\mathrm{l}}=\int_{0}^{\mathrm{T}}\left[\mathrm{r}(0)-0.5 \mathrm{~s}_{\mathrm{T}}(0)\right]+\mathrm{c}_{1}\left[\mathrm{r}(\mathrm{T})-0.5 \mathrm{~s}_{\mathrm{T}}(\mathrm{T})\right] \\
\left.\left.\mathrm{c}_{\mathrm{lm}}=0.5 \int_{0}^{\mathrm{T}}\left[\mathrm{k}^{2} \mathrm{~h}(\mathrm{t}-\mathrm{t}-\mathrm{mT})-\mathrm{h}^{(2)}(\mathrm{t}-\mathrm{m} \mathrm{h})\right] \mathrm{h}(\mathrm{t}-\mathrm{lT}) \mathrm{dt}-\mathrm{tT}\right)\right] \mathrm{r}(\mathrm{t}) \mathrm{dt}
\end{gathered}
$$


For the simulation a raised cosine channel of impulse response

$$
h(t)=\frac{1}{2 \mathrm{LT}}\left\{1-\operatorname{Cos}\left(\frac{2 \Pi}{\mathrm{LT}}\right) \mathrm{t}\right\} \quad, 0 \leq \mathrm{t} \leq \mathrm{LT}
$$

is used.

\section{(ii) Colored noise with a white noise component}

$$
S_{n}(\omega)=\frac{\sigma_{\mathrm{n}}^{2}\left(\omega^{2}+\gamma^{2}\right)}{\left(\omega^{2}+\mathrm{k}^{2}\right)}=\sigma_{\mathrm{n}}^{2}+\frac{2 \mathrm{k} \sigma_{\mathrm{c}}^{2}}{\left(\omega^{2}+\mathrm{k}^{2}\right)}
$$

Because of the white noise component the results are dependent on the channel impulse response. The response that is used here for the channel is that of the simple low pass single pole filter;

$$
\begin{aligned}
h(t) & =a^{-b t} \quad ; \quad 0 \leq h(t) \leq L T \\
s_{T}(t) & =\sum_{1=-v}^{0} a_{1} h(t-1 T), 0 \leq t \leq T
\end{aligned}
$$

The integral equation to be solved for $g(t)$ is

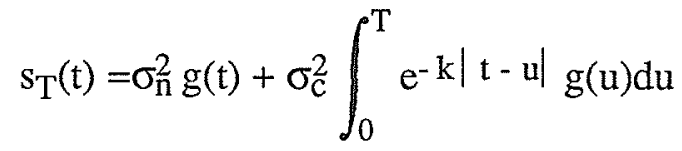

From (3.24) the complete solution for $g(t)$ is found to be

$$
g(t)=\left[\sum_{1=-v}^{0} a_{1} e^{b l T}\right]\left(A_{1} e^{-b t}+A_{2} e^{-\gamma t}+A_{3} e^{\gamma t}\right)
$$

The branch metric, from equation (3.1), then is

$$
\begin{aligned}
\lambda_{\mathrm{T}} & =\left[\sum_{\mathrm{l}=-\mathrm{v}}^{0} \mathrm{a}_{1} \mathrm{e}^{\mathrm{bT}}\right]\left(\mathrm{R}_{\mathrm{T}}-\mathrm{c} \sum_{\mathrm{m}=-\mathrm{v}}^{0} \mathrm{a}_{\mathrm{m}} \mathrm{e}^{\mathrm{bmT}}\right) \\
\text { where } \quad \mathrm{R}_{\mathrm{T}} & =\int_{0}^{\mathrm{T}} \mathrm{r}(\mathrm{t})\left(\mathrm{A}_{1} \mathrm{e}^{-\mathrm{bt}}+\mathrm{A}_{2} \mathrm{e}^{-\gamma \mathrm{t}}+\mathrm{A}_{3} \mathrm{e}^{\gamma \mathrm{t}}\right) d \mathrm{t}
\end{aligned}
$$

and $\mathrm{c}$ is a known constant.

In the above two examples finite time whitening has been discussed. For comparison consider whitening over an infinite time interval. The metric can be 


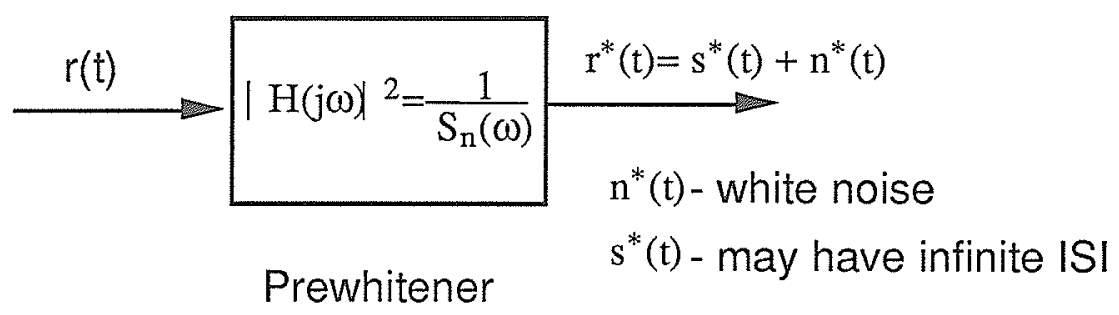

Figure 3.3

obtained simply by finding $g_{\infty}(t)$ instead of $g(t)$ and evaluating the following equation,

$$
\begin{aligned}
\lambda & =\int_{-\infty}^{\infty} r(t) g_{\infty}(t) d t-1 / 2 \int_{-\infty}^{\infty} s(t) g_{\infty}(t) d t \\
G_{\infty}(\omega) & =\frac{S(\omega)}{S_{n}(\omega)}
\end{aligned}
$$

where $G_{\infty}(\omega)$ is the Fourier transform of $g_{\infty}(t)$.

$$
\mathrm{s}(\mathrm{t})=\sum \mathrm{a}_{\mathrm{k}} \mathrm{h}(\mathrm{t}-\mathrm{kT}) \quad,-\infty<\mathrm{t}<\infty
$$

Or, one may use the prewhitener in frequency domain as shown in Figure 3.3.

The metric for this method is

$$
\lambda=\int_{-\infty}^{\infty} r^{*}(t) s^{*}(t) d t-1 / 2 \int_{-\infty}^{\infty}\left[s^{*}(t)\right]^{2} d t
$$

where $\quad s *(t)=\sum_{1=-N}^{N-1} a_{1} f(t-1 T)=s(t) * h_{p w}(t) ; f(t)=h(t) * h_{p w}(t)$

The metric for the above examples for infinite time whitening can easily be obtained from equations (3.31) and (3.32). Using these, the metric simplifies to

$$
\begin{aligned}
& \lambda=\sum_{1}\left(R_{1}-\sum_{j=1}^{v 1} a_{1}-j f_{j}\right) a_{1}, R_{1}=\int_{-\infty}^{\infty} r^{*}(t) f(t-l T) d t \\
& f_{j}=\int_{-\infty}^{\infty} f(t) f(t-j T) d t
\end{aligned}
$$

where $\mathrm{v} 1$ is the length of interference due to $\mathrm{f}(\mathrm{t})$. 
For the first example of single pole noise

$$
\begin{aligned}
& f(t)=c_{1} \cdot h(t)+c_{2} \cdot h^{\prime}(t) \\
& \quad \text { where } c_{1} \text { and } c_{2} \text { are constants. }
\end{aligned}
$$

In general if the noise spectrum is all pole then $f(t)$ consists only of derivatives of $h(t)$. Therefore in this case the number of interference terms is equal to that obtained for the finite solution.

For the second example $f(t)=c_{3} \cdot h(t)+c_{4} \cdot e^{-\gamma t}$

where $c_{3}$ and $c_{4}$ are constants.

Because of the term $e^{-\gamma t}, f(t)$ lasts for an infinite time. This means that in this case if the infinite time solution is to be used infinite intersymbol interference results. Therefore in this case the tail of the interference terms has to be truncated to v1 which is generally larger than the interference terms due to channel.

\subsection{Comparison between finite and infinite time metrics}

For the finite time solution initially the branch metric is evaluated which is directly used by the Viterbi algorithm. Here $g(t)$ is always dependent on the present input and the previous $v$ inputs which constitute the ISI. Thus the general form of $g(t)$ is

Therefore

$$
\begin{aligned}
g(t) & =\sum_{1=-v}^{0} a_{1} f_{1}(t), 0 \leq t \leq T \\
\lambda_{T} & =\sum_{1=-v}^{0} \int_{0}^{T} r(t) f_{1}(t) d t-1 / 2 \int_{0}^{T} s(t) g(t) d t \\
\lambda_{T} & =\sum_{1=-v}^{0} a_{l} R_{1}-1 / 2 \int_{0}^{T} s(t) g(t) d t
\end{aligned}
$$

$\lambda_{\mathrm{T}}$ is the branch metric which is affected only by the $\mathrm{v}$ interfering terms.Thus the amount of ISI is independent of the whitening process. The term $\sum_{1=-\mathrm{v}}^{0} a_{1} R_{1}$ indicates that $\mathrm{L}$ observed variables are necessary to calculate $\lambda_{\mathrm{T}}$. Thus $\mathrm{L}$ matched filters are required at the receiver. 
For the infinite time whitening as seen from equation (3.32)

$$
f(t)=h(t) * h_{p w}(t)
$$

If $S_{n}(\omega)$ contains zeros they would appear in $h_{p w}(t)$ as exponential terms $\sum_{i} p_{i} e^{-a_{i} t}$ which span an infinite time. This immediately implies that unless these terms are truncated, infinite ISI results .

The complete metric, from equation (3.33)

$$
\lambda=\sum_{1}\left(R_{1}-\sum_{j=1}^{v 1} a_{1-j} f_{j}\right) a_{l} \quad, R_{1}=\int_{-\infty}^{\infty} r^{*}(t) f(t-l T) d t
$$

Hence only one observed variable is needed to calculate the metric requiring only one matched filter as opposed to $L$ required for the implementation of the finite time metric.

\subsection{Application of the Sequential algorithm}

To apply the sequential algorithm the approach developed by Xiong is used here. For this approach a sufficient condition is that the noise samples at the output of the receiver must be statistically independent. A prewhitener is used up front to whiten the colored noise as in the previous section dealing with the infinite time interval whitening. This, as shown in section 3.3, could lead to infinite intersymbol interference. Since the output of the prewhitener can be considered as a signal with intersymbol interference in additive white Gaussian noise, a whitened matched filter is followed next as shown by Forney [5], representing the standard procedure for this kind of system. The communication system is shown in Figure 3.4 in block diagram form.

$$
\begin{aligned}
\mathrm{s} *(\mathrm{t}) & =\mathrm{s}(\mathrm{t}) * \mathrm{~h}_{\mathrm{pw}}(\mathrm{t})=\mathrm{x}(\mathrm{t}) * \mathrm{~h}(\mathrm{t}) * \mathrm{~h}_{\mathrm{pw}}(\mathrm{t}) \\
& =\mathrm{x}(\mathrm{t}) * \mathrm{~h}_{\mathrm{R}}(\mathrm{t})=\sum_{\mathrm{k}} \mathrm{x}_{\mathrm{k}} \mathrm{h}_{\mathrm{R}}(\mathrm{t}-\mathrm{kT})
\end{aligned}
$$

Now as in the usual case sufficient statistics can be obtained after passing $r^{*}(t)$ through 


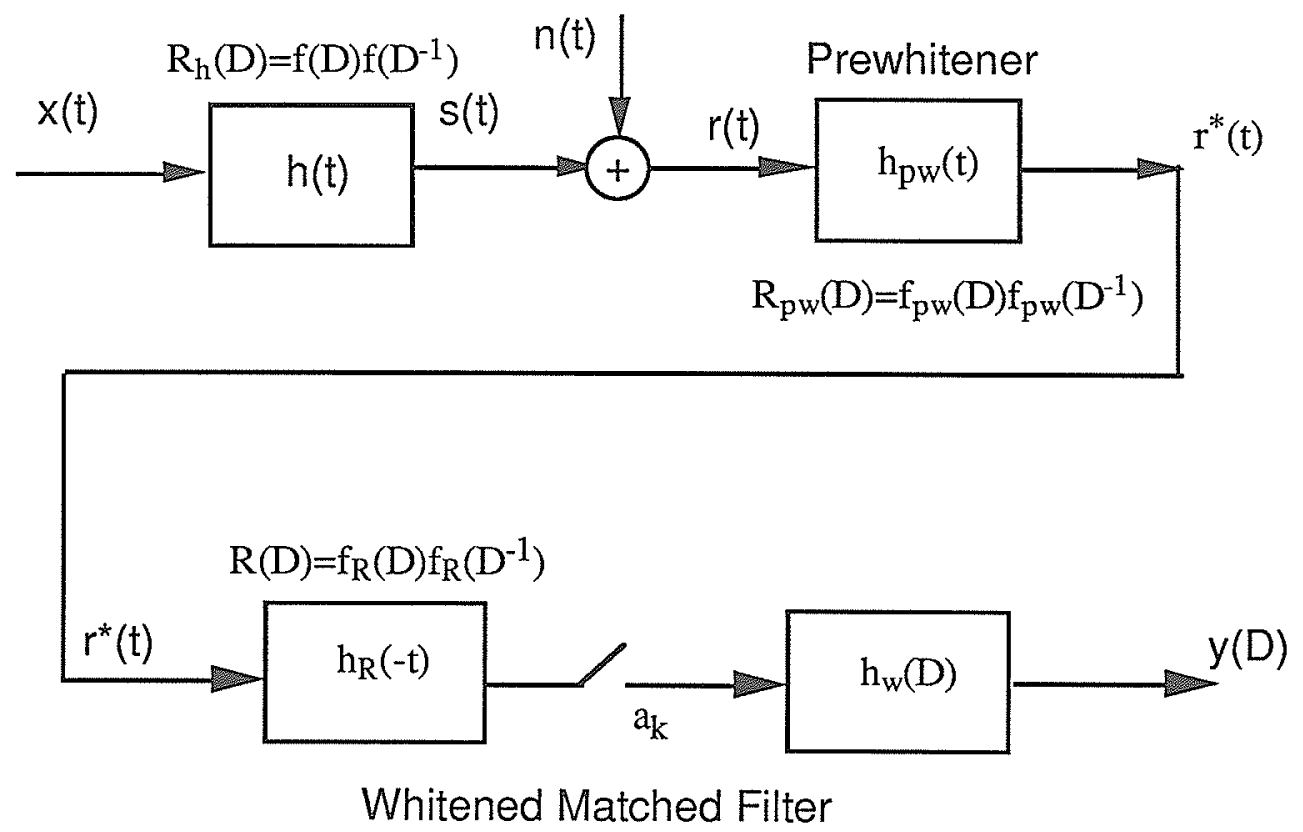

Figure 3.4 
the matched filter $h_{R}(-t)$. At the output of $h_{R}(-t)$ the noise samples have to be whitened again.

$$
\begin{aligned}
a_{j} & =\int_{-\infty}^{\infty} \sum_{k} x_{k} h_{R}(t-k T) h_{R}(t-j T) d t+\int_{-\infty}^{\infty} w(t) h_{R}(t-j T) d t \\
& =\sum_{i} x_{j-i} h_{R_{i}}+n_{j}
\end{aligned}
$$

In $\mathrm{D}$ transform notation

$$
a(D)=x(D) R(D)+n(D)
$$

Using spectral factorization

$$
R(D)=f_{R}(D) f_{R}\left(D^{-1}\right)
$$

where $R(D)$ is the discrete autocorrelation function of $h_{R}(t)$.

Following Forney's approach

$$
a(D)=x(D) f_{R}(D) f_{R}\left(D^{-1}\right)+w(D) f_{R}\left(D^{-1}\right)
$$

Since statistically independent samples are required, a(D) has to be passed through a whitening filter in the discrete domain, ie, $1 / \mathrm{f}_{\mathrm{R}}\left(\mathrm{D}^{-1}\right)$.

$$
\begin{aligned}
y(D) & =\frac{a(D)}{\left.f_{R} D^{-1}\right)}=x(D) f_{R}(D)+w(D) \\
h_{w}(D) & =\frac{1}{f_{R}\left(D^{-1}\right)}
\end{aligned}
$$

where $h_{w}(D)$ is the whitening filter.

Since $h_{R}(t)=h(t) * h_{p w}(t), R(D)$ can be expressed as

$$
\mathrm{R}(\mathrm{D})=\mathrm{R}_{\mathrm{h}}(\mathrm{D}) * \mathrm{R}_{\mathrm{pw}}(\mathrm{D})
$$

Also

$$
R_{h}(D)=f(D) f\left(D^{-1}\right) \text { and } R_{p w}(D)=f_{p w}(D) f_{p w}\left(D^{-1}\right)
$$

Therefore one can express $f_{R}(D)=f(D) f_{p w}(D)$

Thus

$$
y(D)=x(D) f(D) f_{p w}(D)+w(D)
$$


$y_{j}$ can be found from this and hence the sequential algorithm can be applied following the standard procedure. In general the form of $f_{p w}(D)$ is $\frac{V(D)}{U(D)}$ which usually gives rise to infinite ISI.

$$
y(D)=x(D) f(D) \frac{V(D)}{U(D)}+w(D)
$$




\section{Chapter 4}

\section{Simulation Results}

\subsection{Introduction}

Simulations have been carried out using both the Viterbi algorithm and the Sequential algorithm for different channels, namely the truncated single pole channel, the Butterworth channel and the raised cosine channel. In the case of the Viterbi algorithm, the finite time metric and infinite time metric were investigated. The Sequential algorithm was applied using the approach described in 3.4.

\subsection{Simulation : General}

All the simulations were run on the IBM AMDHAL V7 mainframe computer at the University of Manitoba. The programming language used was FORTRAN 77. The sequential algorithm used in the simulations is a modified version of the one developed by Dr. F.Xiong, and a listing of the program is given in appendix C. Also included is a listing of a program for the Viterbi algorithm in appendix B.

To generate the white noise samples a random number generator subroutine was used. By passing the white noise samples through a shaping filter in the discrete time domain colored noise samples were generated. The discrete shaping filter must be such that the output noise samples have the corresponding discrete autocorrelation function 
of the colored noise considered. This can usually be done by first finding the shaping filter in the continuous time domain and then obtaining the discrete spectral factorization of it's autocorrelation function. This procedure is described in detail in appendix A along with an example.

\subsection{The Raised Cosine Channel}

The first channel studied was the raised cosine channel; a channel commonly found in communication systems. The noise model is single pole, zero mean colored Gaussian noise. As shown in 3.2 the intersymbol interference in this case is finite. Different bandwidths of the noise with respect to the signal were considered for two different lengths of interference; the impulse response being three symbol intervals long and five symbol intervals long.

For an intersymbol interference channel in additive white Gaussian noise the signal to noise ratio is defined at the output of the whitened matched filter. It cannot be defined at the receiver input because the noise power is infinite there. However the power of colored noise is finite, and therefore the signal to noise ratio is, for colored noise, defined at the receiver input.

The simulation results for the finite time metric and the infinite time metric with the Viterbi algorithm are presented in Figures 4.1-4.5. From the results it is seen that the finite time metric performs better when the bandwidth of the colored noise is less than that of the signal, or when the noise looks more colored.

\subsection{The Truncated Single Pole Channel}

This channel was used to gain more insight into the colored noise problem. The impulse response of the channel was truncated at three symbol intervals. The noise in this case was single pole colored noise with a white component, 


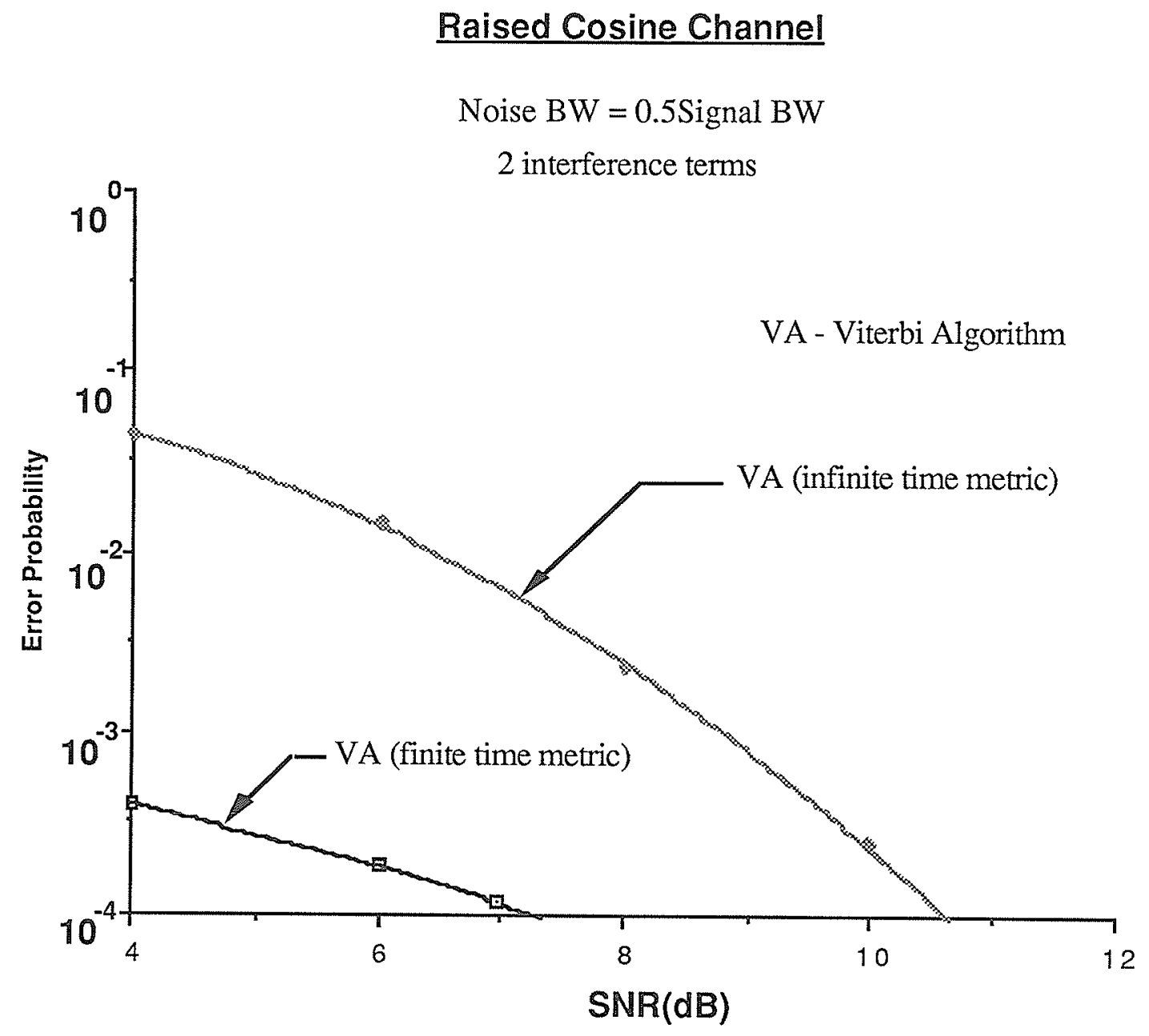

Figure 4.1 


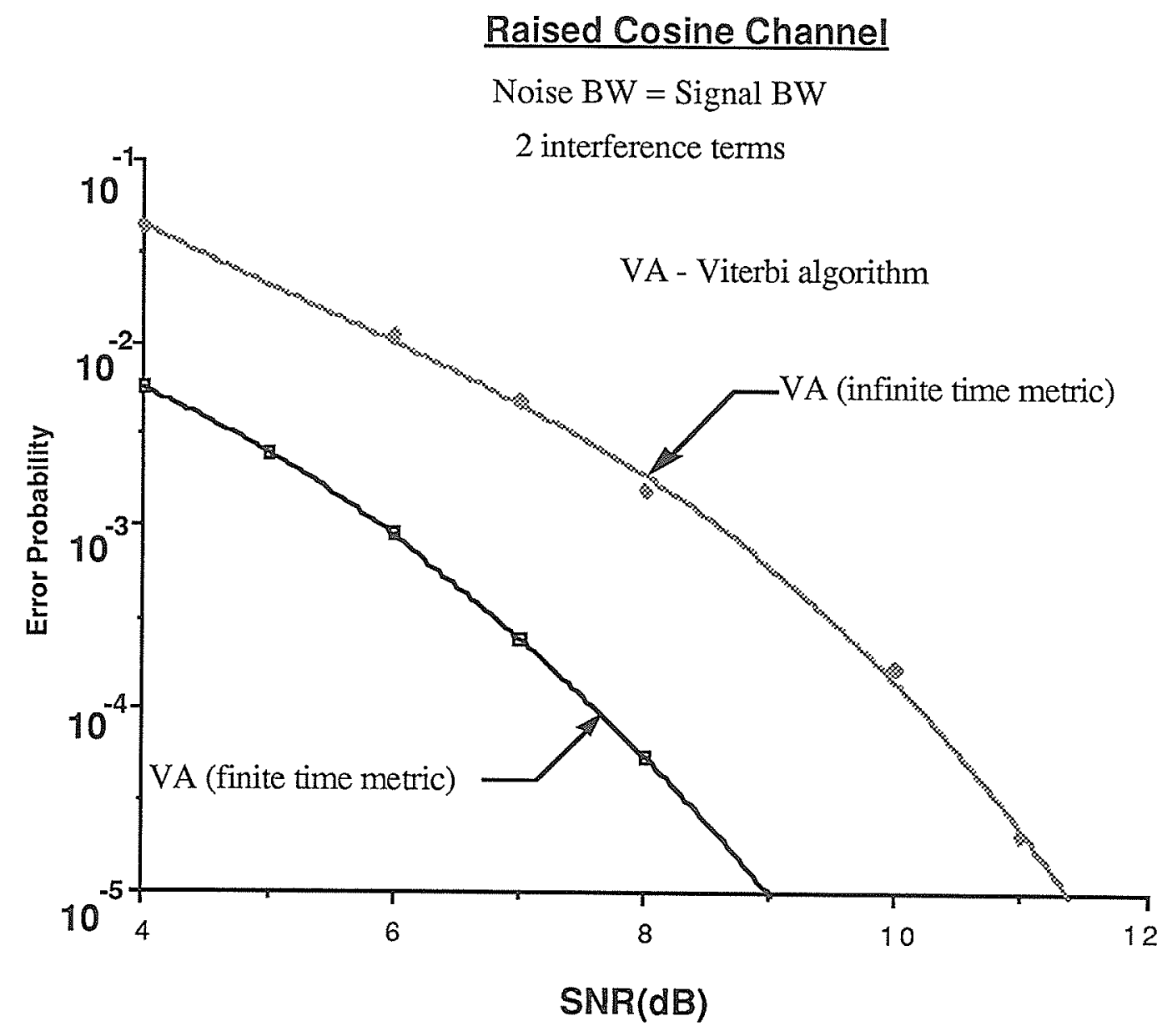

Figure 4.2 


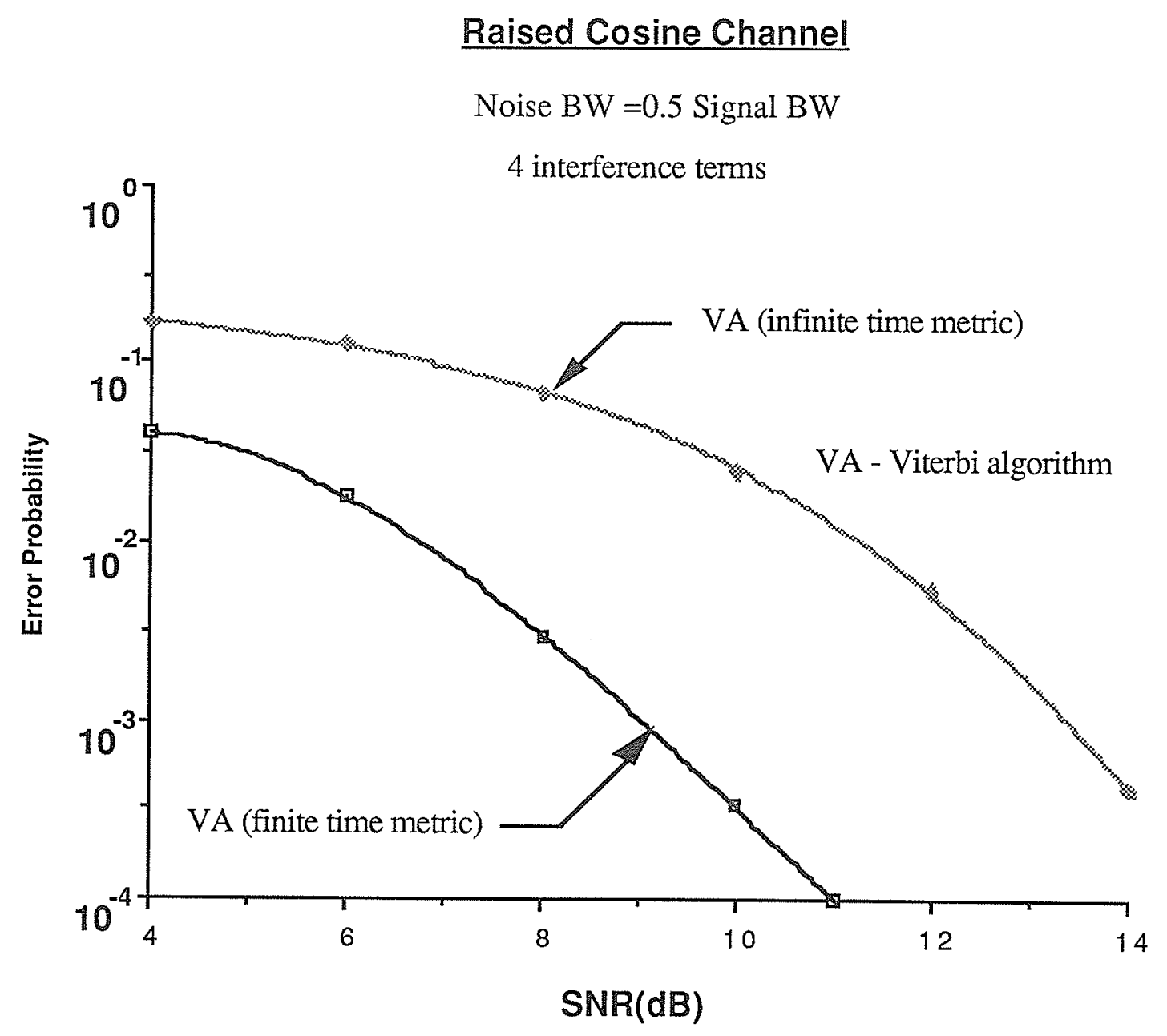

Figure 4.3 


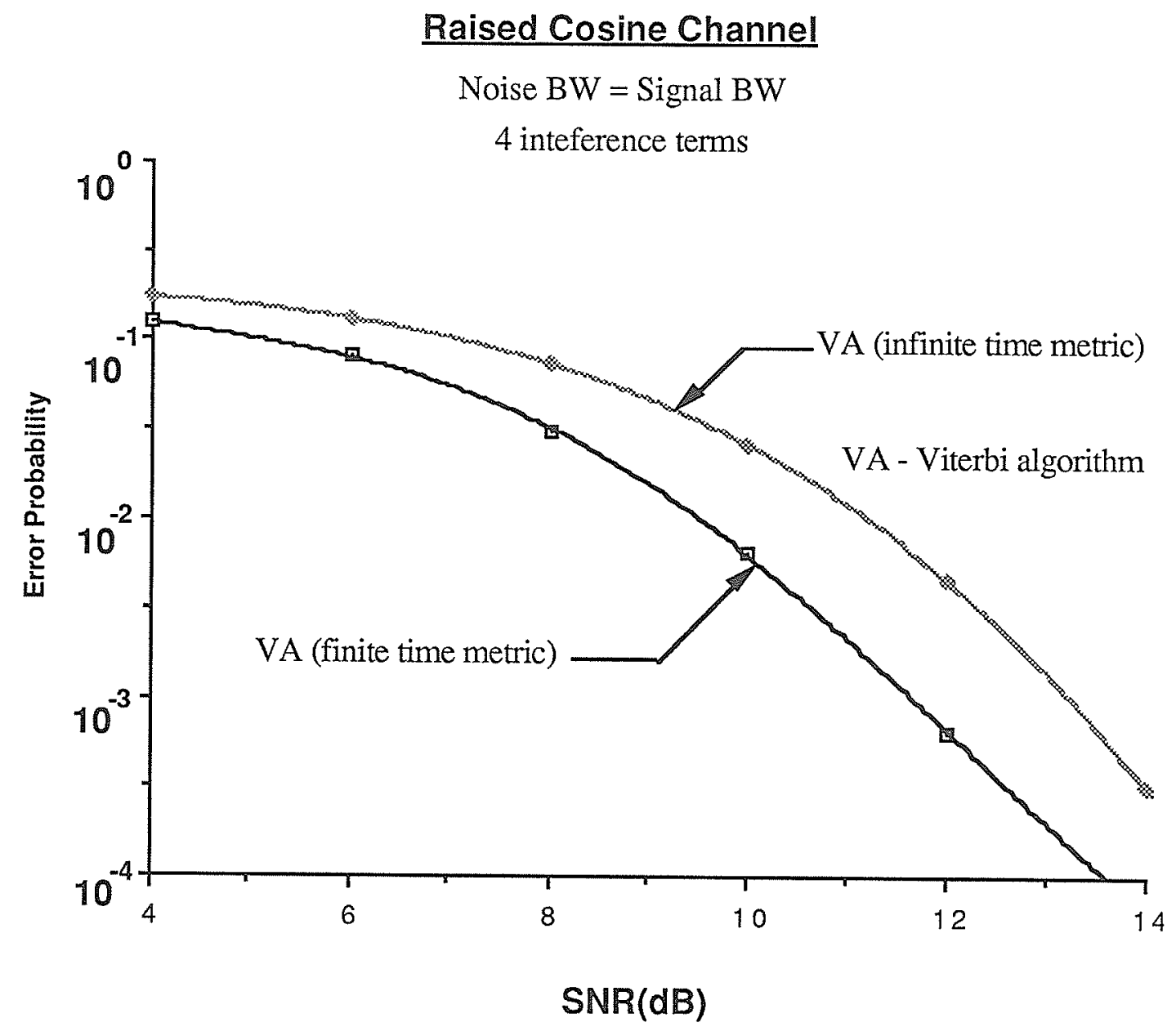

Figure 4.4 


\section{Raised Cosine Channel}

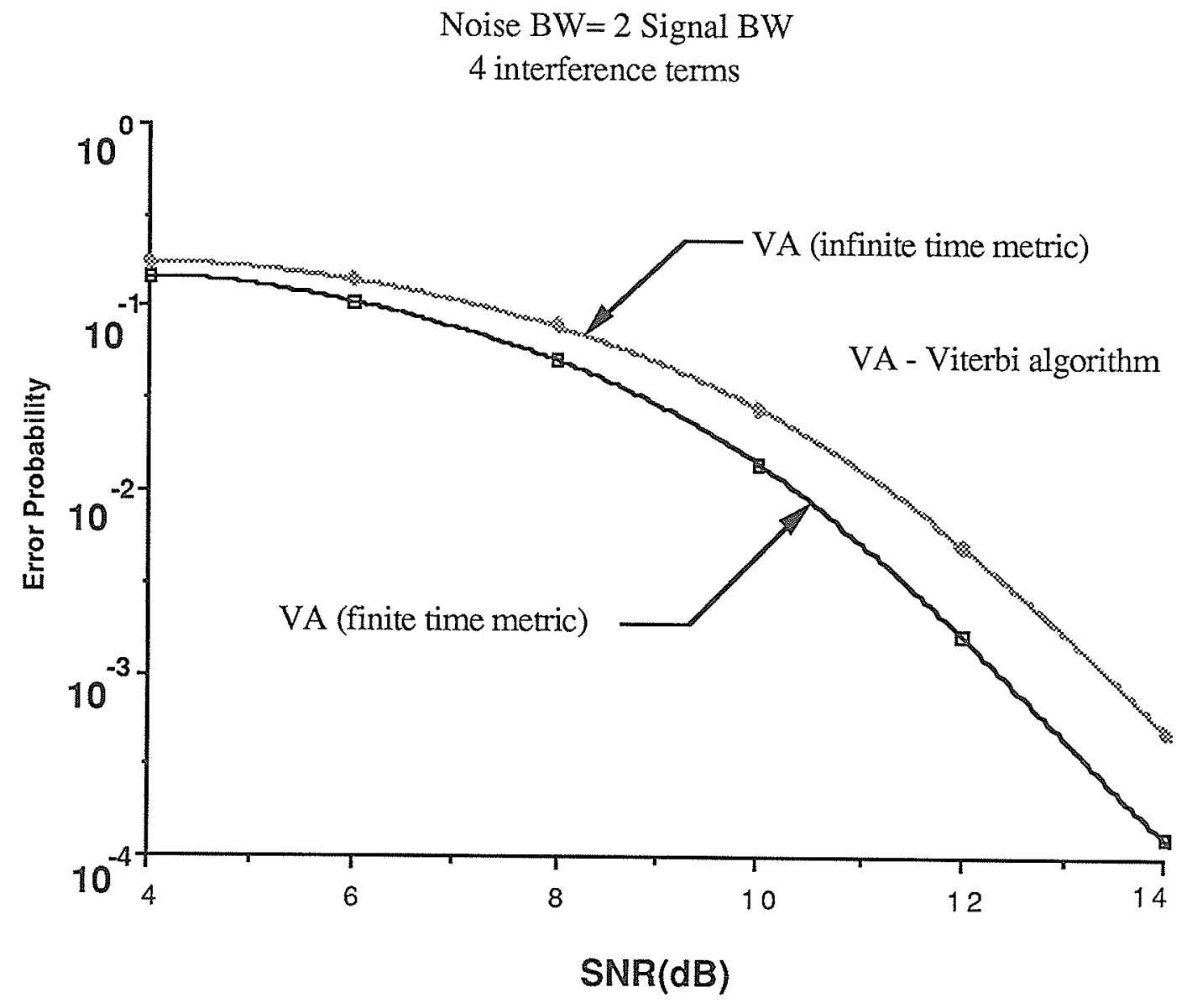

Figure 4.5 
and therefore the noise spectrum has a zero and a pole. Three different mixtures of the colored and white components of the noise spectrum were considered, with the bandwidth of the colored component being the same as that of the signal.

Both the finite time and infinite time metrics for the Viterbi algorithm were applied to this channel with the signal to noise ratio is defined at the receiver input here as well. For the infinite time case, infinite intersymbol interference results due to the zero in the noise spectrum. Thus the interference terms were truncated to five terms. The truncation was based on the decay of the coefficients, where the coefficients smaller than $0.1 \%$ of the leading coefficient, were neglected. For all three noise mixtures the length of truncation was five terms. The number of the states of the trellis for the finite time metric is four compared to thirty two required for the truncated infinite time metric.

The Sequential algorithm was also applied for each of the noise mixtures in an effort to compare the performances of the three approaches. The signal to noise ratio (SNR) was defined at the output of the whitened matched filter as it is the standard way to define the SNR. Simulation results for the algorithms are shown in Figures 4.6-4.9. The number of computations and the CPU time taken per decoded symbol by the two algorithms in each noise mixture are given in Tables 4.1a and 4.1b.

\subsection{The Butterworth Channel}

Finally the Butterworth channel, another commonly encountered channel in communication systems was studied. Since this channel produces infinite intersymbol interference only the Sequential algorithm was applied. For the simulation a two pole Butterworth channel was selected. The noise in this case was Butterworth with a white component; i.e. having a two pole two zero spectrum. As in the single pole case three different combinations of the colored and white components were considered. The 


\section{Truncated Single Pole Channel}

Colored noise $75 \%$ White noise $25 \%$

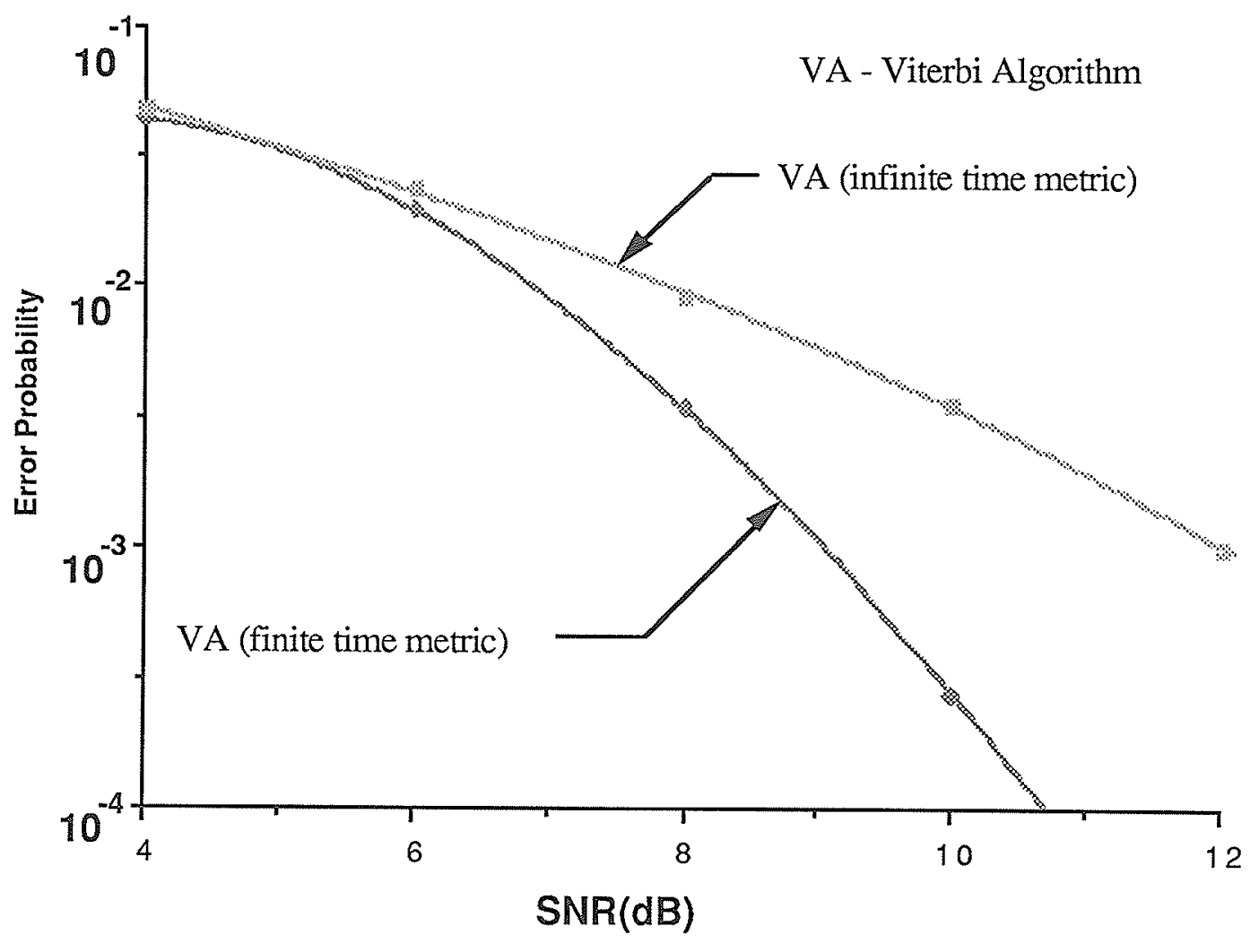

Figure 4.6 


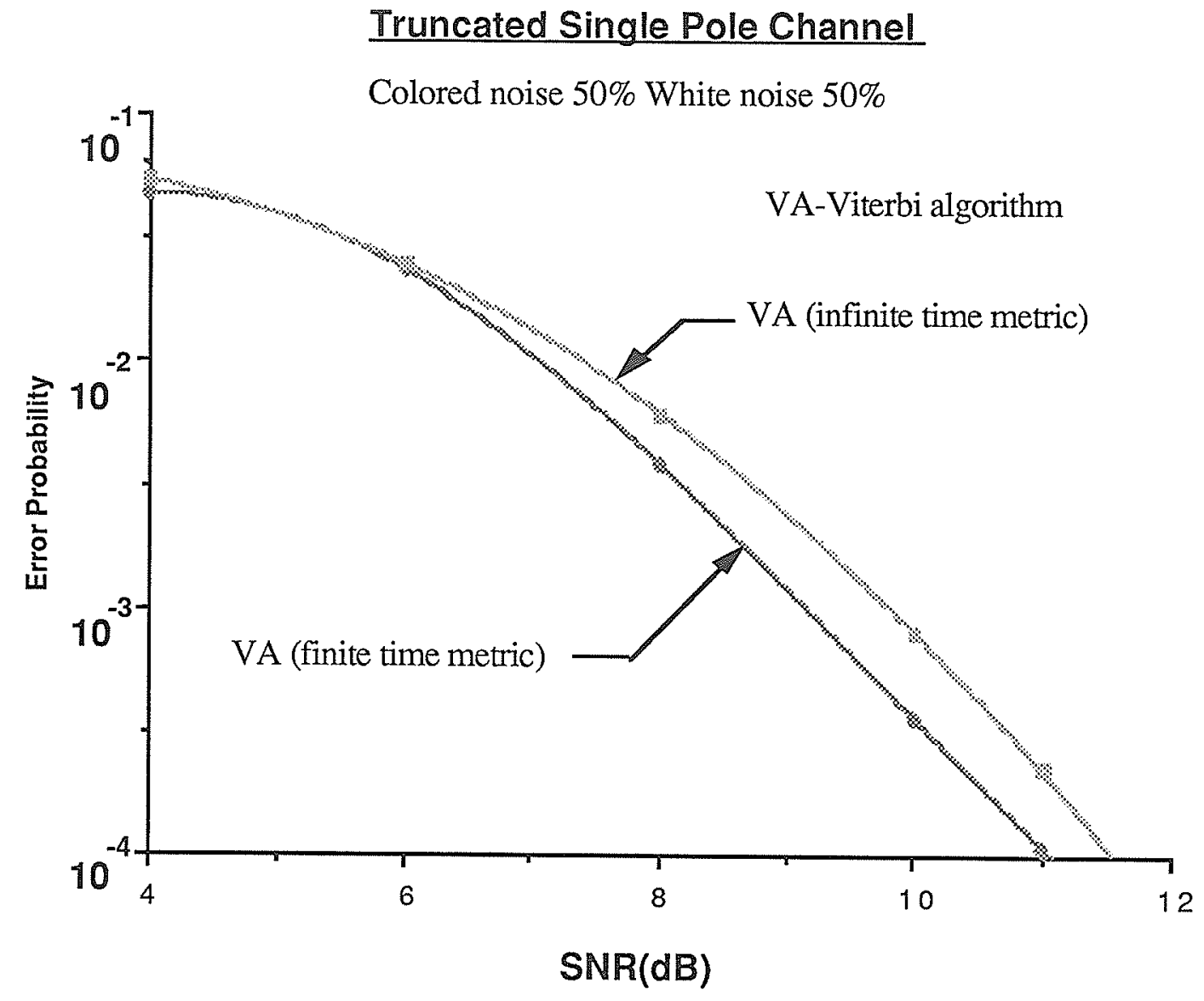

Figure 4.7 


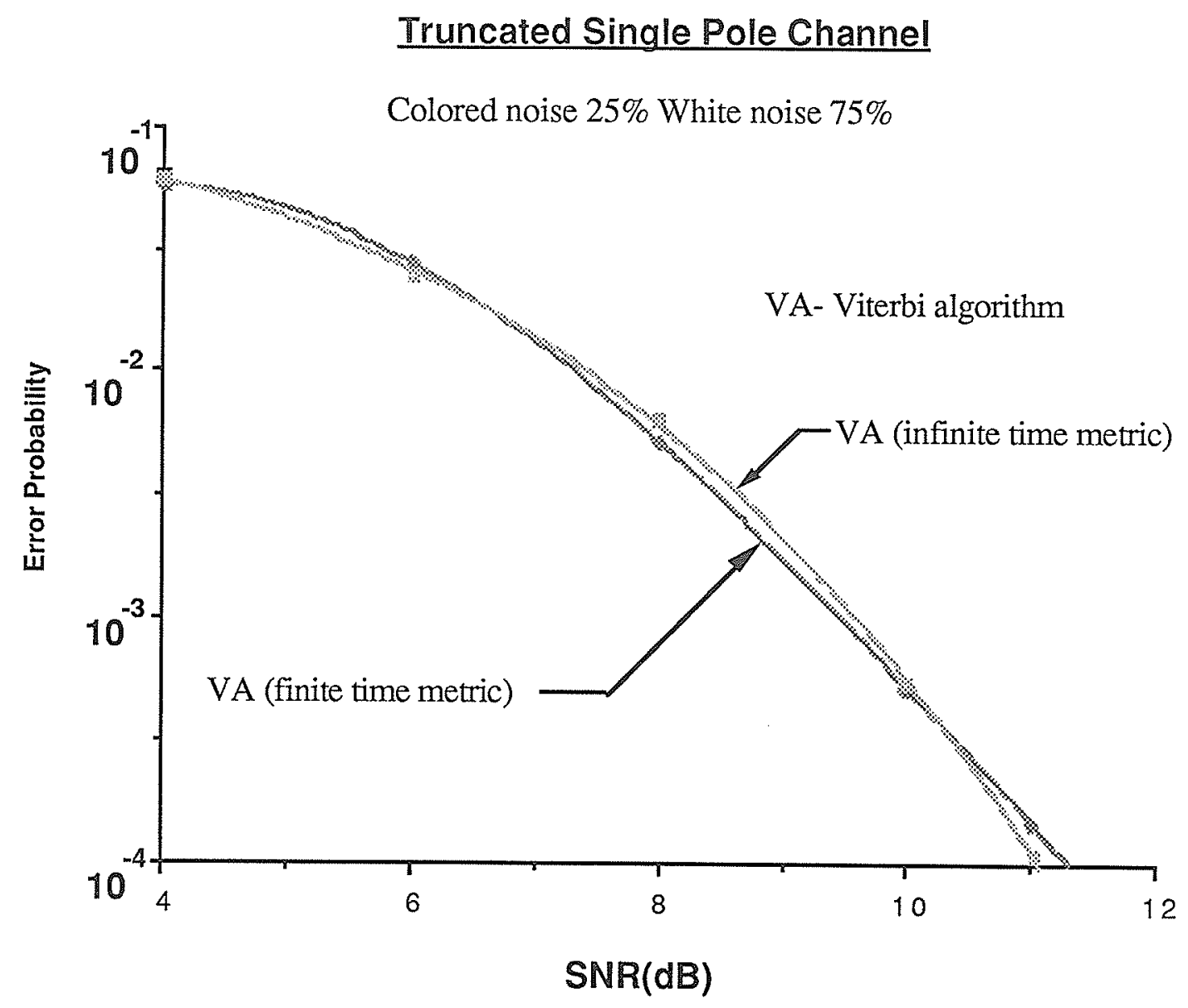

Figure 4.8 


\section{Truncated Single Pole Channel - Sequential Alg.}

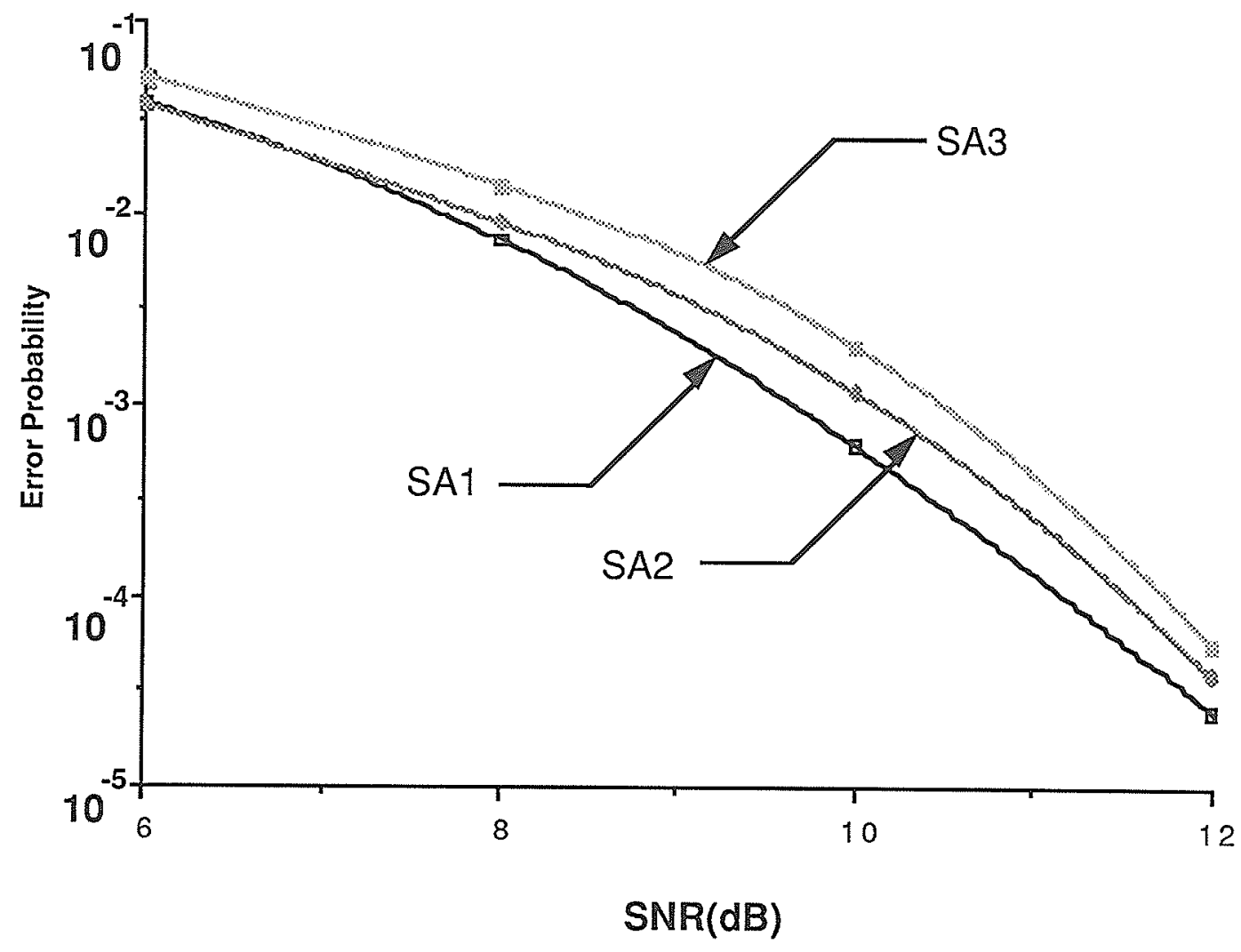

SA1 -Col. noise $75 \%$ White $25 \%$

SA2-Col. noise 50\% White 50\%

SA3-Col. noise $25 \%$ White $75 \%$

Figure 4.9 
Average no. of Computations / decoded symbol

\begin{tabular}{|c|c|c|c|c|c|}
\hline SNR(dB) & $\begin{array}{c}\text { Sequential } \\
25 \% \text { W. N. }\end{array}$ & $\begin{array}{c}\text { Sequential } \\
50 \% \text { W. N. }\end{array}$ & $\begin{array}{c}\text { Sequential } \\
75 \% \text { W. N. }\end{array}$ & $\begin{array}{c}\text { VA1 } \\
\text { L=3 }\end{array}$ & $\begin{array}{c}\text { VA2 } \\
\text { L=6 }\end{array}$ \\
\hline 6 & 9.82 & 9.71 & 8.9 & 4 & 32 \\
\hline 8 & 4.62 & 4.8 & 5.17 & 4 & 32 \\
\hline 10 & 3.34 & 3.46 & 3.59 & 4 & 32 \\
\hline 12 & 2.72 & 2.8 & 2.92 & 4 & 32 \\
\hline
\end{tabular}

W.N.-White Noise

Single Pole Truncated Channel VA1- Viterbi finite time

VA1- Viterbi infinite time

Table $4.1 \mathrm{a}$

Average CPU time / decoded symbol (seconds)

\begin{tabular}{|c|c|c|c|c|c|}
\hline SNR(dB) & $\begin{array}{c}\text { Sequential } \\
25 \% \text { W. N. }\end{array}$ & $\begin{array}{c}\text { Sequential } \\
50 \% \text { W. N. }\end{array}$ & $\begin{array}{c}\text { Sequential } \\
75 \% \text { W. N. }\end{array}$ & $\begin{array}{c}\text { VA1 } \\
\text { L=3 }\end{array}$ & $\begin{array}{c}\text { VA2 } \\
\text { L=6 }\end{array}$ \\
\hline 6 & 0.107 & 0.107 & 0.105 & 0.002 & 0.016 \\
\hline 8 & 0.042 & 0.045 & 0.05 & 0.002 & 0.016 \\
\hline 10 & 0.026 & 0.027 & 0.03 & 0.002 & 0.016 \\
\hline 12 & 0.02 & 0.021 & 0.023 & 0.002 & 0.016 \\
\hline
\end{tabular}

W.N.-White Noise

Single Pole Truncated Channel VA1- Viterbi finite time

VA1- Viterbi infinite time

Table $4.1 \mathrm{~b}$ 
signal to noise ratio was defined at the output of the whitened matched filter.

Figure 4.10 gives the results for the channel in each case. The number of computations and the CPU time per decoded symbol are also given as shown in Tables $4.2 \mathrm{a}$ and $4.2 \mathrm{~b}$. The computational complexity of the Sequential algorithm is compared with that of the Viterbi algorithm, which would be required had a simulation been done obtaining a reasonable length of truncation for the interference terms using the procedure described in 4.4. The Sequential algorithm seems to be following the general trend of giving a better error performance when the noise mixture is more colored.

\subsection{Summary and Discussion}

\subsection{Summary}

\section{(a) The Viterbi Algorithm}

\section{(i) The Raised Cosine Channel Results : Single Pole Noise}

For the raised cosine channel the finite time metric performs better when the noise bandwidth decreases relative to signal bandwidth. The computational complexity of both metrics with the Viterbi algorithm is the same for this case. Generally, in the case of all pole colored noise model the prewhitener consists of differentiators, which do not produce more interference terms. Thus the amount of interference present is determined by the channel. The solutions for the finite time metric and the infinite time metric are different in this situation because of the samplers present in the finite solution due to the singular functions added to satisfy the end conditions of the integral equation. Therefore the Viterbi algorithm behaves differently for each metric. 


\section{Butterworth Channel-Sequential Alg.}

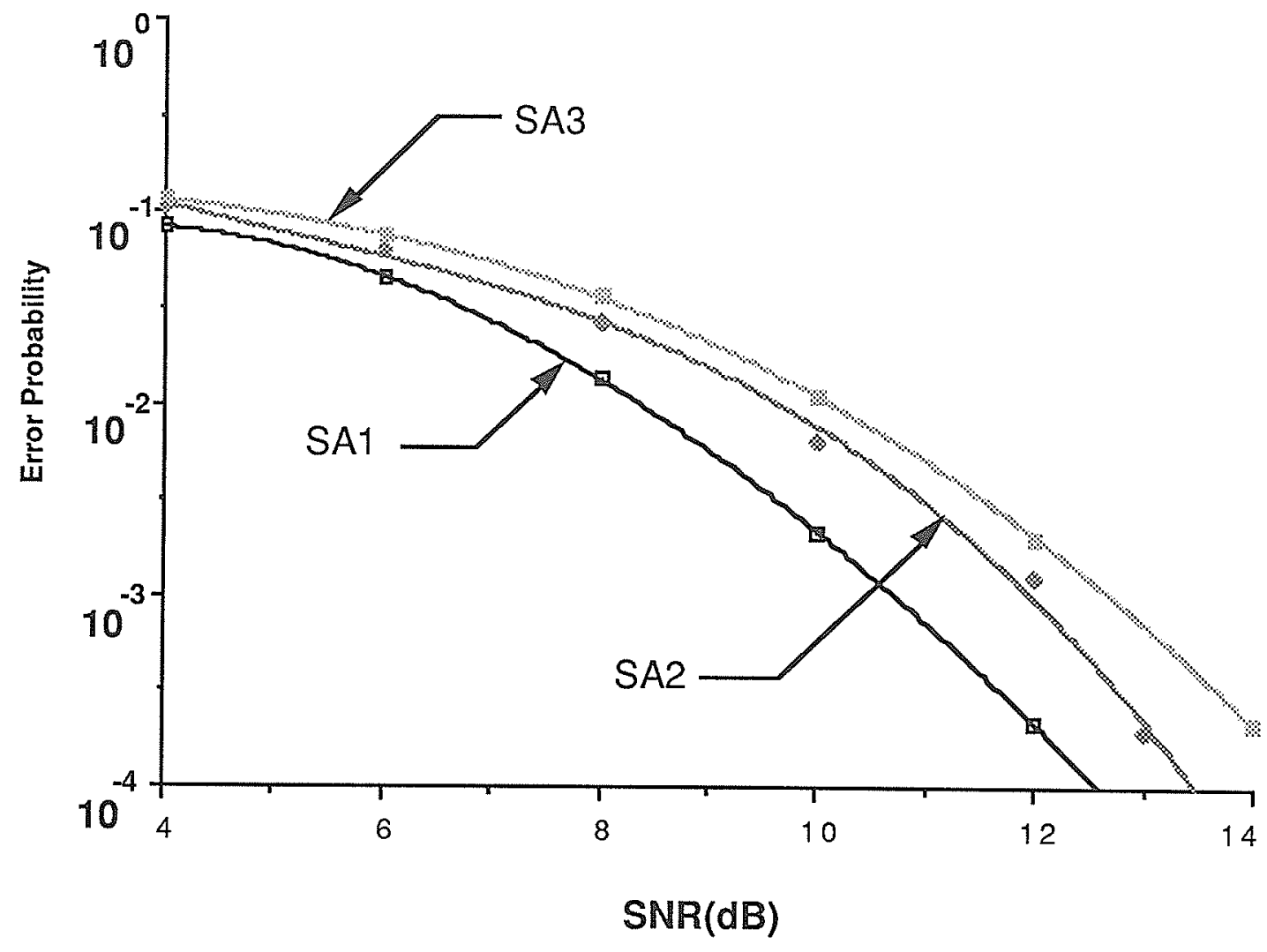

SA1 -Col. noise $75 \%$ White $25 \%$

SA2-Col. noise 50\% White 50\%

SA3-Col. noise $25 \%$ White $75 \%$

Channel Transfer Function $:|H(j \omega)|^{2}=\frac{1}{1+\left(\frac{\omega}{\omega_{c}}\right)^{4}}$

Figure 4.10 
No. of Computations / decoded symbol

\begin{tabular}{|c|c|c|c|c|}
\hline SNR(dB) & $\begin{array}{c}\text { Sequential } \\
25 \% \text { W. N. }\end{array}$ & $\begin{array}{c}\text { Sequential } \\
50 \% \text { W. N. }\end{array}$ & $\begin{array}{c}\text { Sequential } \\
75 \% \text { W. N. }\end{array}$ & $\begin{array}{c}\text { Viterbi } \\
\text { L=10 }\end{array}$ \\
\hline 4 & 17.35 & 17.35 & 17.39 & 512 \\
\hline 6 & 5.4 & 5.64 & 6.14 & 512 \\
\hline 8 & 1.77 & 1.9 & 2.1 & 512 \\
\hline 10 & 1.42 & 1.47 & 1.58 & 512 \\
\hline 12 & 1.31 & 1.37 & 1.44 & 512 \\
\hline
\end{tabular}

W.N.-White Noise

Butterworth Channel

Table $4.2 \mathrm{a}$

Average CPU time / decoded symbol (seconds)

\begin{tabular}{|c|c|c|c|c|}
\hline SNR(dB) & $\begin{array}{c}\text { Sequential } \\
25 \% \text { W. N. }\end{array}$ & $\begin{array}{c}\text { Sequential } \\
50 \% \text { W. N. }\end{array}$ & $\begin{array}{c}\text { Sequential } \\
75 \% \text { W. N. }\end{array}$ & $\begin{array}{c}\text { Viterbi } \\
\text { L=10 }\end{array}$ \\
\hline 4 & 0.184 & 0.185 & 0.189 & 0.303 \\
\hline 6 & 0.055 & 0.056 & 0.064 & 0.303 \\
\hline 8 & 0.013 & 0.014 & 0.016 & 0.303 \\
\hline 10 & 0.011 & 0.011 & 0.012 & 0.303 \\
\hline 12 & 0.01 & 0.01 & 0.011 & 0.303 \\
\hline
\end{tabular}

W.N.-White Noise

Butterworth Channel

Table $4.2 b$ 


\section{(ii) The Truncated Single Pole Channel Results : Pole Zero Noise}

In the case of the truncated single pole channel where the noise has a pole zero spectrum the error performance of the finite and infinite metrics with the Viterbi algorithm are quite close though the finite time metric is the better one.

\section{(iii) Discussion of Metrics}

Generally, the simulations indicate that the finite time metric gives a better error performance than the infinite time metric. The main advantage of the finite time metric is that no truncation is required if the channel intersymbol interference is finite. Therefore the number of computations and the CPU time is mainly determined by the channel.

For the infinite time metric the effective intersymbol interference is determined by the convolution of the channel impulse response and the prewhitener impulse response. When there is a zero in the noise spectrum giving rise to an exponential term in the impulse response for the prewhitener, the effective impulse response increases giving rise to a large number of interference terms. Since these should be truncated to apply the Viterbi algorithm, the length of truncation determines the computational complexity for the infinite time metric.

\section{(b) The Sequential Algorithm}

The metric for the Sequential algorithm can be considered as an infinite metric without truncation. First consider the single pole channel. The error performance of the Sequential algorithm is better when the noise is more colored. It is difficult to compare the error performances of the Sequential and Viterbi algorithms since the signal to noise ratios have been defined at different points. When the computational complexities are compared, one can easily see that as expected, if the signal to noise ratio is sufficiently 
high the number of computations required for the Sequential algorithm is much less than that required by the Viterbi algorithm .

For the Butterworth channel a Viterbi simulation was not carried out. The computational requirements are compared based on a truncated model. As in the previous case the computational complexity of the Sequential algorithm is much less justifying its use in the colored noise problem.

\subsection{Discussion}

In general, from the simulation results one can conclude that the algorithms especially the Viterbi algorithm with the finite time metric and the Sequential algorithm perform better when the noise is more colored, either compared to the signal or to the noise itself when it contains a white component.

This result may be explained in the following way. When the noise samples are correlated the receiver can extract more information about the transmitted sequence rather than when the noise samples are statistically independent. The metric for the colored noise represents this information contained in the correlation of the received samples. Therefore, the metric gives a better performance when the noise is more colored. For the extreme case in the context of the colored noise, the noise spectrum becomes a delta function in the frequency domain or alternatively noise can be treated as an unknown constant in the time domain. Thus one can obtain virtually an error free channel since the noise amplitude does not change with time. 


\section{Chapter 5}

\section{Conclusions}

The problem of the maximum likelihood sequence estimation (MLSE) of data in the presence of the additive colored Gaussian noise has been studied in this thesis. Application of both the Viterbi and the Sequential algorithms have been discussed. The approach is based on the whitening of the colored noise using a prewhitener at the receiver. In general, prewhitening results in infinite intersymbol interference.

Thus, to apply the Viterbi algorithm one should obtain a whitening filter with a finite impulse response. This is achieved by solving an integral equation derived using the noise autocorrelation function as shown in [21]. The time interval selected for whitening is one symbol interval over which the branch metric is evaluated in the algorithm. Basically two types of noise models have been considered; one which contains a white component and the other does not. For the latter case singular functions appear in the solution for the corresponding integral equation to satisfy the end conditions. The receiver in this finite time metric case needs $\mathrm{L}$ matched filters at the receiver where the duration of the impulse response of the channel is LT seconds. The amount of intersymbol interference for the calculation of the metric is determined by the channel, independent of whitening for this procedure. 
If one considers an infinite time interval for whitening, exponential terms are present in the prewhitener impulse response when the noise spectrum contains zeros. The total amount of interference terms that need to be considered increases due to this reason. Therefore, these terms have to be truncated in order to apply the Viterbi algorithm. The Sequential algorithm, on the other hand, does not require any truncation as it can be applied to the infinite intersymbol interference case. The procedure for the Sequential algorithm has been developed based on the Xiong' s work [24]. The receiver requires only one matched filter with the metric being the same as that derived by Xiong.

Simulation results have been obtained for both the Viterbi and the Sequential algorithms considering several channels and noise types. The error performance and the computational complexity have been analyzed. The results are compared to those obtained using an infinite time metric with the Viterbi algorithm. From the simulation, one can see that the finite time metric and the Sequential algorithm give a better error performance, when the noise looks more colored. Also at relatively high signal to noise ratios, the computational complexity of the Sequential algorithm is comparatively less than that for the Viterbi algorithm.

Performance of the Sequential algorithm needs further investigation to determine whether it in fact gives a better error performance when the noise is more colored and also to gain more knowledge about the algorithm since it has only been recently applied to the intersymbol interference problem. Establishment of the equivalence of the Viterbi and Sequential receivers is required to properly compare the error performances of the two algorithms. Also the application of the reduced state algorithms, such as the M algorithm and the $\mathrm{T}$ algorithm is a possible extension to the work presented here. 


\section{REFERENCES}

[1] M.Austin, Decision Feedback Equalization for Digital Communication over Dispersive Channels, M.I.T.Research Lab. on Electronics, Tech. Report 461, Aug.1967.

[2] R.W.Chang, J.C. Hancock, On Receiver Structure for Channels Having Memory, IEEE Trans, on Inf. Theory, Vol IT-12, pp.463-468, Oct. 1966.

[3] A. Duel and C. Heegard, Delayed Decision Feedback Sequence Estimation, 23rd Annual Allerton Conf. on Comm., Control and Computing, pp. 878-887, 1985.

[4] M. V. Eyuboglu and S. U. Qureshi, Reduced State Sequence Estimation with Set Partitioning and Decision Feedback, IEEE Trans. on Comm., Vol 36, No. 1, pp.13-20, Jan. 1988.

[5] G.D. Forney, Jr., Maximum Likelihood Sequence Estimation of Digital Sequences in the Presence of Intersymbol Interference, IEEE Trans. on Inf. Theory, Vol IT-18, pp. 363-378, May 1972.

[6] R. A. Gonsalves, Maximum Lilkelihood Receiver for Digital Data Transmission, IEEE Trans. on Comm. Tech., Vol COM- 16, pp.392-398, June 1968.

[7] E.R. Kretzmer, Binary Data Communication by Partial Response Transmission, Conference record, IEEE Annual Comm. Convention, pp451-455, 1965.

[8] J. H. Lee, R. H. French, Error behaviors of binary DPSK system due to Intersymbol Interference and Correlated Noise, Conference record of IEEE 1978 National Telecom. Conf., Pt II, Birmingham, AL, USA, Dec. 1978, pp. 27.2.127.2 .5

[9] A. Lender, Correlative Digital Communication Techniques, IEEE Trans. on Comm. Tech, Vol. COM-12, pp.128-135, Dec.1964. 
[10] A.Lender, Correlative Level Coding for Binary - Data Transmission, IEEE Spectrum, Vol.3, No.2, pp104-115, Feb.1966.

[11] R. W. Lucky, J. Salz, and E. J. Weldon, Jr., Principles of Data Communication., McGraw-Hill, Inc., New York, N. Y., 1968.

[12] H. Nyquist, Certain Topics in Telegraph Transmission Theory, Trans. AIEE (Comm. and Electronics), Vol 47,pp 617-644, April 1928.

[13] A. Polydoros and D. Kazakos, Maximum Likelihood Sequence Estimation in the Presence of Infinite Intersymbol Interference, Proc. ICC'79, Boston, MA, June 1979.

[14] S.Prasad, S.Pathak, Optimum data receivers for low SNR data signals in nonGaussian noise and intersymbol interference:receiver structures and their performance analysis, IEE Proceedings, Vol.35, No.5, October 1988, pp.471 480.

[15] N. Seshadri, J. B. Anderson, An M-Algorithm Receiver for Severe Infinite Intersymbol Interference Channels, Abstracts of papers, International Symposium on Information theory, Kobe, Japan, pp.68, June 1988.

[16] S. Shitz, Maximum likelihood detection of discrete time PAM in Non-Gaussian Noise, Convention of Electrical \& Electronic Engineers in Israel Proceedings, March 1985, p1.1.1/1-6.

[17] S. J. Simmons, Breadth - First Trellis Decoding with Adaptive Effort, IEEE Trans. on Comm., Vol. 38, No. 1, pp. 3-12, June 1990.

[18] M. Tomlinson, New automatic equalizer employing modulo arithmetic, Electron. Lett.,Vol. 7, pp. 138 - 139, 1971.

[19] G. Ungerboeck, Nonlinear Equalization of Binary Signal in Gaussian Noise, IEEE Trans. on Comm. Tech., Vol. COM-19, pp. 1128-1137, Dec. 1971. 
[20] G.Ungerboeck, Adaptive Maximum-Likelihood Receiver for Carrier-Modulated Data-Transmission Systems, IEEE Trans. on Comm., Vol. 22, No. 5, May 1974 , pp. $624-636$.

[21] H.L.Van Trees, Detection, Estimation and Modulation Theory: Part I.J.Wiley and Sons, Inc., 1968.

[22] A. J. Viterbi, Error bounds for Convolutional Codes and an Asymptotically Optimum Decoding Algorithm, IEEE Trans. on Inf. Theory, Vol IT-13, pp. 260-269, April 1967.

[23] A. J. Viterbi and J. K. Omura, Principles of Digital Communication and Coding, McGraw-Hill Inc., New York , N. Y., 1979.

[24] F.Xiong, A.Zerik, E.Shwedyk, Sequential sequence estimation for channels with intersymbol interference of finite or infinite length, IEEE Trans. on Comm., Vol.38, No. 6, June 1990, pp. 795 - 804.

[25] F. Xiong, Sequential Sequence Estimation for Channels with Intersymbol Interference, Ph. D. Thesis, Dept. of Elec. and Comp. Eng., University of Manitoba, 1989.

[26] A. Zerik, Discrete Spectral Factorization in Intersymbol Interference Problems, M. Sc. Thesis, Dept. of Elec. and Comp. Eng., University of Manitoba, 1988. 


\section{APPENDIX A}

\section{Generation of Colored Noise :}

The procedure can be given by following steps.

1. Find the impulse response of the shaping filter for noise.

2. Obtain the discrete spectral factorization of the autocorrelation function of the shaping filter.

3. Obtain the difference equation to generate the noise samples.

Step 3 is described for a general channel in [26].

Consider the example given below.

Ex : Power density spectrum of noise

$$
\mathrm{S}_{\mathrm{n}}(\omega)=\frac{2 \mathrm{k} \sigma_{\mathrm{n}}^{2}}{\left(\omega^{2}+\mathrm{k}^{2}\right)} \Leftrightarrow \mathrm{K}_{\mathrm{n}}(\tau)=\sigma_{\mathrm{n}}^{2} \mathrm{e}^{-\mathrm{k}|\tau|}
$$

where $K_{n}(\tau)$ is the autocorrelation function

A stable filter to generate this spectrum using white noise of strength $\sigma_{\Omega}^{2}$ is

$$
H(j \omega)=\frac{\sqrt{2 k}}{j \omega+k}
$$

The impulse response is

$$
h(t)=\sqrt{2 k} e^{-k t} u(t)
$$

As a verification, the autocorrelation function of $h(t)$ can be found. The autocorrelation function is defined as

$$
\begin{aligned}
R(\tau) & =\int_{-\infty}^{\infty} h(t) h(t+\tau) d t \\
& =2 k \int_{0}^{\infty} e^{-k t} e^{-k(t+\tau)} d t \quad, \tau>0
\end{aligned}
$$




$$
\begin{aligned}
& =2 k e^{-k \tau} \int_{0}^{\infty} e^{-2 k t} d t \\
& \text { i.e., } \quad R(\tau)=e^{-k \tau} \\
& \text { From symmetry } \\
& \mathrm{R}(\tau)=\mathrm{R}(-\tau)=\mathrm{e}^{-\mathrm{k}|\tau|}
\end{aligned}
$$

Now using the D- Transform theory

$$
\begin{aligned}
R(D) & =\sum_{m=-\infty}^{\infty} R_{m} D^{m} \\
& =\frac{1}{2}+\sum_{m=1}^{\infty}\left[e^{-k T}\right]^{m} D^{-m}+\frac{1}{2}+\sum_{m=1}^{\infty}\left[e^{-k T}\right]^{m} D^{m} \\
& =g\left(D^{-1}\right)+g(D) \\
g(D) & =\frac{1}{2}+\sum_{m=1}^{\infty}\left[e^{-k T}\right]^{m} D^{m}-1 \\
& =\sum_{m=1}^{\infty}\left[e^{-k T}\right]^{m} D^{m}-\frac{1}{2} \\
& =\frac{1}{1-e^{-k T D}-\frac{1}{2}}
\end{aligned}
$$

Therefore,

$$
\begin{aligned}
R(D) & =\frac{1}{1-e^{-k T} D}-\frac{1}{2}+\frac{1}{1-e^{-k T} D^{-1}}-\frac{1}{2} \\
& =\frac{1-e^{-2 k T}}{\left(1-e^{-k T} D^{-1}\right)\left(1-e^{-k T D}\right)}=f(D) f\left(D^{-1}\right)
\end{aligned}
$$

This is the spectral factorization. Using $f(D)$ as the discrete transfer function, the difference equation to generate noise samples can easily be obtained.

$$
f(D)=\frac{N(D)}{W(D)}=\frac{\sqrt{1-e^{-2 k T}}}{\left(1-e^{-k T} D\right)}
$$

where N(D) and W(D) are the colored and white noise in discrete domain.

$$
A-2
$$


Hence the difference equation;

$$
\mathrm{n}(\mathrm{m})=\sqrt{1-\mathrm{e}^{-2 \mathrm{kT}}} \mathrm{w}(\mathrm{m})+\mathrm{e}^{-\mathrm{kT}} \mathrm{n}(\mathrm{m}-1)
$$

To check the result, the autocorrelation function can be found using equation (18)

$$
E\{n(m) n(m-j)\}=\sqrt{1-e^{-2 k T}} E\{w(m) n(m-j)\}+e^{-k T} E\{n(m-1) n(m-j)\}
$$

Using the stationarity of noise,

$$
\begin{aligned}
\mathrm{R}_{\mathrm{j}} & =\mathrm{E}\{\mathrm{n}(\mathrm{m}) \mathrm{n}(\mathrm{m}-\mathrm{j})\} \quad, \quad \mathrm{R}_{\mathrm{j}-1}=\mathrm{E}\{\mathrm{n}(\mathrm{m}-1) \mathrm{n}(\mathrm{m}-\mathrm{j})\} \\
\mathrm{R}_{\mathrm{j}} & =0+\mathrm{e}^{-\mathrm{kT}} \mathrm{R}_{\mathrm{j}-1} \\
\mathrm{R}_{\mathrm{j}} & =\mathrm{e}^{-\mathrm{kT}} \mathrm{R}_{\mathrm{j}-1} \\
\mathrm{E}\left\{\mathrm{n}^{2}(\mathrm{~m})\right\} & =\mathrm{R} 0=\left\{1-\mathrm{e}^{-2 \mathrm{kT}}\right\} \mathrm{E}\left\{\mathrm{w}^{2}(\mathrm{~m})\right\}+ \\
2 & \sqrt{1-\mathrm{e}^{-2 \mathrm{kT}}} \mathrm{e}^{-\mathrm{kT}} \mathrm{E}\{\mathrm{w}(\mathrm{m}) \mathrm{n}(\mathrm{m}-1)\}+\mathrm{e}^{-2 \mathrm{kT}} \mathrm{E}\left\{\mathrm{n}^{2}(\mathrm{~m}-1)\right\} \\
\mathrm{R}_{0} & =\left\{1-\mathrm{e}^{-2 \mathrm{kT}}\right\} \sigma_{\mathrm{n}}^{2}+0+\mathrm{e}^{-2 \mathrm{kT}} \mathrm{R}_{0} \\
\mathrm{R}_{0} & =\sigma_{\mathrm{n}}^{2}
\end{aligned}
$$

Thus the difference equation, in this case, generates noise samples according to the statistics desired. 


\section{$A P P E N D I X \mathbb{B}$}

\section{Viterbi algorithm program listing}

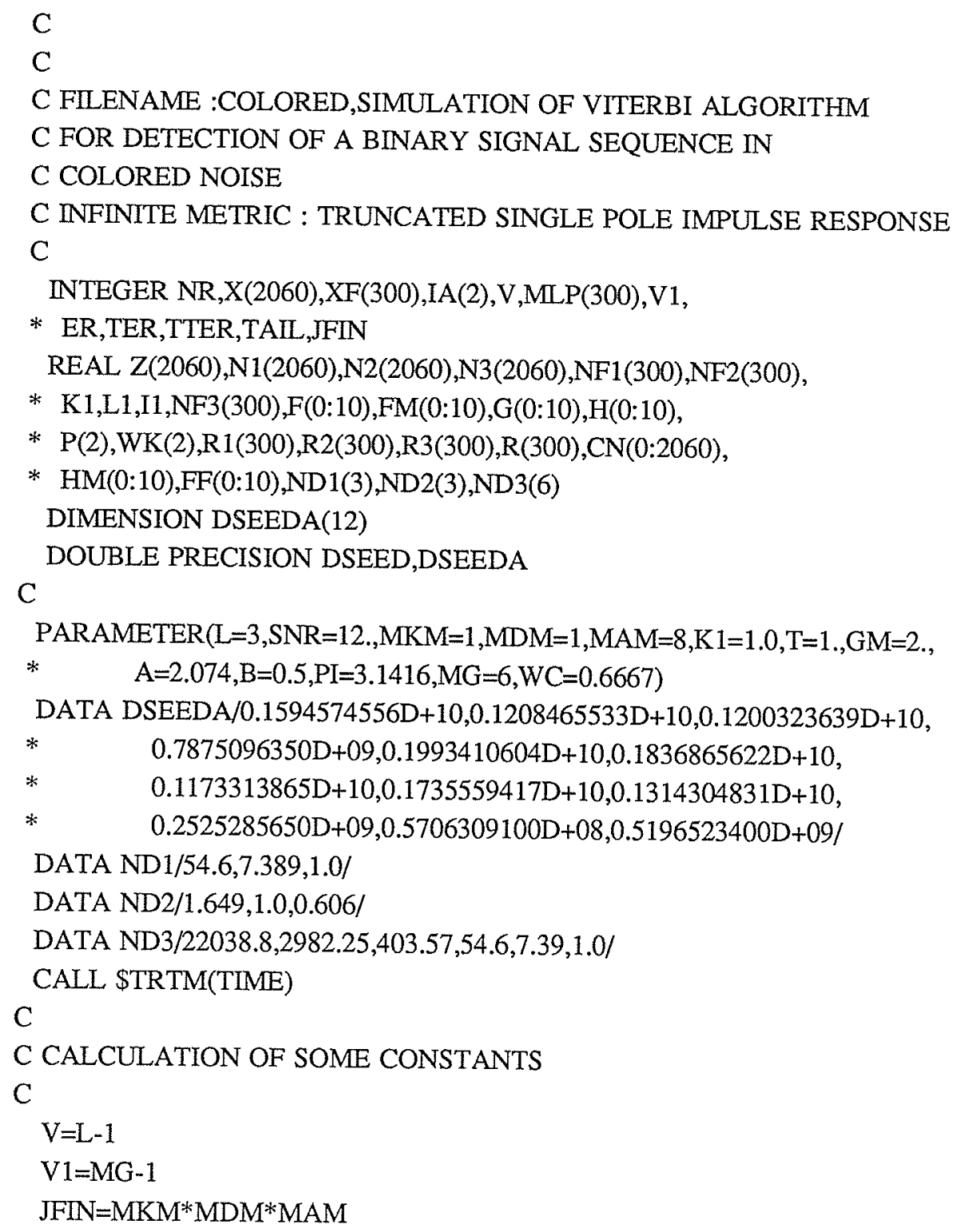




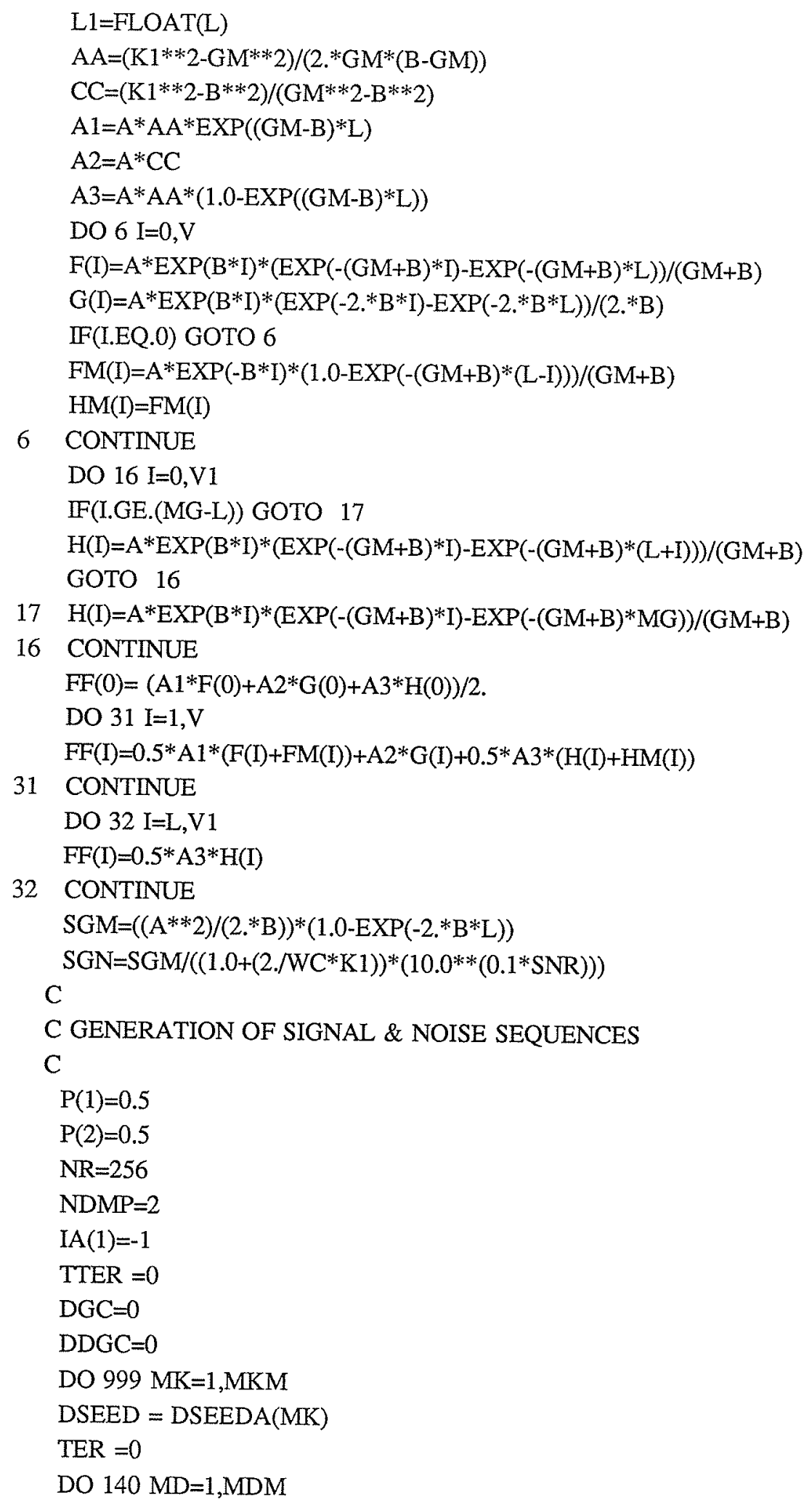




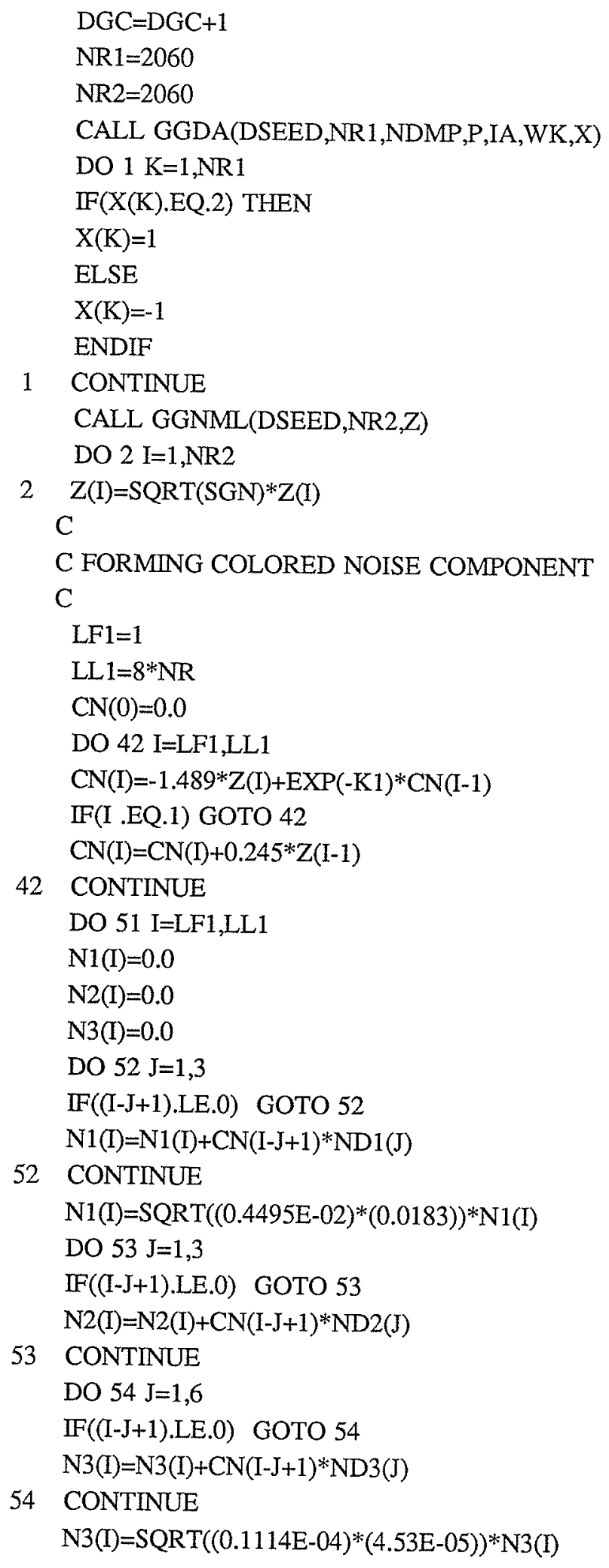




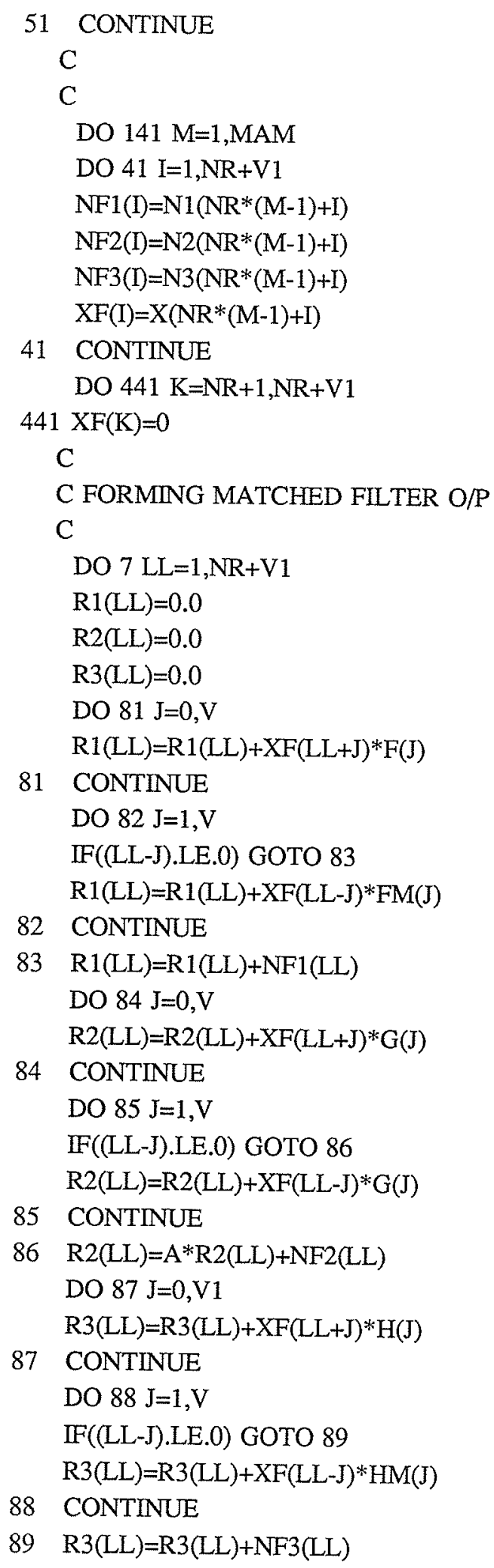




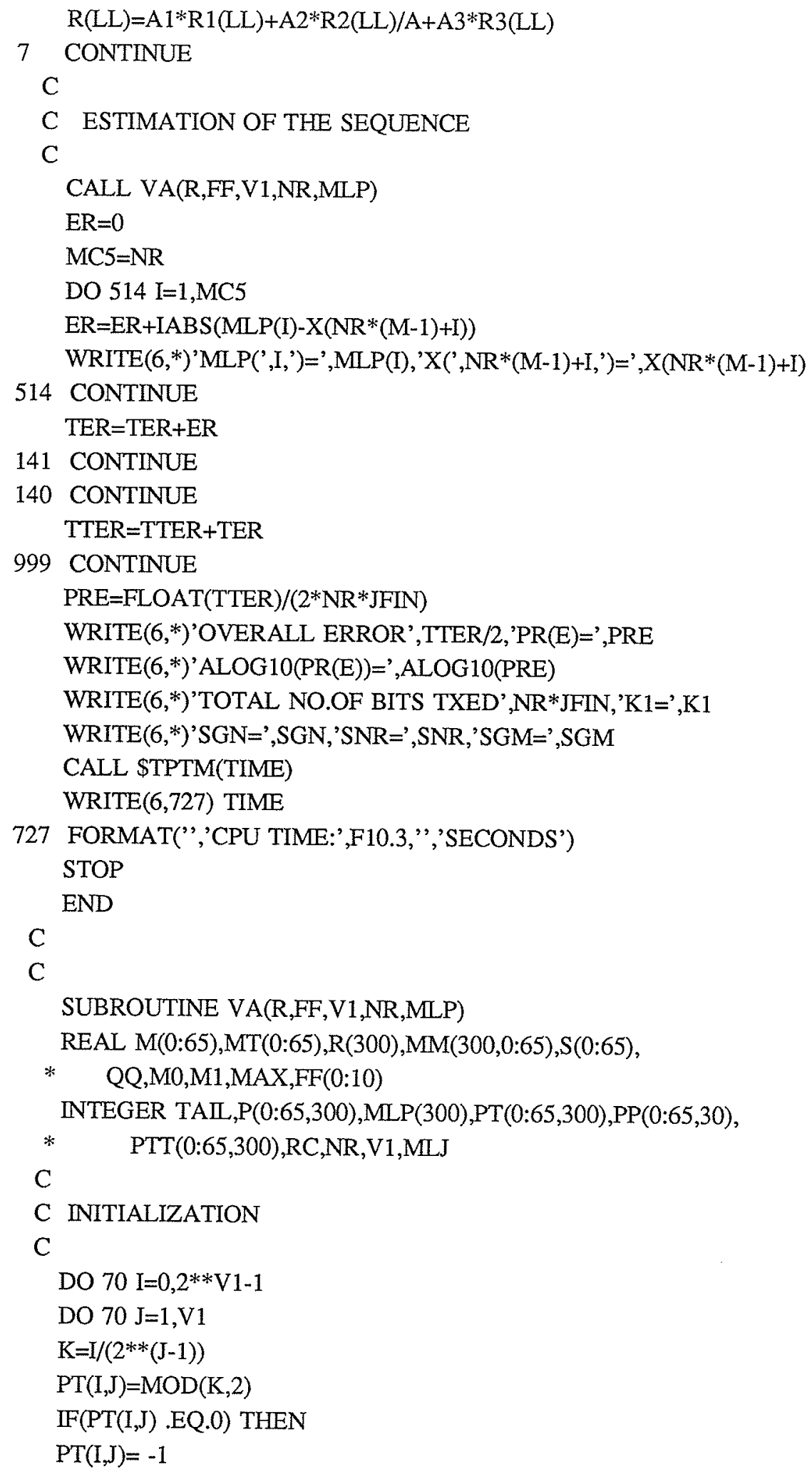


ENDIF

70 CONTINUE

DO $75 \mathrm{I}=0,2 * \mathrm{~V} 1-1$

DO $75 \mathrm{~J}=1, \mathrm{~V} 1$

$\mathrm{P}(\mathrm{I}, \mathrm{V} 1-\mathrm{J}+1)=\mathrm{PT}(\mathrm{I}, \mathrm{J})$

75 CONTINUE

DO $80 \mathrm{~J}=0,2 * * \mathrm{~V} 1-1$

$\mathrm{M}(\mathrm{J})=0.0$

DO $80 \mathrm{~K}=1, \mathrm{~V} 1$

$\mathrm{QQ}=0.0$

DO $85 \mathrm{I}=1, \mathrm{~K}$

$\mathrm{QQ}=\mathrm{QQ}+\mathrm{FF}(\mathrm{I}-1) * \mathrm{P}(\mathrm{J}, \mathrm{K}-\mathrm{I}+1)$

85 CONTINUE

$\mathrm{M}(\mathrm{J})=\mathrm{M}(\mathrm{J})+(\mathrm{R}(\mathrm{K})-\mathrm{QQ}) * \mathrm{P}(\mathrm{J}, \mathrm{K})$

80 CONTINUE

DO $90 \mathrm{~J}=0,2^{* *} \mathrm{~V} 1-1$

$S(J)=0.0$

DO $95 \mathrm{I}=1, \mathrm{~V} 1$

$\mathrm{S}(\mathrm{J})=\mathrm{S}(\mathrm{J})+\mathrm{FF}(\mathrm{I}) * \mathrm{P}(\mathrm{J}, \mathrm{V} 1-\mathrm{I}+1)$

95 CONTINUE

90 CONTINUE

$\mathrm{C}$

C VITERBI ALGORITHM

$\mathrm{C}$

$\mathrm{LF} 1=\mathrm{V} 1+1$

LN1=NR

DO $100 \mathrm{~K}=\mathrm{LF} 1, \mathrm{LN} 1$

DO $951 \mathrm{~J}=0,2 * * \mathrm{~V} 1-1$

IF (MOD(J,2) .EQ. 0) THEN

$\mathrm{J} 0=\mathrm{J} / 2$

$\mathrm{J} 1=(\mathrm{J}+2 * * \mathrm{~V} 1) / 2$

$\mathrm{P}(\mathrm{J}, \mathrm{K})=-1$

ELSE

$\mathrm{J} 0=(\mathrm{J}-1) / 2$

$\mathrm{J} 1=(\mathrm{J}-1+2 * \mathrm{~V} 1) / 2$

$\mathrm{P}(\mathrm{J}, \mathrm{K})=1$

ENDIF

$\mathrm{M} 0=\mathrm{M}(\mathrm{J} 0)+(\mathrm{R}(\mathrm{K})-\mathrm{S}(\mathrm{J} 0)-\mathrm{FF}(0) * \mathrm{P}(\mathrm{J}, \mathrm{K})) * \mathrm{P}(\mathrm{J}, \mathrm{K})$

$\mathrm{M} 1=\mathrm{M}(\mathrm{J} 1)+(\mathrm{R}(\mathrm{K})-\mathrm{S}(\mathrm{J} 1)-\mathrm{FF}(0) * \mathrm{P}(\mathrm{J}, \mathrm{K})) * \mathrm{P}(\mathrm{J}, \mathrm{K})$

IF (M0 .GT. M1) THEN

$\mathrm{MT}(\mathrm{J})=\mathrm{M} 0$

DO $110 \mathrm{I}=1, \mathrm{~K}-1$ 


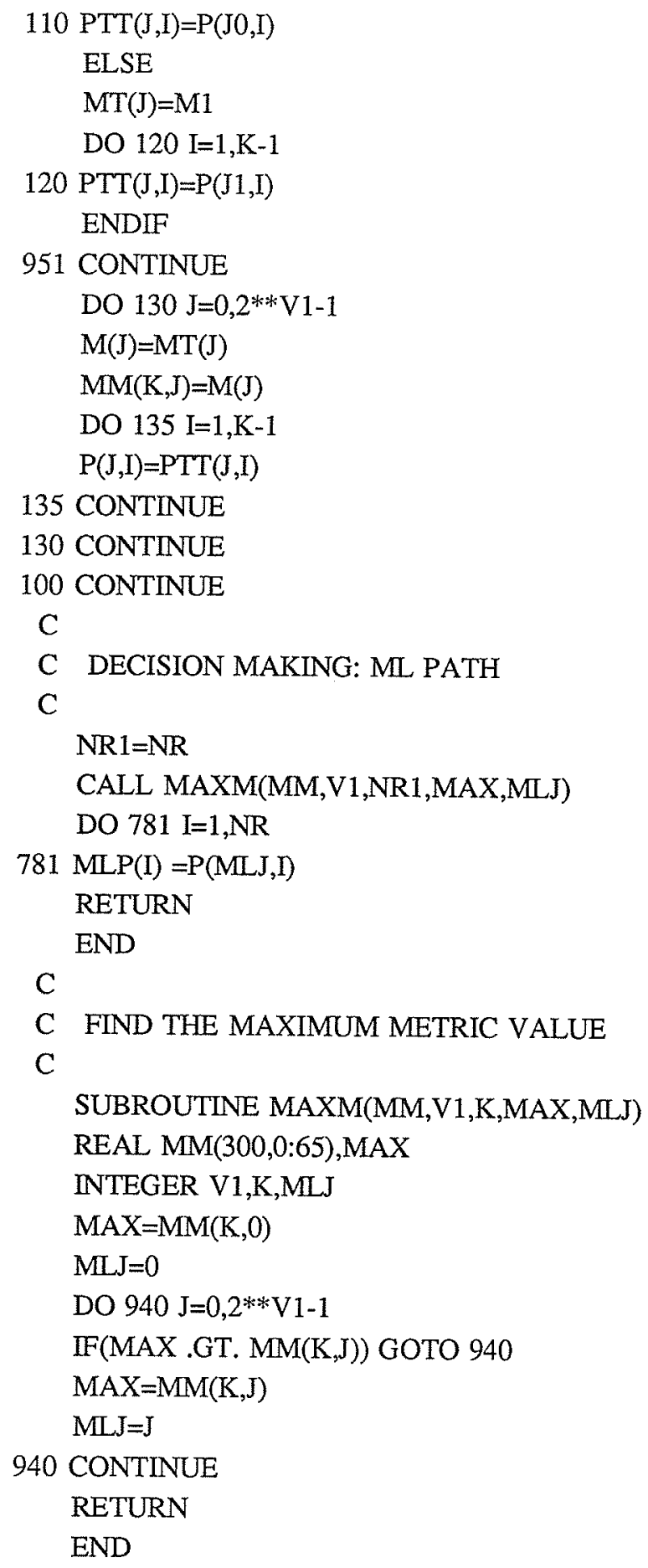




\section{APPENDIX C}

\section{Sequential algorithm program listing}

C FILENAME:SIMULATION OF SEQUENTIAL DETECTION OF BINARY

C SIGNAL SEQUENCE IN THE PRESENCE OF INFINITE ISI AND

C COLORED GAUSSIAN NOISE

C BUTTERWORTH CHANNEL

$\mathrm{C}$

INTEGER NR,NDMP,X(2048),XF(280),XEF(256),IA(2),V,ER,TER,CL,TCL

REAL P(2),PO(200),WK(2),Z(2160),ZF(280),Y(280),

* $\mathrm{F}(2), \mathrm{G}(10), \mathrm{AA}(2), \mathrm{AAA}(2)$

DIMENSION DSEEDA(25)

DOUBLE PRECISION DSEED,DSEEDA

$\mathrm{C}$

DATA DSEEDA/0.1594574556D+10, 0.1208465533D+10, 0.1200323639D+10,

* $\quad 0.7875096350 \mathrm{D}+09,0.1993410604 \mathrm{D}+10,0.1836865622 \mathrm{D}+10$,

* $\quad 0.1173313865 \mathrm{D}+10,0.1735559417 \mathrm{D}+10,0.1314304831 \mathrm{D}+10$,

* $\quad 0.2525285650 \mathrm{D}+09,0.5706309100 \mathrm{D}+08,0.5196523400 \mathrm{D}+09$,

* $\quad 0.2827359430 \mathrm{D}+09,0.1943029728 \mathrm{D}+10,0.4351107100 \mathrm{D}+08$,

* $\quad 0.1910901950 \mathrm{D}+10,0.1893766405 \mathrm{D}+10,0.4715504610 \mathrm{D}+09$,

* $\quad 0.2134076531 \mathrm{D}+10,0.1814803971 \mathrm{D}+10,0.1970428848 \mathrm{D}+10$,

* $\quad 0.4805104160 \mathrm{D}+09,0.2093775370 \mathrm{D}+10,0.3952421830 \mathrm{D}+09$,

* $0.2092423249 \mathrm{D}+10 /$

DATA F/0.1385,0.5355/

DATA AAA/0.3474,-0.1222/

CALL \$TRTM(TIME)

$\mathrm{C}$

C ** READING IN P0(Z)

$\mathrm{C}$

$\operatorname{READ}(8,150) \mathrm{L}, \mathrm{SNR}, \mathrm{SGN}$

150 FORMAT(3X,I2,5X,F6.3,5X,F8.3)

$\operatorname{READ}(8,200)(\mathrm{PO}(\mathrm{I}), \mathrm{I}=1,200)$

WRITE $(6,200)(\mathrm{P} 0(\mathrm{I}), \mathrm{I}=1,200)$

200 FORMAT(1X,5E15.6)

C 


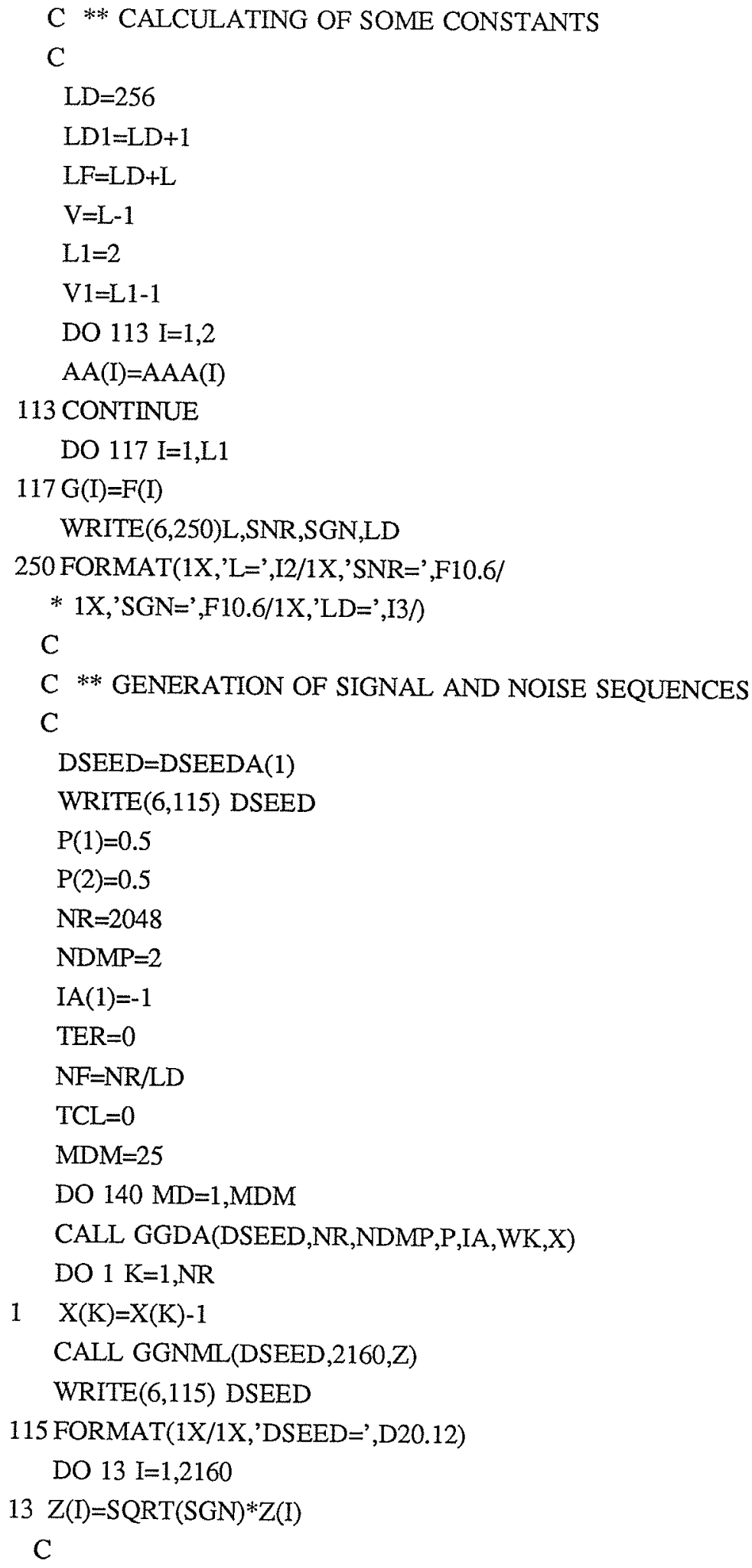




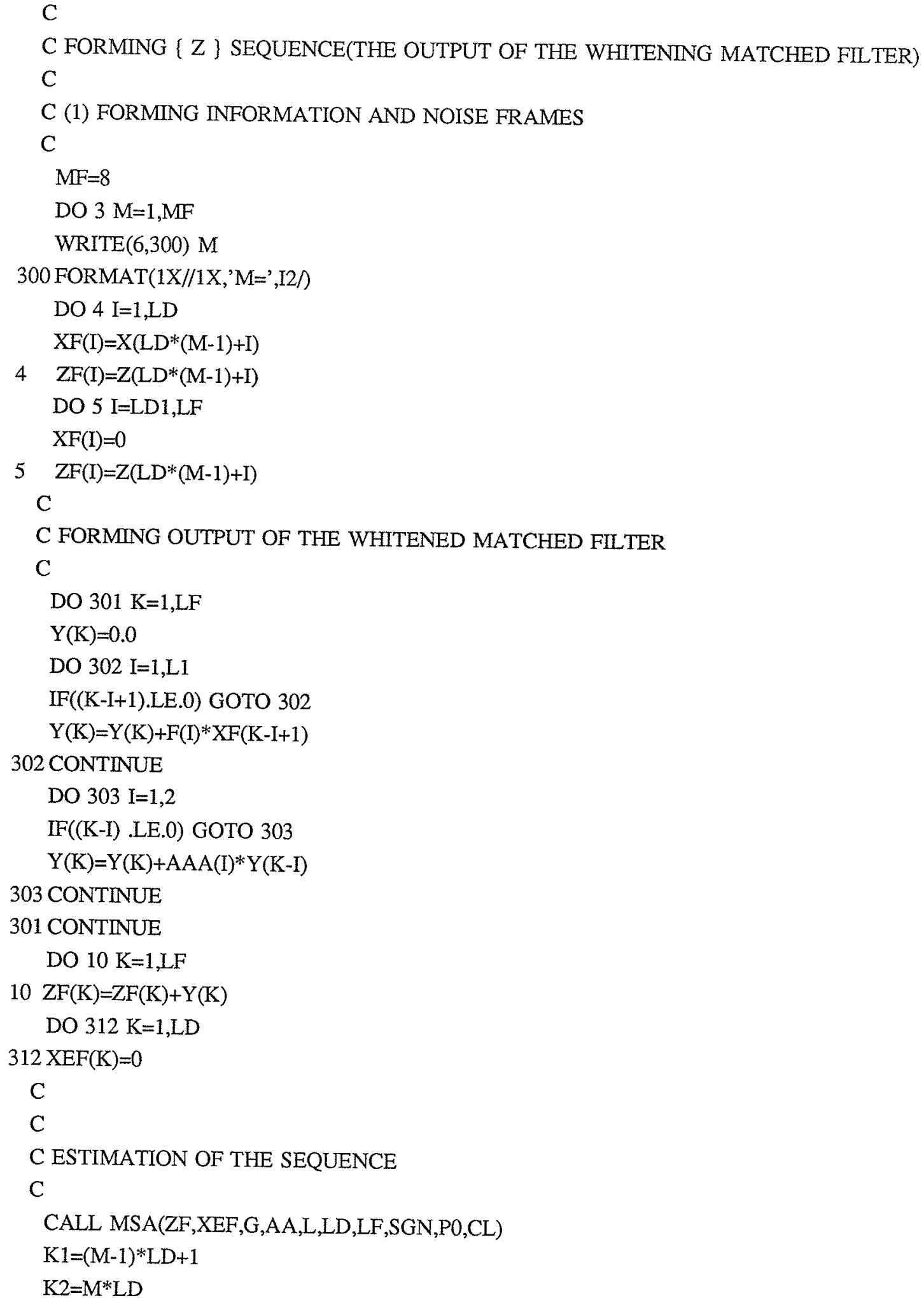




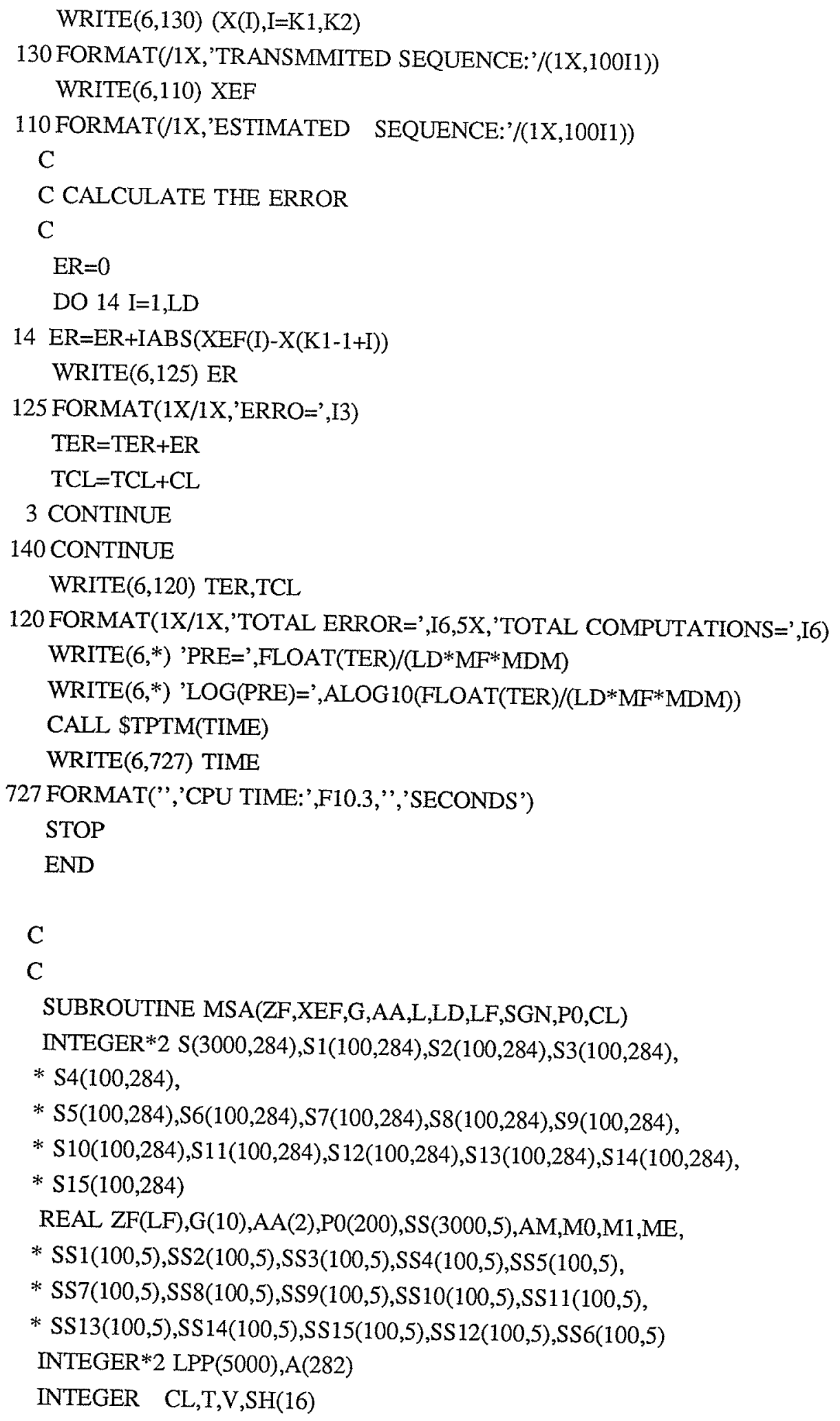




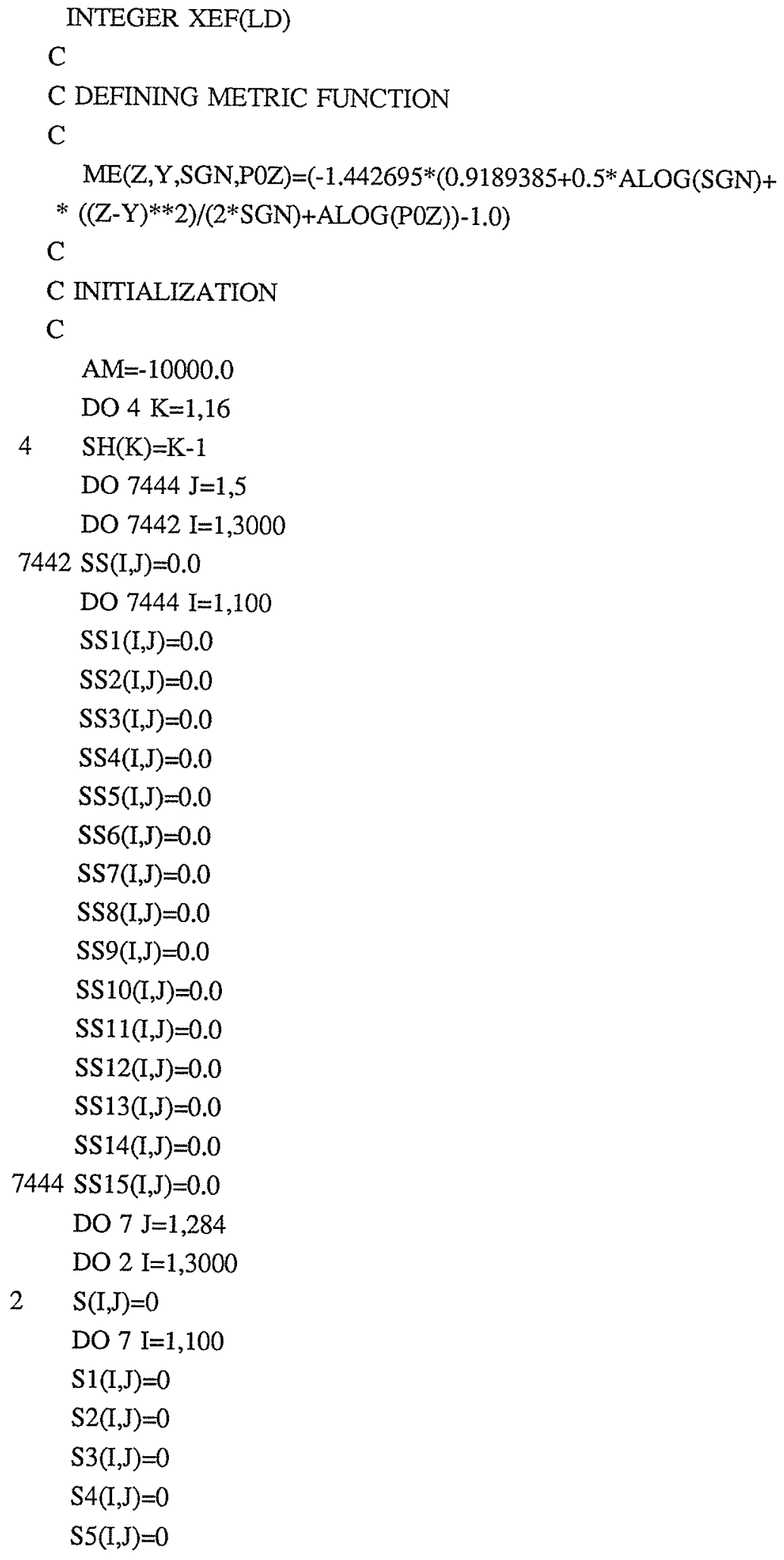




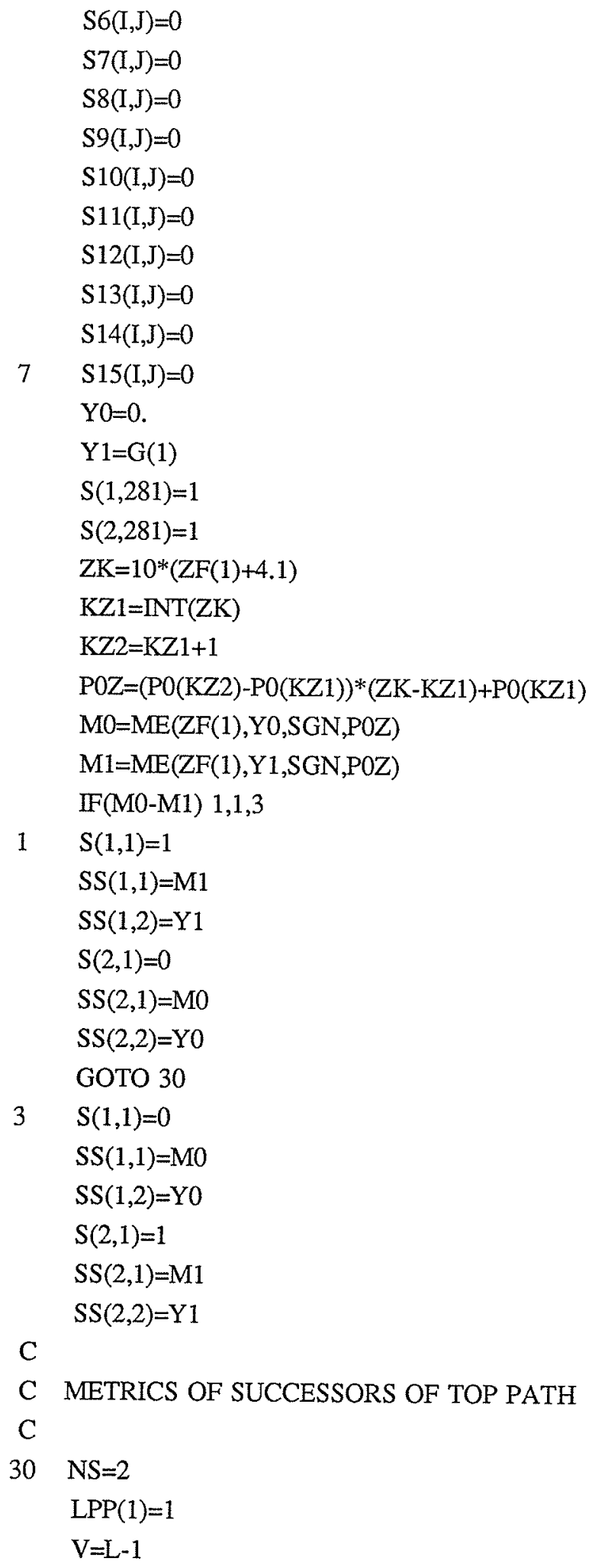




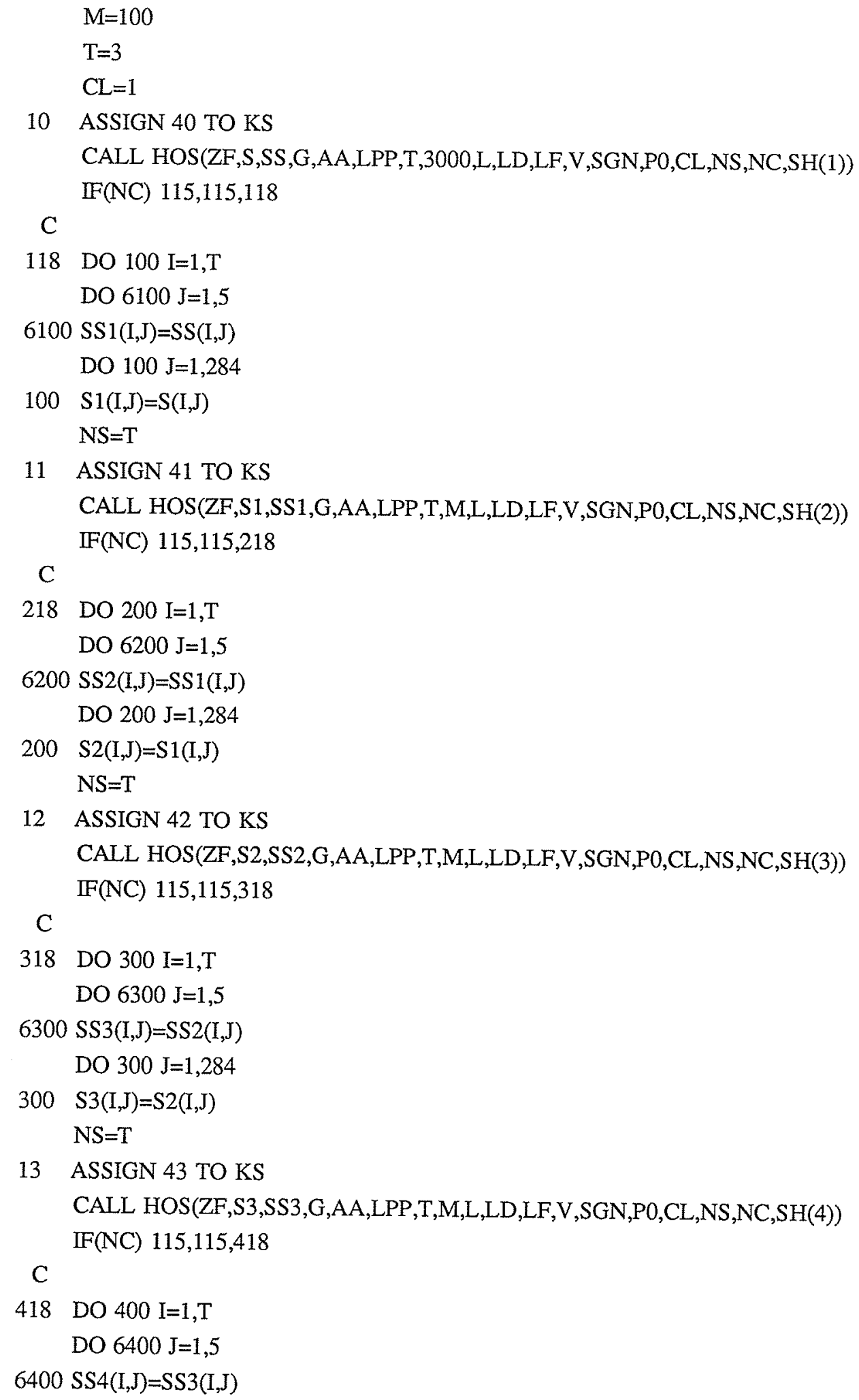




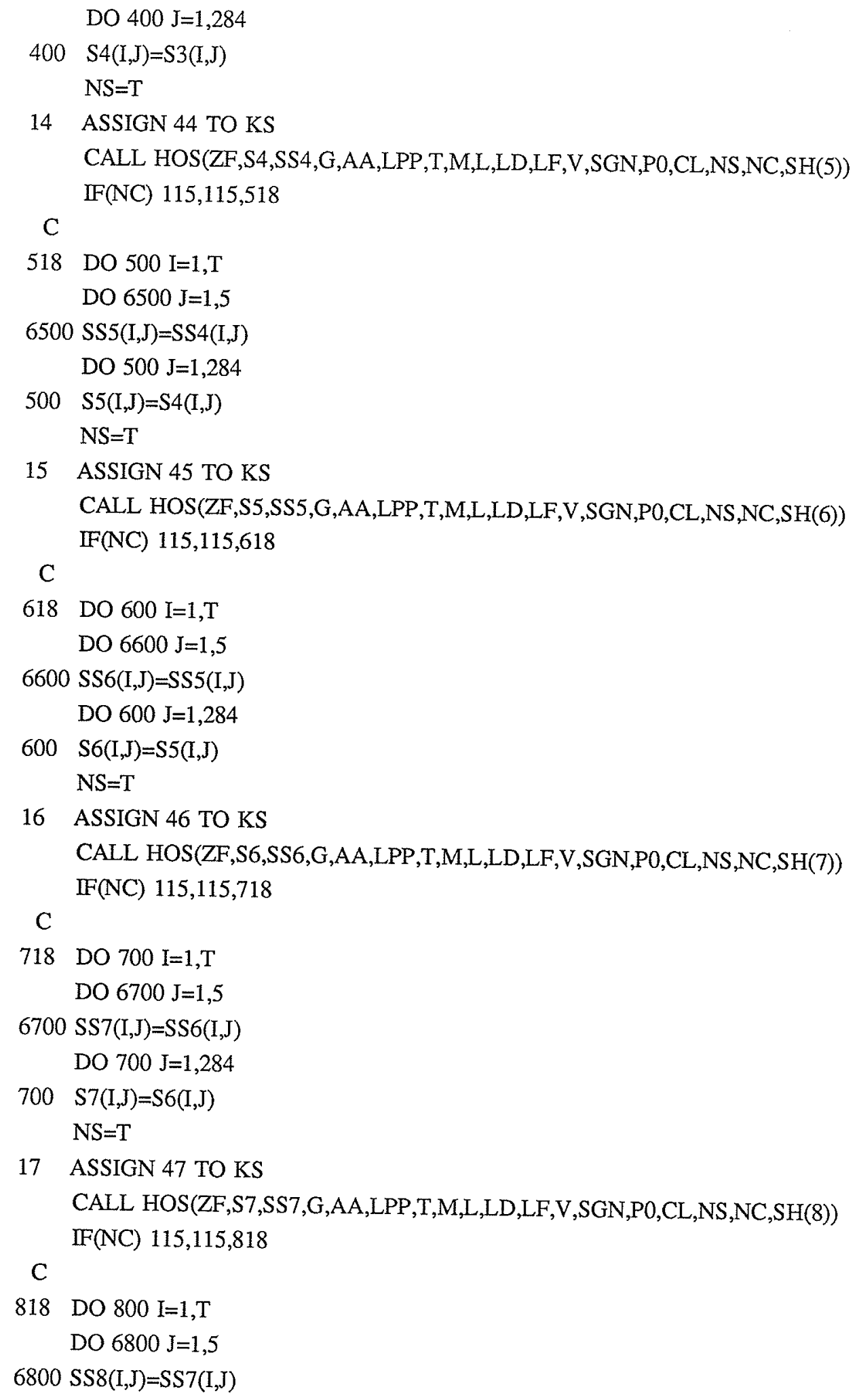




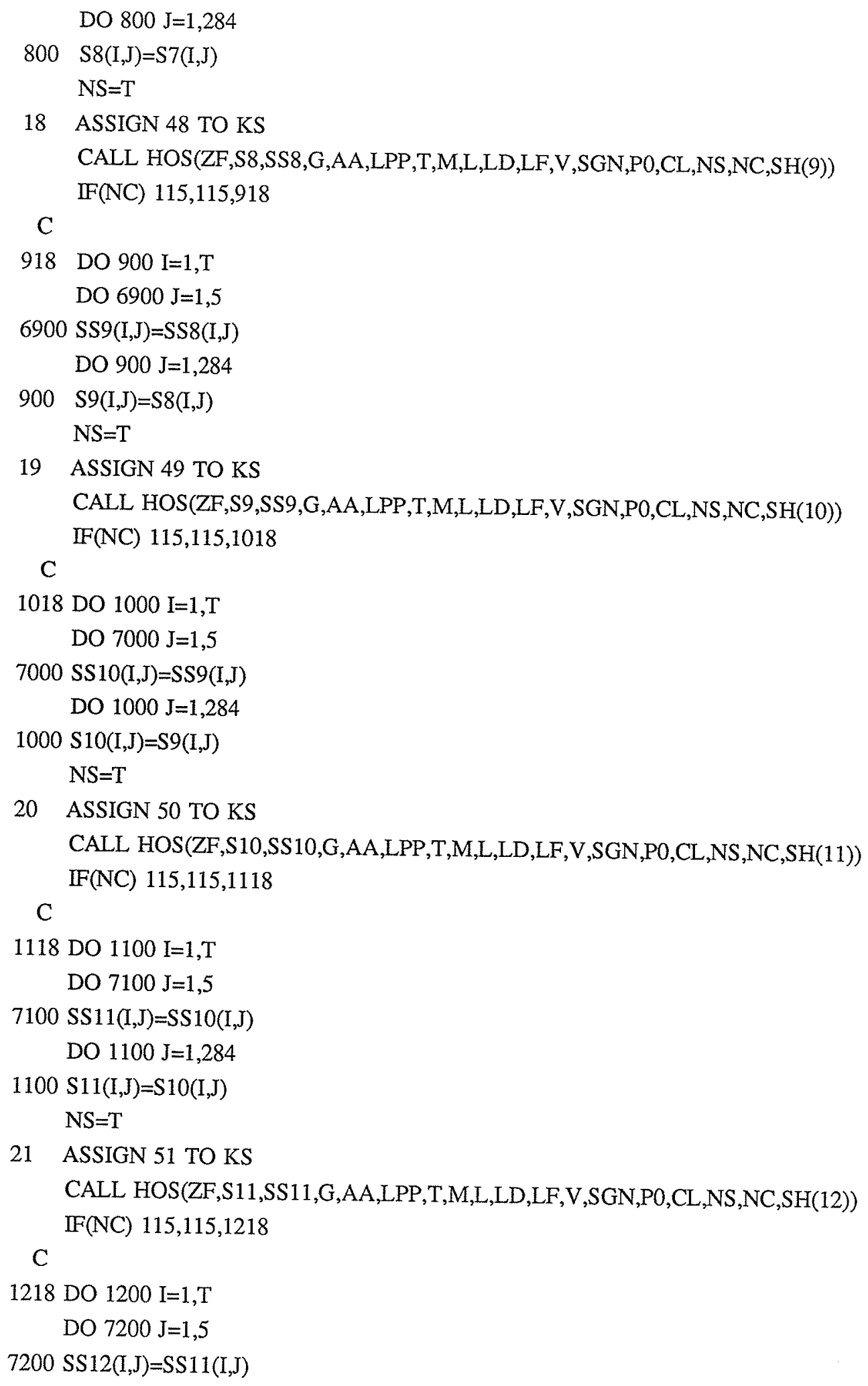




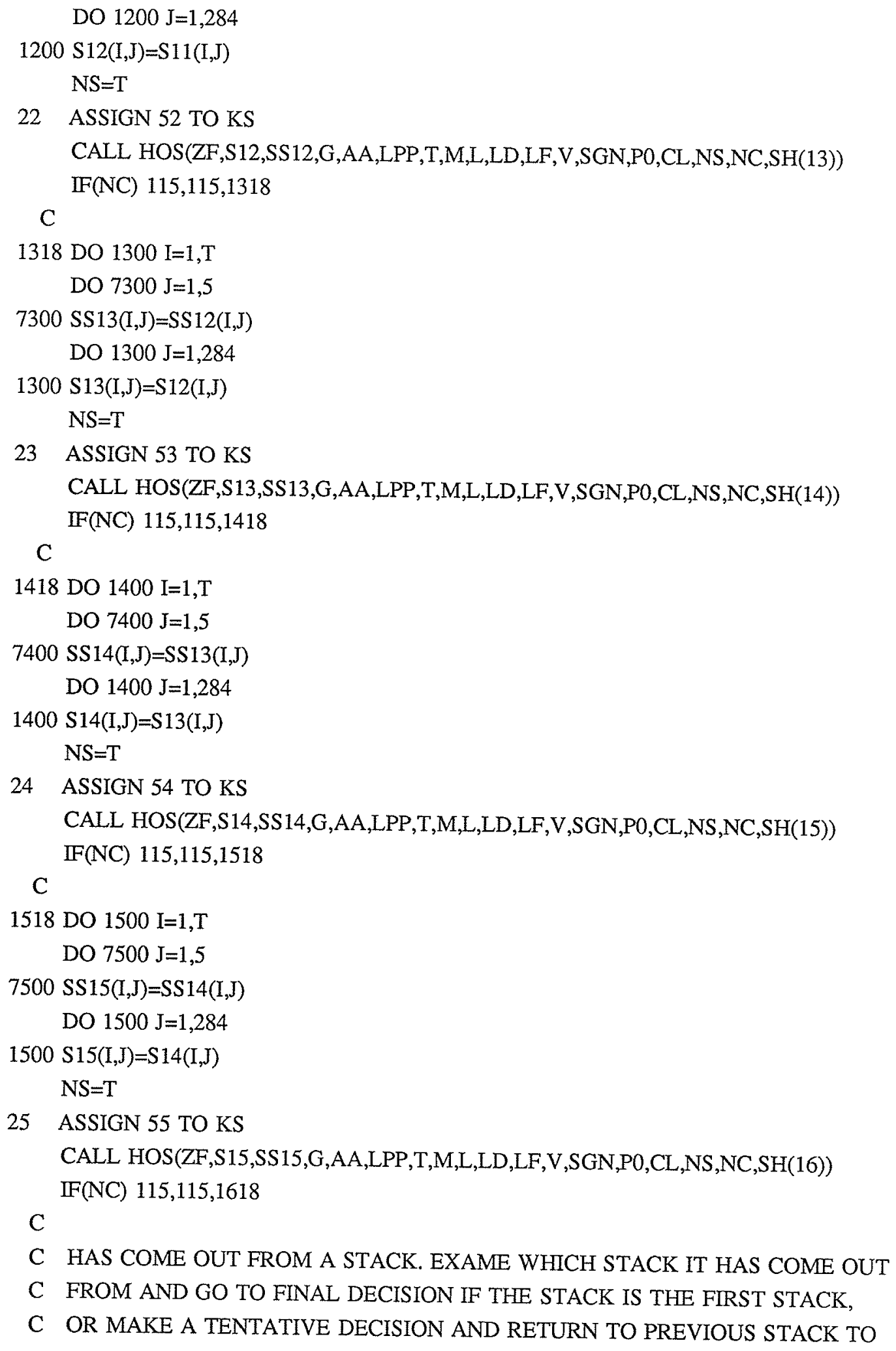




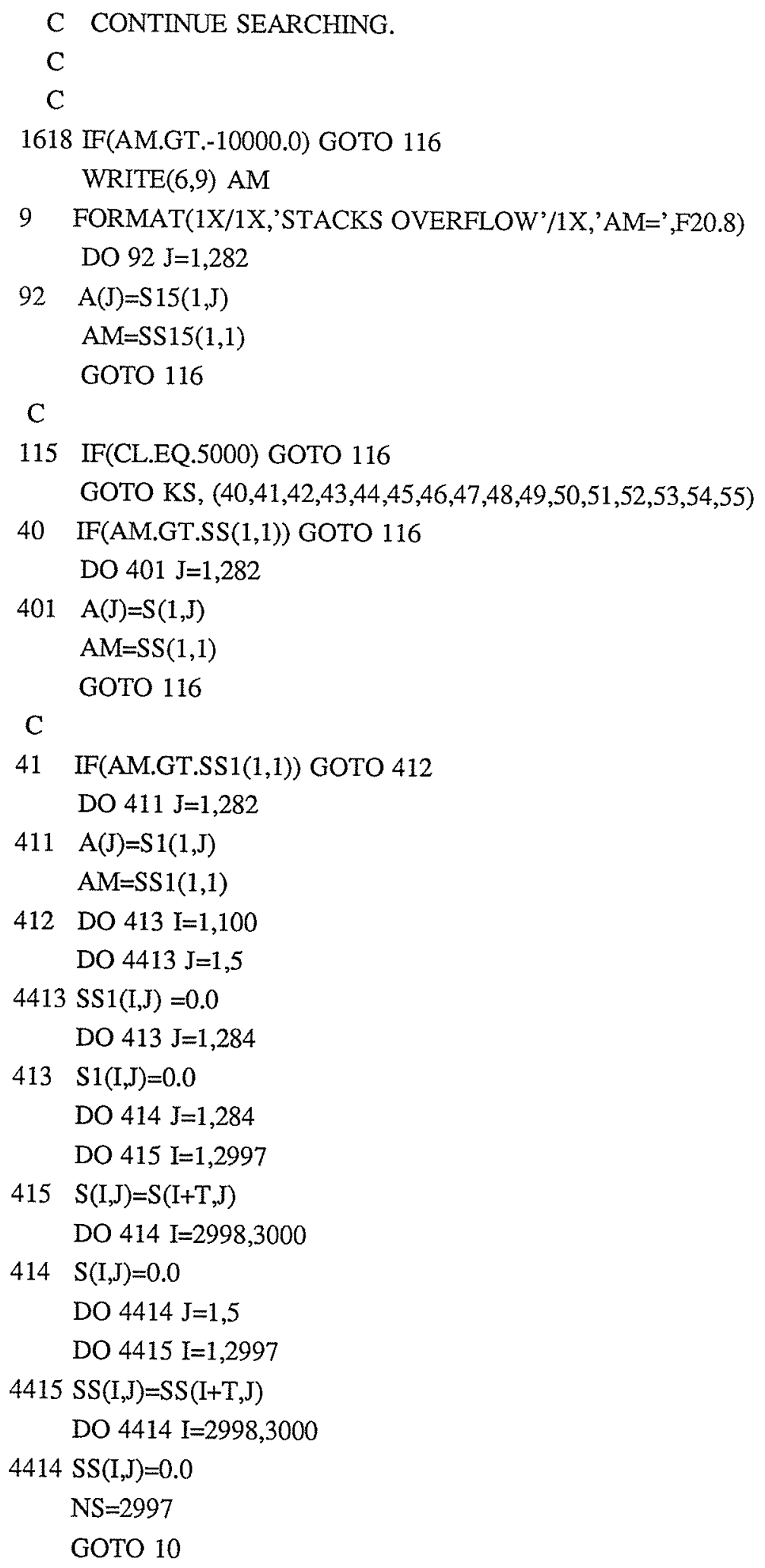




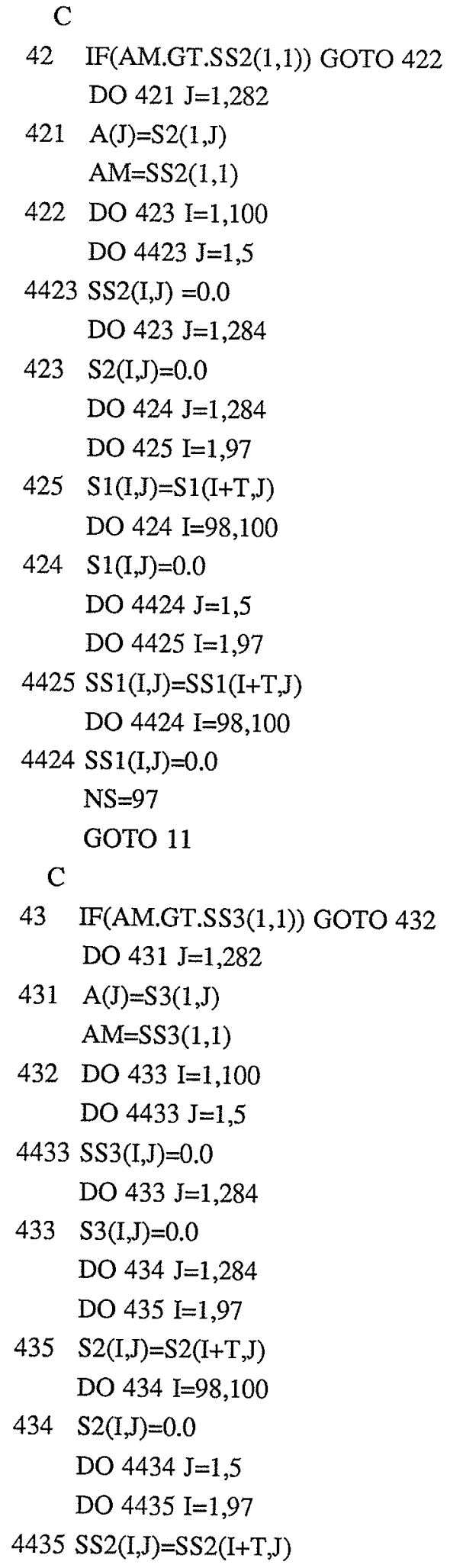




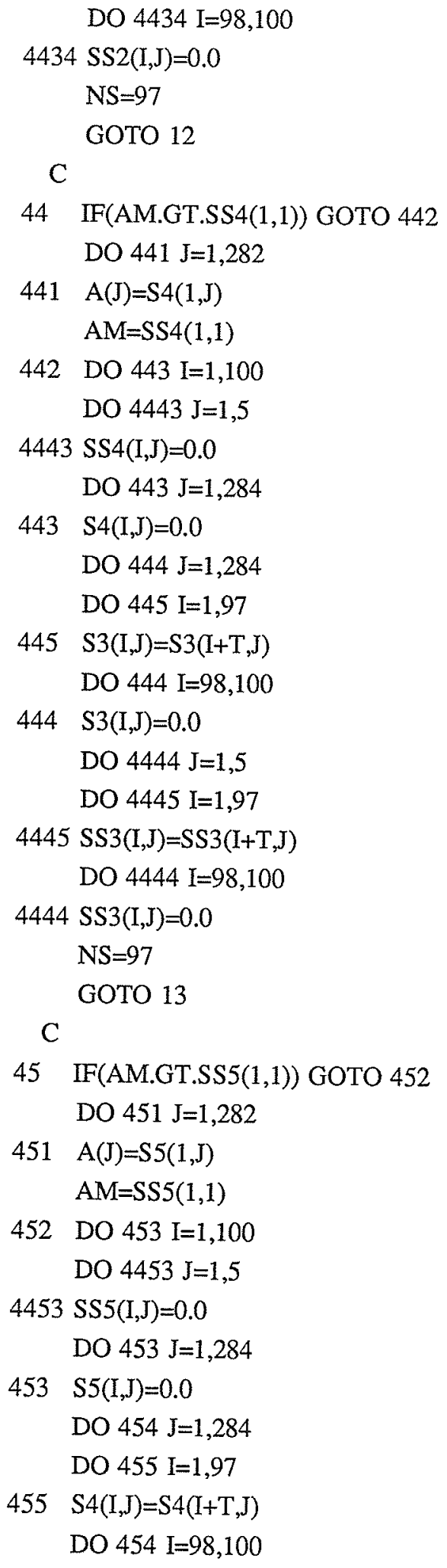




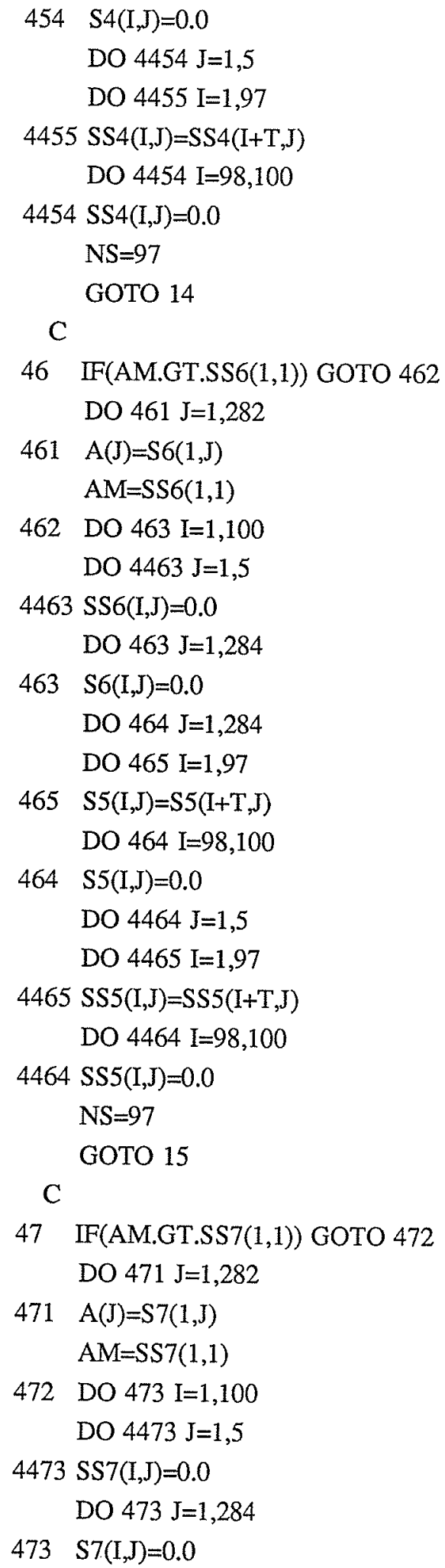

$473 \quad S 7 .\left(I_{,} J\right)=0.0$ 


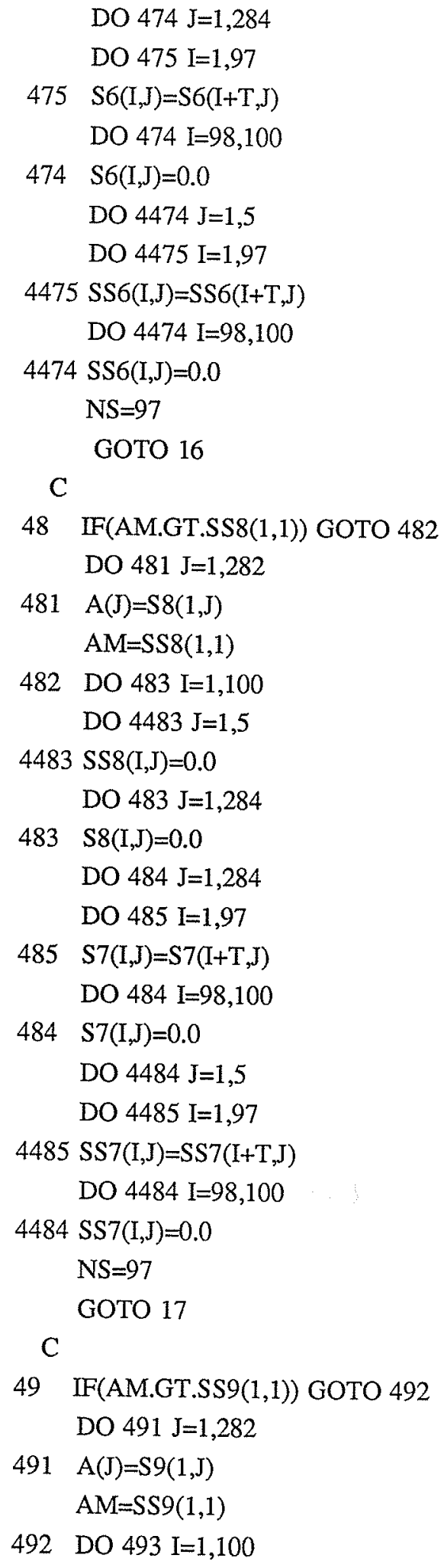




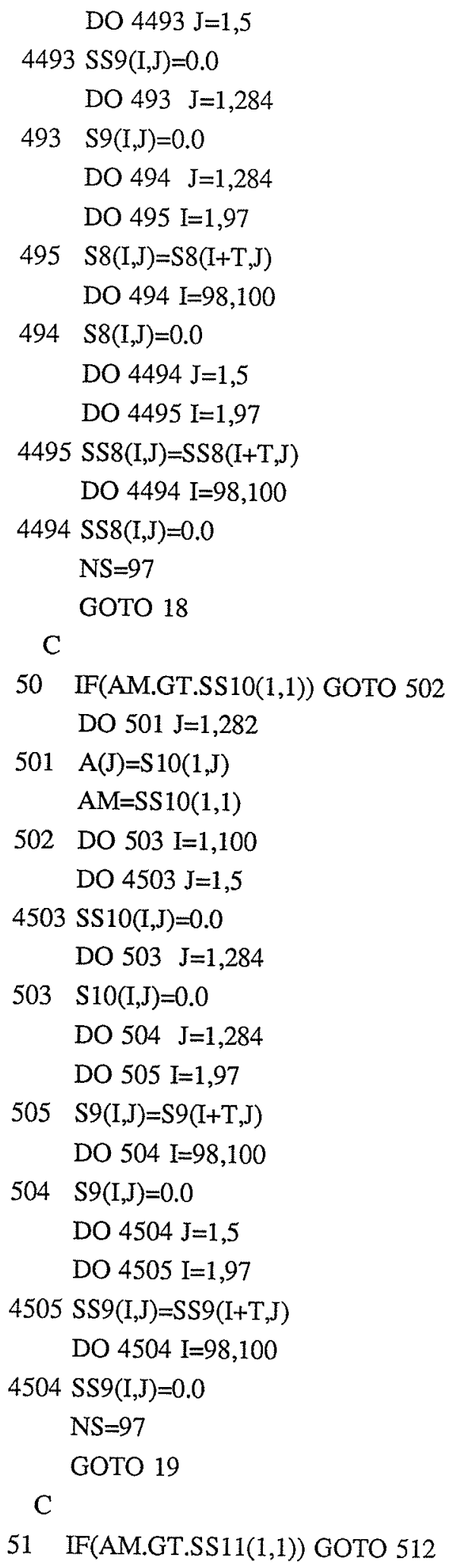




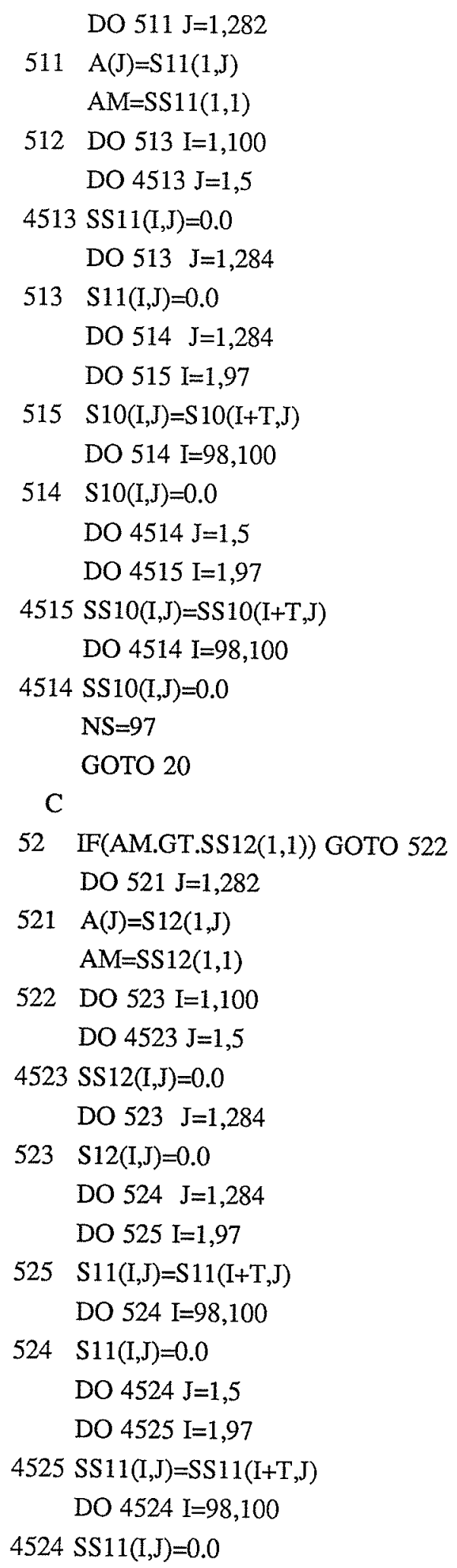




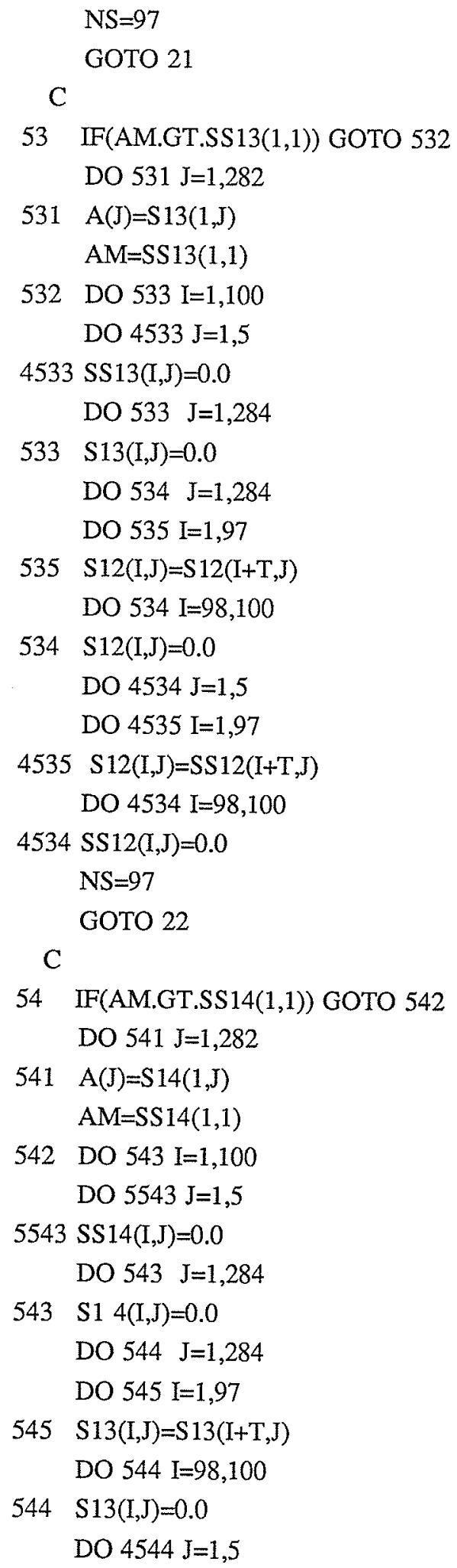




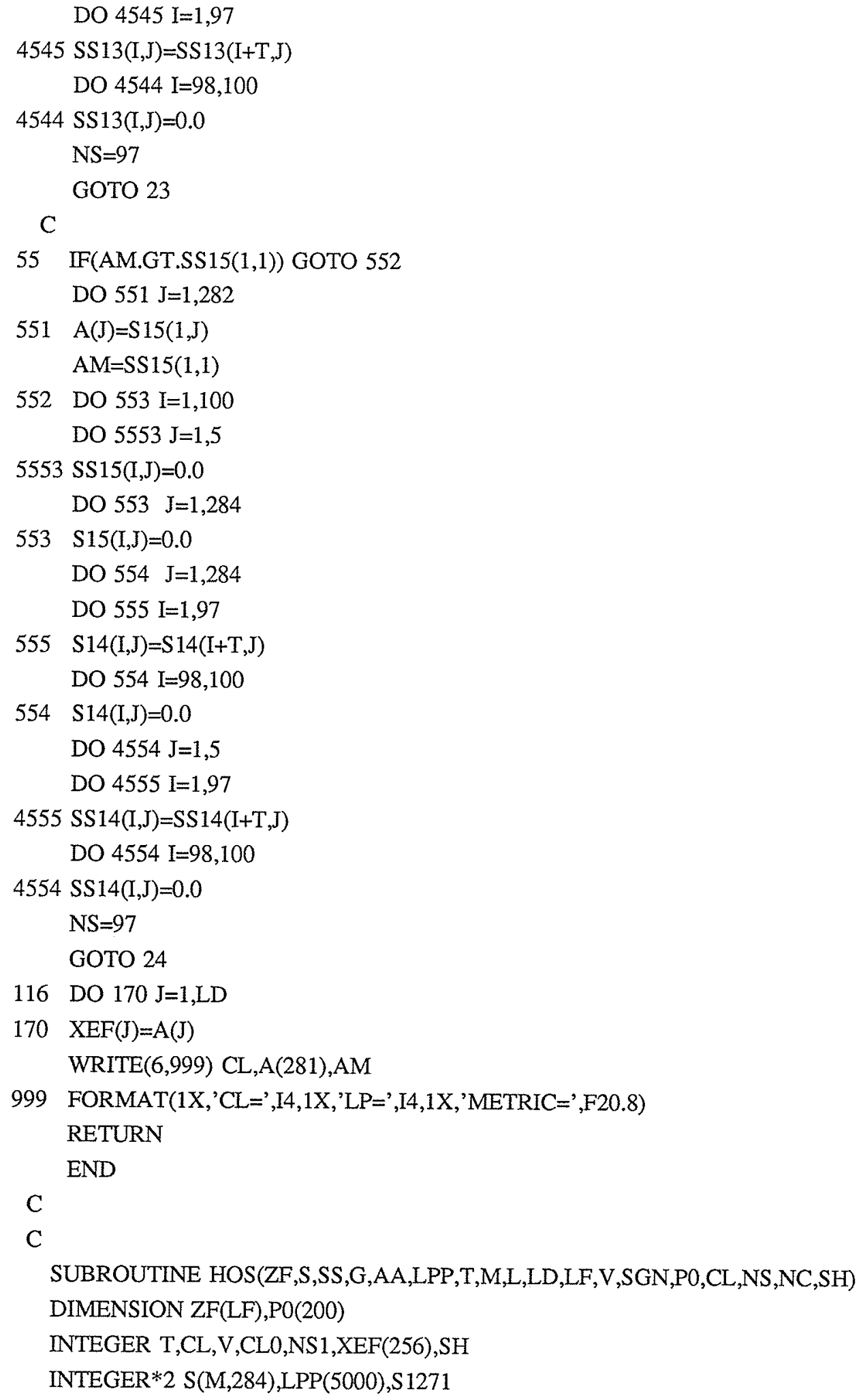




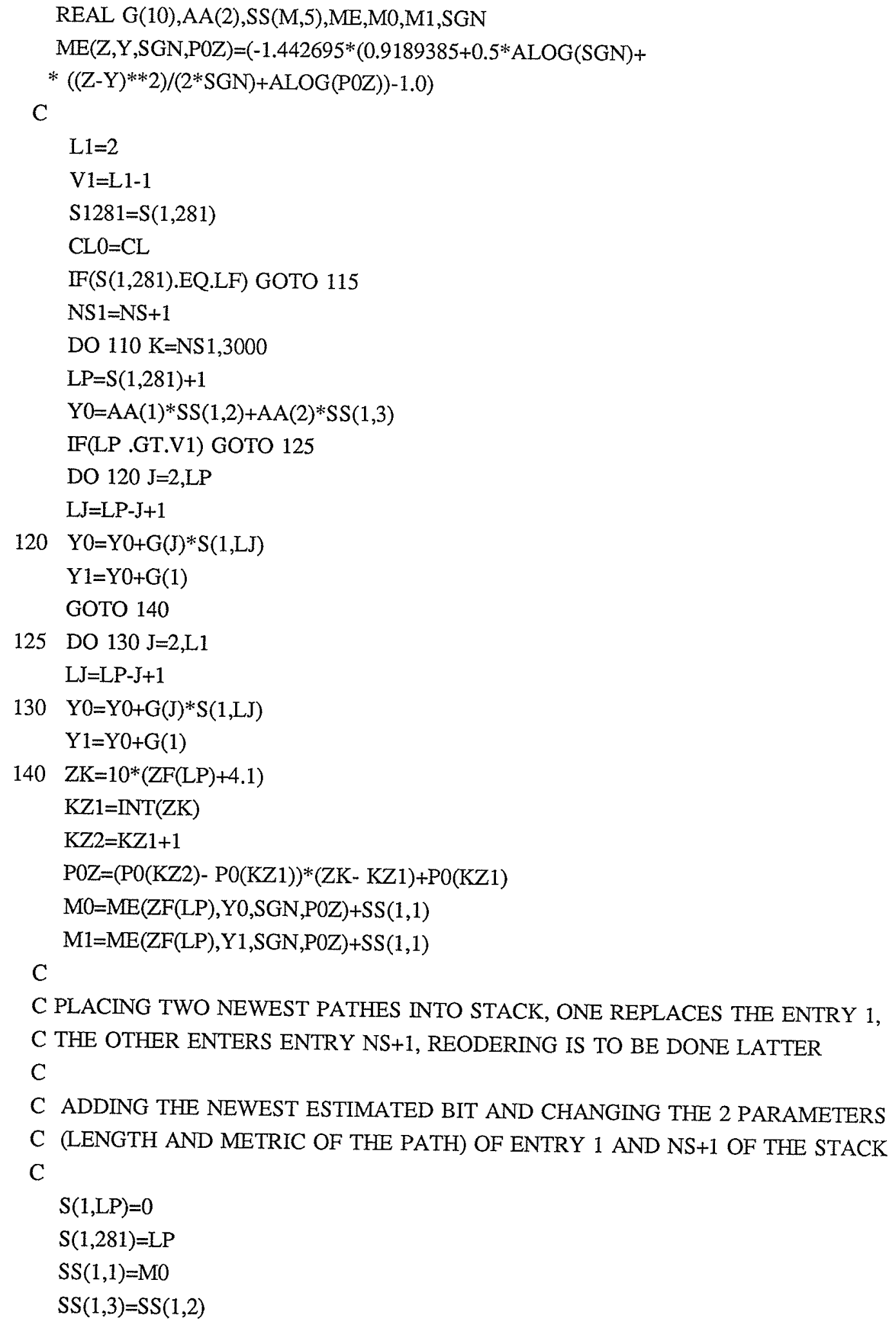




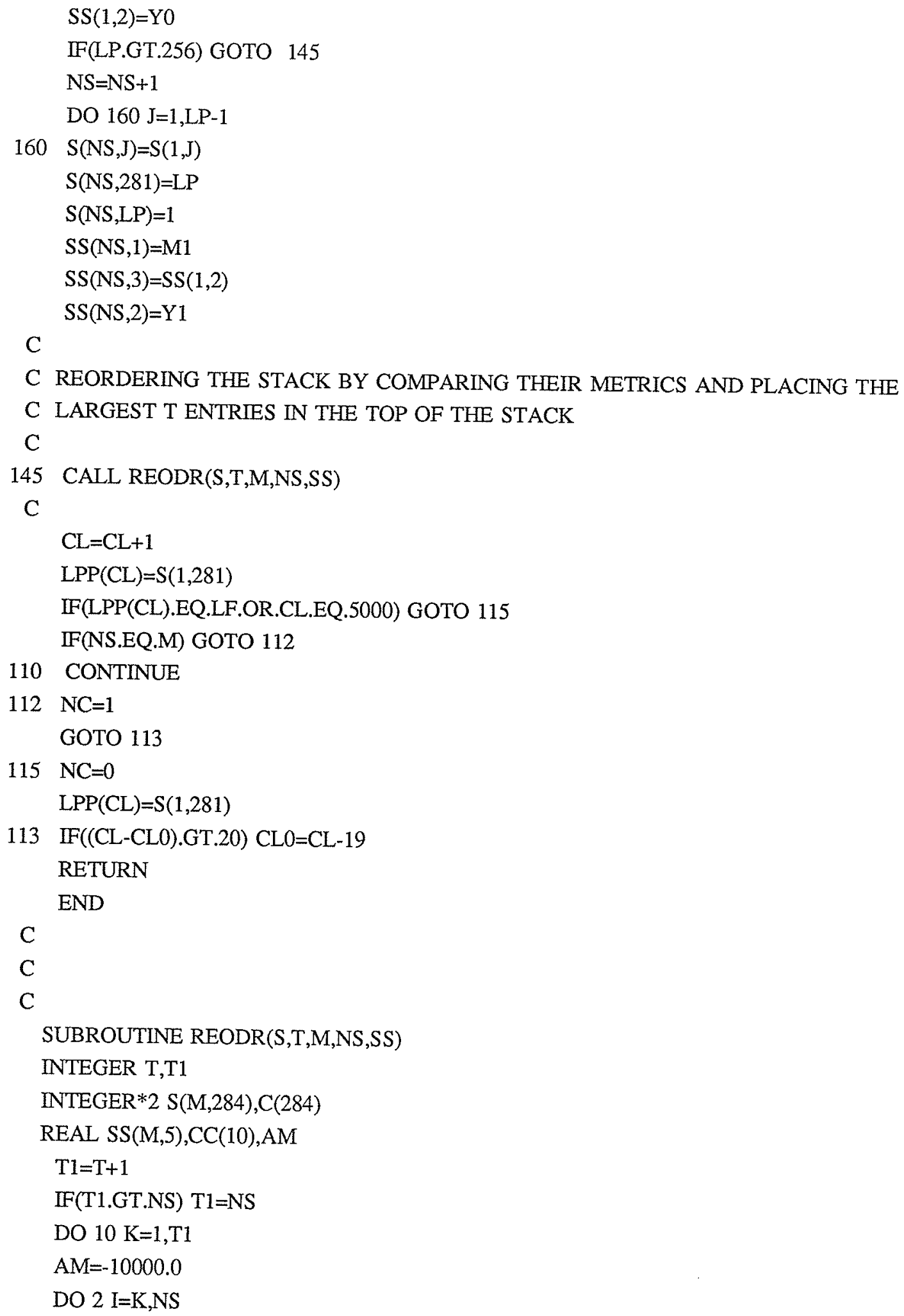


IF(SS(I,1).GT.AM) AM=SS(I, I)

2 CONTINUE

DO $3 I=K, N S$

IF(SS(I,1).EQ.AM) NM=I

3 CONTINUE

IF(NM.EQ.K) GOTO 10

DO $5 \mathrm{~J}=1,5$

$\mathrm{CC}(\mathrm{J})=\mathrm{SS}(\mathrm{K}, \mathrm{J})$

$\mathrm{SS}(\mathrm{K}, \mathrm{J})=\mathrm{SS}(\mathrm{NM}, \mathrm{J})$

$5 \quad \mathrm{SS}(\mathrm{NM}, \mathrm{J})=\mathrm{CC}(\mathrm{J})$

DO $4 \mathrm{~J}=1,284$

$\mathrm{C}(\mathrm{J})=\mathrm{S}(\mathrm{K}, \mathrm{J})$

$\mathrm{S}(\mathrm{K}, \mathrm{J})=\mathrm{S}(\mathrm{NM}, \mathrm{J})$

$4 \quad \mathrm{~S}(\mathrm{NM}, \mathrm{J})=\mathrm{C}(\mathrm{J})$

10 CONTINUE

RETURN

END 